\title{
AGGRADATION AND DEGRADATION OF ALLUVIAL-CHANNEL BEDS
}

by

Wilson F. Jaramillo Torres

and

Subhash C. Jain

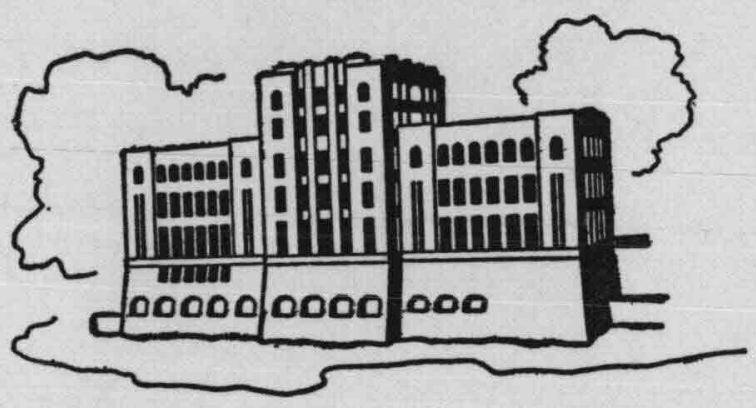

IIHR Report No. 274

Iowa Institute of Hydraulic Research

The University of Iowa

Iowa City, Iowa 52242

May 1984 


\title{
AGGRADATION AND DEGRADATION OF ALLUVIAL-CHANNEL BEDS
}

\author{
by \\ Wilson F. Jaramillo Torres \\ and \\ Subhash C. Jain
}

IIHR Report No. 274

Iowa Institute of Hydraulic Research

The University of Iowa

Iowa City, Iowa 52242

May 1984 
In Memory of

Wilson F. Jaramillo Torres

(1946-1983) 


\section{ABSTRACT}

The objectives of the present investigation were the determination of the characteristic parameters of morphological processes in alluvial channels. Special attention was directed toward the aggradation process due to totalsediment-load augmentation and degradation due to either sediment-discharge diminution or base-level lowering.

Linear and nonlinear parabolic formulations based on validated mathematical expressions of the equations governing one-dimensional flows over movable beds were developed. The classical linear, parabolic model was revisited as well. Analytical solutions for the characteristic parameters of aggradation and degradation processes in alluvial channels of semi-infinite and finite length subjected to both time dependent and time independent boundary conditions were obtained. The analytical solutions developed can be used in conjunction with almost any of the sediment-transport-rate and friction-factor predictors available.

The validity and limitations of the linear and nonlinear parabolic models and their corresponding solutions were assessed by means of comparison with flume data. The ranges of application for both linear and nonlinear models were established. As a result of its more rigorous formulation, the nonlinear parabolic model, which constitutes the principal contribution of this study, was found to be particularly useful and accurate for a wide range of practical applications. The good prediction capabilities of the nonlinear model can be enhanced through the use of available laboratory and/or field data, which enable an easy and effective calibration of the model. Easy-to-follow application, calibration, and extrapolation procedures are outlined.

Experiments on the evolution of the bed forms during aggradation due to a sudden increase in total sediment discharge were performed. Analyses of the experimental data led to a better understanding of the phenomena involved, to an explanation of the experimental findings of the present and similar investigations, and to justification of some of the main assumptions introduced in the development of mathematical models for unsteady nonuniform flows over deformable beds. 


\section{ACKNOWLEDGEMENTS}

This investigation was supported by the National Science Foundation, under grant CEE 80-23003.

The first author was awarded financial support by the Escuela Politecnica Nacional (Quito-Ecuador), a scholarship from the Latin American Scholarship Program of American Universities, and the Paul C. and Sara Jane Benedict Fellowship for Study of Alluvial River Processes from The University of Iowa.

The material contained in this report was submitted by the first author in partial fulfillment of the requirements for the degree of Doctor of Philosophy at The University of Iowa. The second author served as the research advisor. 
LIST OF FIGURES.

LIST OF TABLES.

LIST OF SYMBOLS.

CHAPTER

A. Introductory Remarks

B. Objectives and Scope. ix

A. General

B. Aggradation

10

1. Examples of aggradation...................5

2. Experimental and analytical studies on

c. Degradation............................................

1. Examples of degradation....................10 10

2. Experimental and analytical studies on

D. Numerical Models..................................11

II LINEAR AND NONLINEAR PARABOLIC MODELS

FOR MORPHOLOGICAL PROCESSES.....................19

A. Theoretical Basis................................19

1. Assumptions............................20

2. Basic considerations.....................20

B. The Classical Parabolic Model (Z-Model)...........21

C. The Alternate Parabolic Model (G-Model)............23

IV LINEAR PARABOLIC MODEL FOR MORPHOLOGICAL PROCESSES

IN CHANNELS OF SEMI-INFINITE LENGTH...............26

A. Aggradation due to Sediment Augmentation and Degradation due to Sediment Diminution.............26 1. Analytical solution by linear G-model.......26

2. Analytical solution by linear Z-model........32

B. Degradation Due to Base-Level Lowering............36 
1. Statement of the problem......................

2. Schematization of the problem..............39

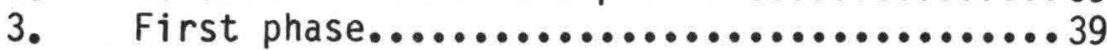

4. Second phase........................40

V LINEAR PARABOLIC MODELS FOR MORPHOLOGICAL

PROCESSES IN ALLUVIAL CHANNELS OF FINITE LENGTH.......42

A. Statement of the Problem....................442

B. Model Selection...............................42

C. Analytical Solution for a Constant Variation

in Total Sediment Discharge....................44

1. Discussion of results...................45

D. Solution for a Time Dependent Variation

in Total Sediment Discharge...................50

E. Comparison of Analytical Results with

Experimental Data.........................51

VI NONLINEAR PARABOLIC MODEL FOR MORPHOLOGICAL PROCESSES

IN A SEMI-INFINITE ALLUVIAL CHANNEL..............57

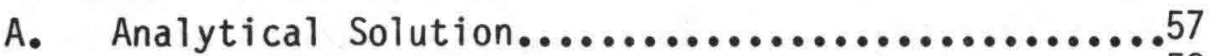

1. The method of weighted residuals..........58

B. Comparison of the Nonlinear Parabolic

Model with Experimental Data..................74

C. Application of the Nonlinear Solution

to Practical Problems........................81

VII EXPERIMENTAL STUDY...........................

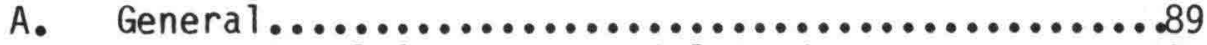

B. Experimental Apparatus and Procedures...........90

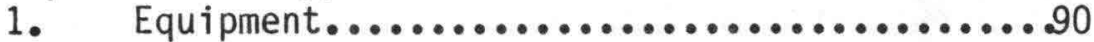

2. Experimental procedure................93

C. Qualitative Observations.....................94

D. Bed Profile Analysis.........................99

VIII SUMMARY AND CONCLUSIONS......................113

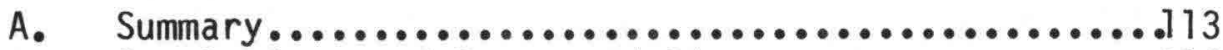

B. Conclusions and Recommendations................113

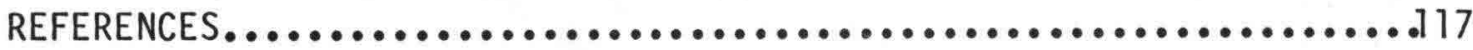

APPENDIX I LINEAR AND NONLINEAR DIFFUSION COEFFICIENTS $\ldots \ldots \ldots$ I26

APPENDIX II DEGRADATION DUE TO BASE LEVEL LOWERING

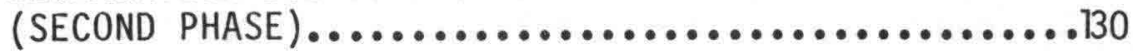




\section{LIST OF FIGURES}

Figure

Page

2.1 Lane's Balance Analogy for Morphological Processes........ 6

4.1 Morphological Processes in a Semi-Infinite Alluvial....... 27

4.2 Normalized Bed-Profile ( $\left(z_{0}\right.$ versus $n$ ) for Various Sediment Discharge Variations $\left(\Delta G=C_{0} t^{m / 2}\right) \ldots \ldots \ldots \ldots . . .33$

4.3 Schematic Illustrating a Degradation Process Due to Base Level-Lowering................................. 38

5.1 Definition Sketch for Morphological Processes in Finite Length Channels.............................. 43

5.2 Normalized Bed Profiles $\left(Z / Z_{0}\right.$ versus $\left.x / L\right)$ for Various Normalized Times.............................. 46

5.3 Normalized Bed Profiles ( $\left(z_{0}\right.$ versus $n$ ) for Various Normalized Times................................... 47

5.4 Normalized Total Sediment-Transport Rate ( ${ }^{*}$ versus $x / L$ ) for Various Normalized Times........................... 48

5.5 Normalized Total Sediment Discharge $\left(G^{*}\right.$ versus $\left.n\right)$ for Various Normalized Times............................... 49

5.6 Comparison Between Analytical Solution and Experimental Data for Bed Aggradation............................. 52

5.7 Comparison Between Analytical Solution and Experimental Data for Bed Degradation........................... 53

5.8 Comparison of the Analytical Solution for Total Sediment-Transport Rate and Experimental Data for Aggradation................................... 54

5.9 Normalized Bed Elevation at $x=0$ versus Normalized Total Sediment Transport Rate Variation.................. 55

6.1 Sensitivity Analysis of the Linear Solution for Total Sediment Load Obtained by the Method of Weighted Residuals $(W=1) \ldots \ldots \ldots \ldots \ldots \ldots \ldots \ldots \ldots \ldots \ldots . \ldots . \ldots . \ldots 6$

6.2 Sensitivity Analysis of the Linear Solution for Total Sediment Load Obtained by the Method of Weighted Residuals. 
6.3 Sensitivity Analysis of the Nonlinear Solution for

Sediment Discharge................................... 71

6.4 Sensitivity Analysis of the Nonlinear Solution for

Bed-Profiles............................................ 72

6.5 Comparison of Experimental Bed-Profile Data for

Aggradation with Nonlinear Solution...................... 75

6.6 Comparison of Experimental Bed-Profile Data for

Aggradation with Nonlinear Solution....................... 76

6.7 Comparison of Experimental Bed-Profile Data for

Aggradation with Nonlinear Solution....................... 77

6.8 Comparison of Experimental Bed-Profile Data for

Aggradation with Nonlinear Solution.....................78

6.9 Comparison of the Nonlinear Solution and

Experimental Bed-Profile Data for Aggradation............. 79

6.10 Comparison of Experimental and Computed Values of $z_{0} \ldots \ldots .80$

6.11 Comparison Between the Nonlinear Solution and

Experimental Bed-Profile Data for Degradation.............82

6.12 Dimensionless Total Sediment Transport Rate Obtained

by the Nonlinear Solution........................... 83

6.13 Dimensionless Bed Profile Obtained by the Nonlinear

Solution..........................................84

6.14 Variation of the Normalized Diffusion Coefficient

with the Normalized Change in Sediment Discharge...........85

6.15 Comparison of the Nonlinear Solution (Using Extrapolation

Procedure) with Experimental Bed-Profile Data..............88

7.1 Longitudinal Elevation View of Experimental Flume..........91

7.2 Sediment Size Distribution........................92

7.3 Bed Profile at $T=0$, Uniform Flow....................95

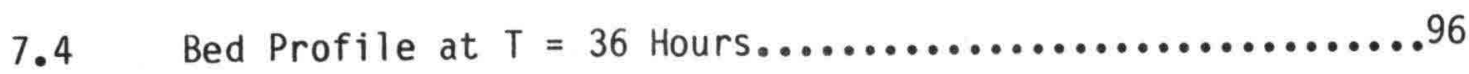

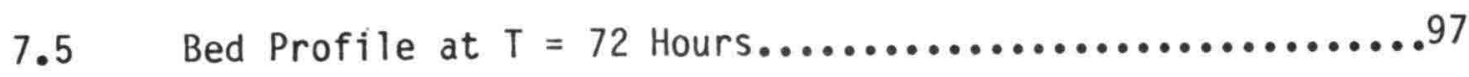

7.6 Definition Sketch of Bed-Profile for Zero-Crossing

and Amplitude Analysis..............................100

7.7 Percent Distribution Histograms for Bed-Form

Characteristics $(T=0$ Hours, Uniform Flow $) .. . . . . . . . .104$ 
7.8 Percent Distribution Histograms for Bed-Form

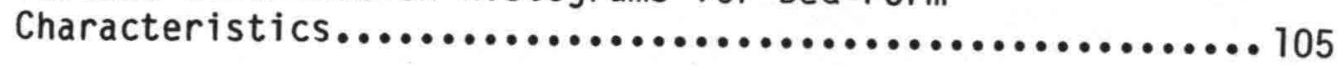

7.9 Initial Bed Configuration........................ 106

7.10 Bed Configuration During Aggradation.................... 107

7.11 View of the Aggrading Front........................ 108 


\section{LIST OF TABLES}

Table

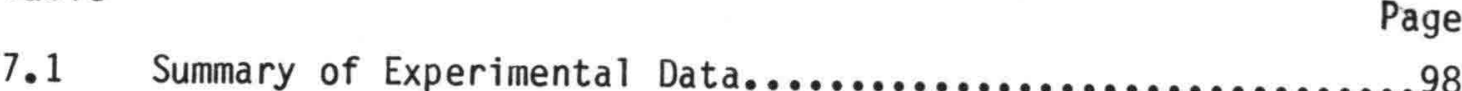

7.2 Statistical Measures of Bed-Form Characteristics...........102

I.1 Expressions for the Coefficients $K$ and $K_{0}$ for Constant

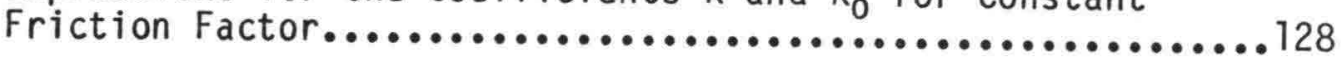

I.2 Expressions for the Coefficients $K$ and $K_{0}$ for Varying Friction Factor. 


\section{LIST OF SYMBOLS}

A

a

$a^{+}$

$a^{-}$

B

b

C

$\mathrm{C}_{\mathrm{O}}$

c

D

d

$\mathrm{d}_{50}$ median sediment diameter

E integration constant, residual

e coefficient in the friction factor equation

F function; Laplace transform of $G(t)$

$\mathrm{Fr} \quad$ Froude number $=\mathrm{U} /(\mathrm{gH})^{1 / 2}$

$\mathrm{Fr}_{0} \quad$ Froude number for the initial uniform flow

f

$f_{0}$

$f^{\prime}$

f"

G

$\mathrm{G}_{\mathrm{C}}$

Go

G*

Darcy-Weisbach friction factor

Darcy-Weisbach friction factor for uniform flow form friction factor

total sediment discharge per unit width

total sediment discharge for critical flow conditions

component of the friction factor due to sand-grain roughness

component of the friction factor due to form-drag, also called bed

total sediment discharge per unit width under uniform flow

normalized reduced sediment discharge $=\left(G-G_{0}\right) / \Delta G_{0}$ 
acceleration of gravity; Laplace transform of $\mathrm{G}^{\prime}$

$\bar{G} \quad$ sediment transport parameter $=G /(1-\lambda)$

H mean water depth

$\mathrm{H}_{\mathrm{O}} \quad$ mean water depth for uniform flow

h dune or bed-form height

$h_{0}$ dune or bed-form height under uniform flow conditions

I integral expression

$k$ diffusion coefficient $=$

$\mathrm{U} \frac{\mathrm{dU}}{\mathrm{dx}}$

$\mathrm{S}_{\mathrm{f}}(1-\lambda)\left(3+\frac{\mathrm{Udf}}{\mathrm{fdu}}\right)$

$K_{0} \quad$ value of $K$ for uniform flow conditions or linear diffusion coefficient

$K^{*} \quad$ nonlinear diffusion coefficient $\left(W=x^{m}\right)$

$\bar{K}^{\star} \quad$ nonlinear diffusion coefficient $\left(W=G^{*} m\right)$

L Laplace transform operator; aggradation or degradation length; length of alluvial channel; nonlinear operator

$\ell$

penetration distance $=\left(K^{*} t\right)^{1 / 2}$ or $=\left(\bar{K}^{*} t\right)^{1 / 2}$

m exponent of weighting function; constant

$\mathrm{m}_{2}, \mathrm{~m}_{3}$ second and third central moments

n

exponent in the sediment transport rate function $G^{*}$

p

integration variable; constant in the friction factor equation

q water discharge per unit width

$S$ bottom slope $=-\frac{d z}{d x}$

$S_{f} \quad$ energy slope

$\mathrm{S}_{0}$

bottom slope (constant) under uniform flow conditions

s

relative specific weight of sediment $=\gamma_{s} / \gamma$; parameter

time scale for degradation due to base-level lowering (first phase)

$T^{*}$

$\mathrm{t}$

time scale for degradation due to base-level lowering (second phase)

time; time scale for morphological processes in finite channels

$t *$

dimensionless time $=\left(K_{0} t\right)^{1 / 2} / \mathrm{L}$ 


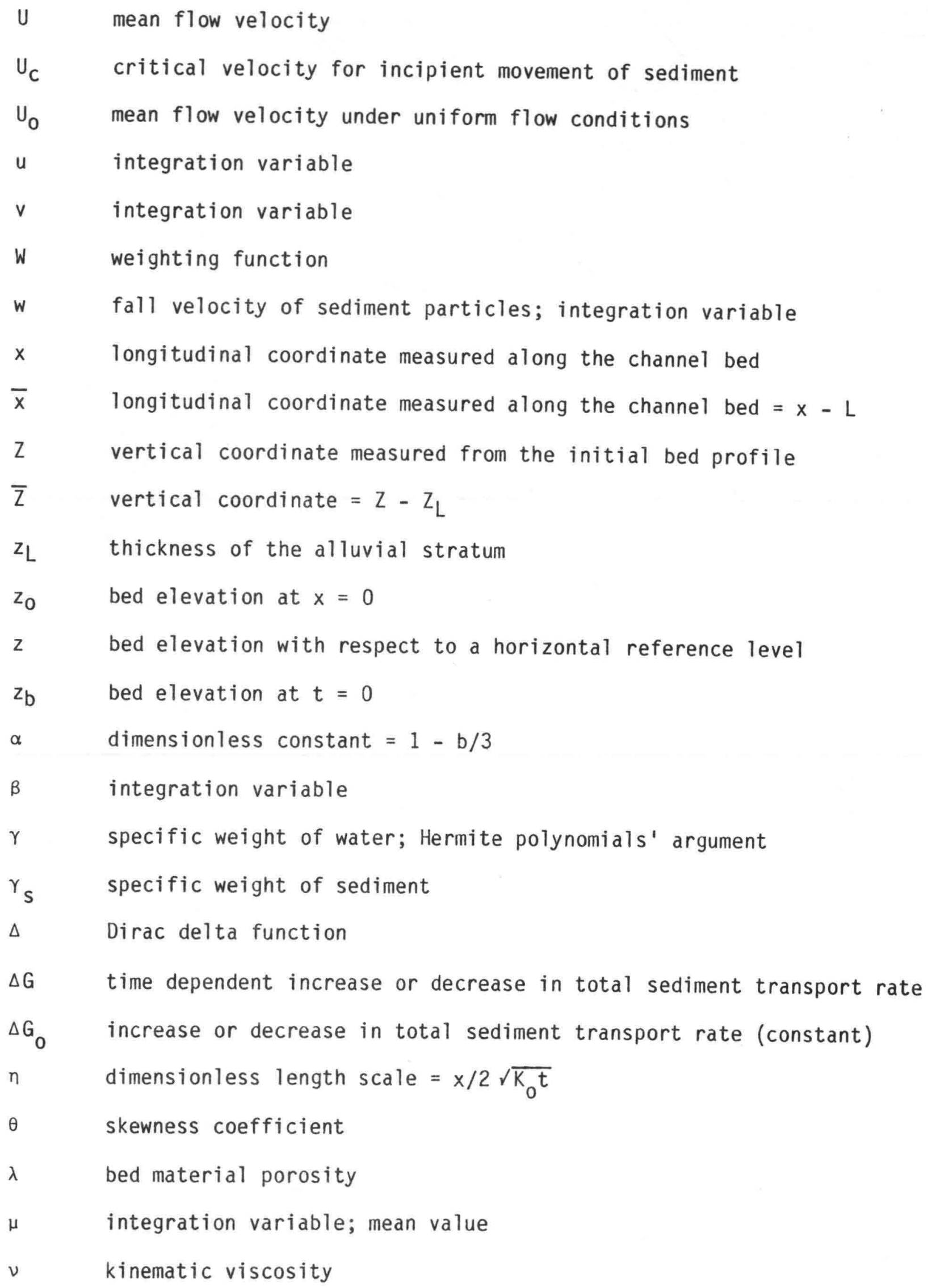




$\begin{array}{ll}\pi & \text { constant }=3.1416 \\ \sigma & \text { standard deviation of sediment particle diameters } \\ \sigma_{\mathrm{g}} & \text { geometric standard deviation of sediment particle diameters } \\ \tau & \text { shear stress } \\ \tau_{\mathrm{C}} & \text { shear stress at incipient movement of sediment } \\ \phi & \text { relative celerity, time dependent bed slope at } x=0 \\ \psi & \text { transport parameter }\end{array}$




\section{INTRODUCTION}

\section{A. Introductory Remarks}

Hydraulic engineers are often confronted with the problem of predicting, with some degree of reliability, certain aspects of alluvial-river flow, such as rate of sediment load, stage-discharge relationship, stable channel geometry, rate of channel deformation, etc. This is a difficult task because of the complex interactions among the many variables that control flow in alluvial rivers. Among these variables are water and sediment discharges, geometrical properties of the channel including bed configuration, valley slope, and sediment and water properties.

The study of steady, uniform flows has attracted the attention of investigators for many decades. Though there exists an immense amount of theoretical, experimental and field information that enables engineers to perform, with some degree of accuracy, hydraulic calculations regarding the control and design of alluvial streams subject to steady, uniform flows, the understanding and formulation are far from completion.

The water and sediment discharges of natural streams which have evolved over geologic times are in equilibrium and produce no objectionable scour or deposition. However, various factors, both man-made and natural, can contribute to disturb the delicate balance among the many variables involved, and in turn lead to aggradation or degradation along river reaches. In fact, rivers in equilibrium constitute the exception rather than the rule. Most of them are subject to some kind of control or disturbance that gives rise to nonequilibrium flow conditions.

Aggradation of a specific river reach occurs when the sediment entering the reach is larger than the carrying capacity of the stream. Consequently, part of the sediment must be deposited, and this results in the rise of the bed level. Degradation of a river stretch occurs when the sediment discharge entering the stretch is lower than the sediment discharge transported downstream of the reach; the extra sediment required to satisfy the stream's carrying capacity is obtained from erosion of the bed and banks, with attendant reduction of the bed level and widening of the stream. 
If the state of the art regarding equilibrium flows leaves a great deal to be desired, the panorama is by no means encouraging for the more prevalent case of nonequilibrium (unsteady and nonuniform) flows. The mathematical and/or empirical "tools" available to the hydraulic engineers to forecast the rates, durations, and extents of channel adjustments are far from being satisfactory. Improved estimates of these parameters, as well as a better insight into the dynamic behavior of alluvial streams undergoing morphological processes, are urgently needed in river-management planning.

\section{B. Objectives and Scope}

Although numerical models are being employed increasingly to analyze morphological processes in alluvial channels, to be useful and reliable, such models require, among other items, enormous amounts of accurate field and experimental data (Nakato and Vadnal 1981), which in many cases is not readily available, even in developed countries. It appears that the analytical line of research in this field has not been advanced significantly during the last several years. The already existing linear analytical models have not been substantially improved nor have their merits and deficiencies been clearly explained. The recent findings in the sediment-transport field and mathematical techniques have not been incorporated into this important and valuable branch of river-modelling. To the best of this writer's knowledge, no attempt to explore the potentials of nonlinear analytical models to analyze morphological processes has been reported.

The purpose of this dissertation is the determination of the characteristic parameters of aggradation processes due to augmentation of the sediment load, and degradation initiated by a diminution in sediment discharge or a lowering of the base level. These morphological processes are among the most frequent and important ones in river-engineering.

A composite approach, involving both mathematical modeling and laboratory experiments, was adopted. Major attention was given to the development of improved linear and nonlinear analytical models based on validated mathematical expressions of the constituent phenomena. Laboratory experiments were directed towards a better understanding of the mechanics of sediment transport in alluvial channels under nonequilibrium conditions. Particular 
emphasis was placed on the study of the modification of the bed configuration with increase in the sediment supply.

In accordance with these objectives, the work done in the past is briefly reviewed in Chapter II. The theoretical basis and the derivation of the linear and nonlinear parabolic models are presented in Chapter III. Chapter IV deals with the application of the linear parabolic models to morphological processes in alluvial channels of semi-infinite length. The mathematical description of nonequilibrium processes in alluvial streams of finite length by means of the linear models is undertaken in Chapter V. The application of the nonlinear model to aggradation and degradation processes is discussed in Chapter VI. The apparatus and procedures used in conducting the experiments, and the experimental results are described in Chapter VII. The present study and its major conclusions are summarized in Chapter VIII. 
II. REVIEW OF PREVIOUS WORK

A. General

Hydraulic engineers and geologists since the origin* of their professions have been concerned with river dynamics; however, they have approached the subject with rather different objectives. The engineer's main concern is knowledge of river response to natural and man-induced disturbances. The geomorphologist's interest is in understanding of earth-surface history documented by river changes through geologic times. Although the interchange of information among engineers and geologists has been significant (Gilbert 1917; Davis 1909; Shulits 1934; Culling 1960), their efforts, due to the

*This note is intended to point out a few relevant mile-stones in the development of sediment-transport mechanics and river hydraulics. The first discoveries in the art of river hydraulics and river control apparently developed in China some 6000 years ago. The first floodcontrol project was undertaken during the supremacy of the Tang dynasty (2357-2258 B.C.). It consisted in the construction of series of impounding levees along the Yellow River (Shu-Tien 1937). The first dam is assumed to have been constructed on the Nile river by King Menes (4000 B.C.). The earliest written statements about erosion and sediment transportation have been attributed to Hippocrates (400 B.C.), who wrote about the separation of sediment into size fractions based on different settling velocities and gave a description of the apparatus used to demonstrate the basic principles involved (Krumbine 1932). Several authors (Graf 1971; Rouse and Ince 1980) considered Domenico Guglielmini (1655-1710) the "father of the science of river hydraulics" and the author of the first book "Della natura dei fiumi" on sediment transport phenomena. However, it appears that a Chinese official named Chi-Hsun Pan (1520-1595) in-charge of the flow-control on the Yellow River published in 1590 a collection of reports under the title "Review of River Protection" (Wong 1939). In fact, Pan published papers and reports which were edited in four Chinese volumes. His "Guiding Principles and Recommendations" show a considerable understanding of the basic sediment transport mechanisms. In 1750 Paul Frisi reported hydraulic model studies, concerning the advantages and drawbacks from the navigation viewpoint, of dividing the Rhine river into several channels. His statement regarding the "absurdity of formulating mathematical theories, when hydraulics was really a branch of physics rather than mathematics" (Rouse and Ince 1980) is noteworthy because it illustrates the emphasis given to experimental methods during the 18th century. 
difference in time-scale of the morphological phenomena in which they are interested in, have remained somewhat isolated up to the present time. The useful concepts of graded and poised streams formerly introduced by geologists (Mackin 1948; Matthes 1941) have been adapted and extended by hydraulic engineers to analyze qualitatively many problems of stream morphology (Lane 1955; Kuiper 1965). Lane's analysis included an impressive list of examples of aggradation and degradation in natural streams. However, the most outstanding feature of his contribution is the lucid explanation of the causes leading to such processes by means of his balance analogy as illustrated in figure 2.1. Lane visualized water and sediment discharges in one pan and slope and sediment size in the other. Its equilibrium is self explanatory and qualitatively consistent, as was shown experimentally by Rathbun and Guy (1967).

During the last part of the present century, the necessity to approach morphological processes from a quantitative viewpoint has become apparent. Accordingly, engineers have devised field studies and laboratory experiments intended to provide quantitative estimates of the characteristic parameters involved in some specific morphological problems. Data collected in field studies and laboratory experiments are the main constituent of the so-called empirical methods of estimation. The increasing understanding of the basic mechanisms of sediment transport has resulted in substantial improvements in the formulation of better mathematical models of such processes. Such models are solved either analytically or numerically.

A review of the technical literature related to nonequilibrium flows, with special attention to aggradation and degradation processes in alluvial channels, is presented in the subsequent sections.

\section{B. Aggradation}

1. Examples of aggradation. Aggradation of a river reach can occur due to various causes, including:

(a) augmentation of sediment discharge

(b) diminution in water discharge 


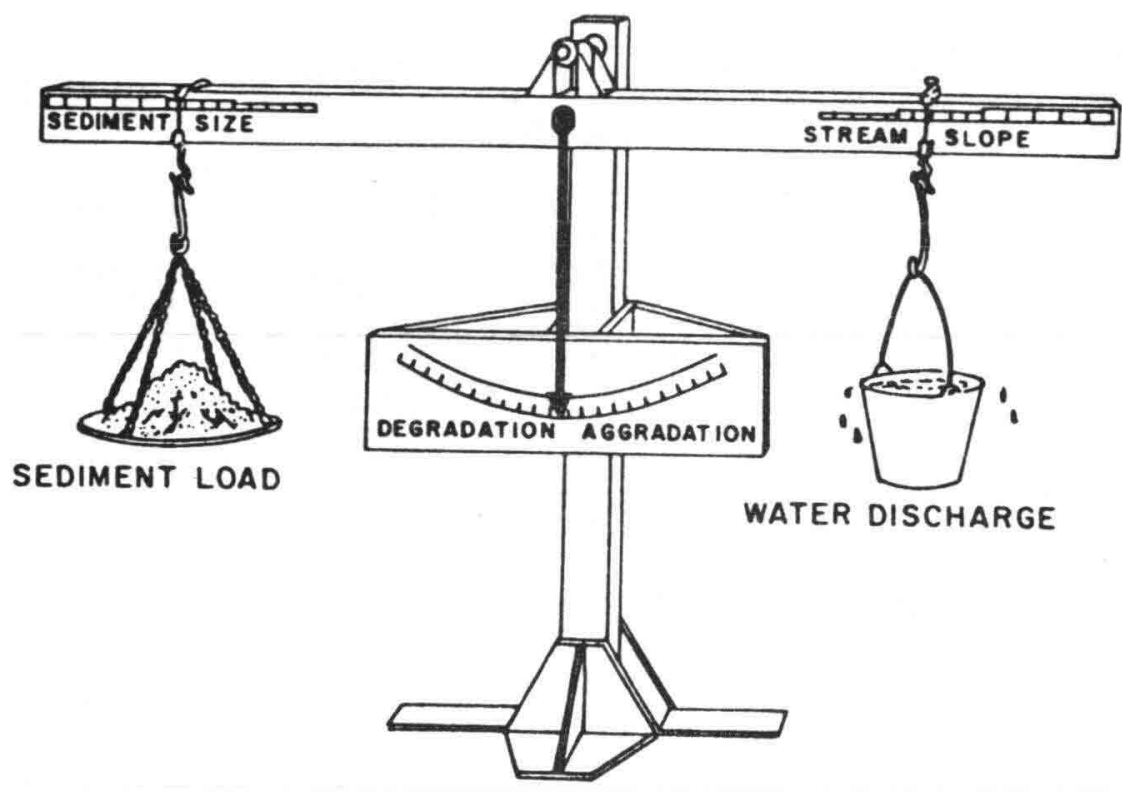

Figure 2.1 Lane's Balance Analogy for Morphological Processes 
(c) raise of base level ${ }^{\star}$.

A selected list of examples of aggradation processes is presented as follows:

Aggradation due to augmentation of the sediment discharge conveyed to the stream by a tributary constitutes a classical example. The sediment deposits downstream from the confluence form some sort of a submerged dam or bar which creates a pool upstream of the tributary confluence. This was the case at Pepin Lake which was formed in the Upper Mississippi River by the enormous sand load supplies by the Chippewa River. Matthes (1941) reported the formation of a $6000 \mathrm{~m}$ long lake upstream of the confluence of the Feather River with its tributary, the Yuba River. The sediment transported by the Feather River originated another temporary dam and its corresponding lake in the Sacramento River, into which the Feather River discharged. Farther down the Sacramento River at the city of Sacramento, California, the water stage was raised $3 \mathrm{~m}$ by the deposits.

A rise of about $6 \mathrm{~m}$ of the Yuba River bed in North California, U.S.A., over a period of 100 years due to sediment overloading caused by gravel wasted in the hydraulic mining of gold was reported by Gilbert (1917). Large volumes of waste materials from lead mining, in the southern part of the Driftless Area in Wisconsin and Illinois, which added considerably to the sediment loads of certain tributaries caused an average filling of about $0.25 \mathrm{~m}$ in 30 years on the Galena River (Adams 1944). A similar problem affected the Serendah River in Malaya, where the river bed rose $6 \mathrm{~m}$ over a period of 11 years due to the addition of sediment produced by the hydraulic mining of tin (Lane 1955).

The catastrophic aggradation of the Upper Ganga Canal in 1970, due to a series of landslides in the Alaknanda Valley is another striking example of aggradation (Garde and Ranga Raju 1973). Another impressive case is the Mu Kwa River in Formosa; the river bed rose $12 \mathrm{~m}$ in 3 years due to landslides. A two-story hydroelectric powerhouse along the side of the river was completely

\footnotetext{
*Base level is the limiting level or elevation below which streams cannot erode. Lakes, for example, for the period of their existenance, control the level of streams entering them and thus form local or temporary base levels for such streams. The ultimate base level is closely related to sea level.
} 
buried. Aggradation due to recent continuous landslides in the Gualpa Valley along the Paute River in Ecuador has been detrimental to the construction of the Cola de San Pablo Dam as well as to the performance of the ski-jump energy dissipator (Jaramillo et al. 1979).

The sediment and water contributed by the 32,392 square kilometers of the Middle Rio Grande Valley produced the bed aggradation of $0.3 \mathrm{~m}$ in 5 years in the lower 24 kilometers of the river. The floodway between the levees in the upper 214 miles of the valley was aggraded $0.3 \mathrm{~m}$ in 12 years during the period 1936-1941 (Jones 1948). Surveys of the Kickapoo River in Wisconsin showed a channel aggradation of $0.3 \mathrm{~m}$ in 20 years (Happ 1948). Recent measurements in the Upper Mississippi River indicated the amount of sediment deposited has ranged from 0.1 to $0.6 \mathrm{~m}$ in the 11 year period since 1964, with an average aggradation of 0.3 to $0.025 \mathrm{~m}$ per year. Depths of sediment deposited since 1957 up to 1975 ranged up to $0.8 \mathrm{~m}$ (McHenry et al. 1976).

As a result of the channelization of the East and West Prairie Rivers in Alberta, Canada, an aggradation of as much as $3 \mathrm{~m}$ occurred in 1972 . The original excavated channel has been filled. Channel depth decreased by $36 \%$ and its width increased by 10\% (Parker and Andres 1976).

Significant rises in the bed level of the Rio Grande and Arkansas River in U.S.A. due to the withdrawal of relatively clear water were observed by Lane (1955). Due to diversion of a part of the Mississippi water discharge into the Atchafalaya channel in 1882, silting (aggradation) of the Mississippi River bed, downstream of the point of diversion (Salisbury 1937).

The upstream propagation of a wave of deposition due to rise in bed level was detected through bed profile modifications brought about within a few years by erection of Debris Barrier \#1 on the Yuba River (Gilbert 1917). The formation of fortuitous local obstacles, such as a driftwood jam together with abnormal sand loads, was thought to be the cause of complete channel occlusions observed in some small tributaries of the Little Tallahachie in a few places in the South Carolina Piedmont and in small valleys of the Upper Mississippi Basin and other scattered localities (Happ 1945, 1948).

2. Experimental and analytical studies on aggradation. One of the early experiments concerning aggradation processes due to sediment augmentation at the upstream end of a laboratory flume were reported by Bhamidipaty and Shen 
(1971). The aggrading upstream reach was characterized by nonuniform flow conditions, where the bed slope increased and the water depth decreased with time. The downstream reach remained practically unaffected by the process until the aggrading front reached there. The slope of the front in all tests was found to remain constant, and nearly equal to the submerged angle of repose of the bed material. Bhamidipaty and Shen proposed a logarithmic relationship between the bed level and time, and suggested some simple procedures to compute the bed slope, the water depth, and the length of the channel affected by degradation at the end of the process.

Adachi and Nakato (1969) showed that under the assumptions of quasisteady and quasi-uniform flow the evolution of the river bed due to top-setbed (aggradation in a silted reservoir) may be represented by a linear parabolic model. A method for evaluating the difussion coefficient in their analytical solution from available field data was also suggested.

Soni, Garde and Ranja Raju (1980) adopted de Vries' (1973) parabolic model and its corresponding solution to study the aggradation process in an alluvial channel due to sediment augmentation at a constant rate at the upstream end of a laboratory flume. Generally poor agreement between the analytical results and the experimental data was found and was attributed to the several simplifications contained in the model. After a disputable discussion about the reasons for the actual diffusion coefficient being smaller than the theoretical one, the authors proceeded to modify empirically the value of the diffusion coefficient which turned out to be a function of the relative overloading. Jain (1981) pointed out an error in the boundary condition applied by Soni et al (1980). He derived a more appropriate boundary condition and obtained an analytical solution which fit better with the experimental results. Mehta, Garde and Ranga Raju (1981, 1982) presented the same solution as given by Jain (1981) and compared it with the experimental data obtained by Soni et al (1980) and their own data which covered a fairly wide range of flow and overloading conditions. In order to improve the agreement between the analytical solutions and the experimental data they again modified the values of the diffusion coefficient. The modified value of the diffusion coefficient was smaller or larger than the theoretical value, depending on the magnitude of the relative overloading. 
Soni (1981), on the basis of his experimental data, theoretical and dimensional analyses, and existing analytical models developed an empirical method that allows the determination of the time dependent bed profile of a channel undergoing aggradation due to sediment augmentation.

Soni (1981a), after some simplifying assumptions, obtained an analytical solution for the sediment load in aggradation processes. To obtain a better fit between the analytical results and the indirectly measured sediment discharge, he proposed another modification to the theoretical value of the diffusion coefficient.

C. Degradation

1. Examples of degradation. Degradation of a river reach can occur due to the following causes:

(a) diminution of the sediment discharge

(b) augmentation in water discharge

(c) lowering of base level

A few typical examples of degradation processes are summarized below.

Cases of degradation below dams, where most or all of the sediment discharge is retained in the reservoir, have been reported frequently in technical publications (Lane 1934, 1947, 1955; Todd and Eliassen 1940; Shulits 1934; Stanley 1947, 1951; Pick 1951; Malhotra 1951; Livesey 1963; Joglekar and Wadekar 1951; Hathaway 1948). Degradation was the cause for the failure of a major dam in India and for the complete reconstruction of Fort Summer Dam on the Pecos River in New Mexico (Lane 1955). A 2.5-m lowering in the bed elevation of the Missouri River in 10 years was observed downstream from Gavins Point Dam, South Dakota (Sayre and Kennedy 1978). Bed degradation of up to $10 \mathrm{~m}$ over a period of 32 years occurred in the Ratmau Torrent downstream of a level-crossing with the Upper Ganga canal at Dhanauri, India (Vittal and Mittal 1980). Bed material removal at a striking rate of 12,000 cubic meters in one year caused by the increase in flow discharge was observed in Five Mile Creek, Wyoming. The material eroded from the stream bed and banks provoked the rapid silting of the downstream reservoir (Lane 1955). 
Due to the diversion of a part of the Mississippi River water discharge into the Atchafalaya channel in 1882, the lowering of the bed slope of the Atchafalaya channel was observed (Salisbury 1937).

A man-made change which accompanies a lowering in base level is the local shortening of a stream by the elimination of meander loops; the general trend of the upvalley effects is indicated by changes in the profile of the Mississippi River brought about by a series of artificial cutoffs and other channel improvements between 1929 and 1939 (Mackin 1948). At Arkansas City, at the head of the cutoffs, the river level was lowered about $4 \mathrm{~m}$. The effect was noted in 1939 at a gauge $65 \mathrm{~km}$ upstream, where there was a lowering of $1 \mathrm{~m}$ in flood stage. The river has certainly not yet adjusted itself to the new conditions; the chief significance of the recorded bed profile changes to date is the sensitivity of the stream to "lowering the base level", and the extremely rapid headward progression of the first effects of that lowering (Ferguson 1939; Mackin 1948). Another case of base-level lowering occurs when a reservoir which is usually held at a constant level is drawn down. The Salton Sea in California was at one time filled to an elevation of $12 \mathrm{~m}$ above sea level and the Whitewater River adjusted its bed to this level. The Salton Sea was cut off from the ocean and lowered by evaporation to $75 \mathrm{~m}$ below sea level, and the Whitewater River is slowly adjusting itself to this new base level (Soderegger 1935).

2. Experimental and analytical studies on degradation. It seems that the first significant experimental work on degradation due to sediment diminution was conducted by Harrison (1950). He stated that the bed degrades as a unit and that the final bed profile is parallel to the initial one if non-moving particles are evenly distributed along the bed. Newton (1951) concluded from his experiments with uniform sand that the rate and pattern of degradation are dependent on bed and flow conditions and the rate of sediment transport at the initial equilibrium condition. The stream-bed elevation and slope at a given location were found to decrease asymptotically with time. Ismail and Wahby (1964) reported that, as the degradation progresses, the value of the bed shear stress approaches to that of Shields for a representative grain size equivalent to approximately the mean diameter of the original bed material. They also stated that the total roughness of the bed at the end of the process is due to the grain roughness only. Al-Khafif (1965) based on his 
experimental results concluded that the Einstein bed-load function and friction factor due to bar resistance (Einstein 1950, 1952) for equilibrium channels can be applied to degrading channels with uniform bed material. Several investigators (Gessler 1965; Lane and Carlson 1953) found that the armor coat is one grain thick and composed of all grain sizes contained in the original bed material. Garde and Hassan (1967) showed that the characteristics of the armor coat at the end of the degradation process depend primarily on the initial standard deviation of the bed material. Little and Meyer (1970) conducted experiments aimed at the quantitative determination of the effect of sediment gradation on channel armoring. They reported simple relations that allow the calculation of the final mean geometric diameter and geometric standard deviation as functions of the initial values of these parameters and the shear velocity. An important finding of the study was that sediments with geometric standard deviations less than 1.30 did not show any armoring. This conclusion was supported by Blaisdell (1977) based on his field observations. Bhamidipaty and Shen (1971) concluded from the analysis of Newton's data (Newton 1951) and their own experimental data that the bed elevation in a degrading channel decreases exponentially with time. The bed profile was found to depend primarily on the initial and final bed slopes, initial and critical shear stresses, as well as on the sediment and water characteristics. The bed forms at the end of the process were found to depend on the sediment size. For materials coarser than $0.6 \mathrm{~mm}$ the final bed slope and water depth could be determined by using Shields' diagram. The friction factor due to form resistance diminishes with time for sand coarser than 0.6 $\mathrm{mm}$ and increases for finer sands. The friction factor diagram developed by Shen (1962) for equilibrium flows was found adequate for degrading channels. Experiments concerning degradation of alluvial channels in response to baselevel lowering have been reported primarily by geologists (Brush and Wolman 1960; Pickup 1975; Holland and Pickup 1976; Begin et al. 1980, 1981). The results of some of these studies show that in homogeneous alluvial sediments, the ultimate result of the base-level lowering by a certain amount is a degradation all along the channel by the same amount. The main impact of erosion is felt in the early stages of the processes, and mainly near the mouth. The rate of degradation at any location along the channel reaches a peak and then slowly decreases with time, and the peak rate is attenuated with distance from the outlet. Because of the tendency for a stream to rapidly 
reduce the slope of any steep reach, the 'knickpoint' (the location of the bed slope discontinuity) migrates upstream only a short distance before it becomes too faint to recognize. At a given flow the rate of migration of the knickpoint depends on the sediment size, and the difference in bed elevations between the upstream and downstream reaches.

The two earliest empirical methods for estimating degradation processes below dams were developed by the U.S. Bureau of Reclamation (USBR 1963). The first method considers the case of uniform bed material, while the second accounts for armoring caused by nonuniformity in the sediment size. The method for uniform sediment is based first on the computation of the stable channel slope and the volume of the expected degradation, and then the determination of the bed profile which is approximated by a three-slope curve to fit the above computed volume. The method for nonuniform sediments is based on the computation of the critical bottom velocity for initiation of sediment motion, the tractive force, and a characteristic sediment size that accounts for the armoring process. It is assumed that the armor coat is three grains thick $\left(d_{50}\right)$ or $0.15 \mathrm{~m}$, whichever is smaller and the sediment transport equations due to Meyer-Peter and Muller and/or Schoklitsch are valid. An updated version of the previous methods is available in a more recent publication (USBR 1977). Aksoy (1970, 1971) proposed a method based on flume experiments and theoretical and dimensional analyses. Its major result is the exponential decrease with time of the bed elevation. Russian investigators (Rzhanitzin et al. 1971) have also devoted considerable efforts to study of river-bed degradation below dams under variety of conditions that included straight or curved rivers, and uniform and nonuniform bed material. However, their main concern was the prediction of the final or equilibrium river-slope rather than the evolution of the process with time. Based in his extensive set of flume experiments 110 and Narasimhan (1976) established a power-law relationship between the increases in bed level and in water depth with the longitudinal distance from the dam. Equations enabling the calculation of the entire bed and water surface profiles, as well as of the armor coat grain size at any time and location were also provided.

Although Newton (1951) reported the availability of an analytical procedure to compute aggradation and degradation processes on alluvial rivers developed by Straub, Einstein and Lane, the first analytical model for 
degradation was published by Culling, a geologist, in 1960 (Culling 1960). Based on the similitude between the flow of sediment in rivers and the heat flow in solids, he derived intuitively the linear heat-conduction equation as the governing equation for various degradation processes. Culling obtained solutions for several boundary and initial conditions, but they could not be used for quantitative estimations because he did not obtain any relationship among the diffusion coefficient and flow and sediment parameters. Nevertheless, it is interesting to point out that Culling stated the need of assuming that the flow of sediment is proportional to the bed slope and the unlikelihood that such assumption would hold true either in valley slopes or flowing streams.

Ashida and Michiue (1971) obtained the parabolic model (linear heatconduction equation), assuming quasi-steady and quasi-uniform flow and combining the sediment continuity equation with the sediment transport equation due to Sato, Kikkawa and Ashida (1958). In spite of an error in the expression for the diffusion coefficient due to an early linearization of the governing equation (de Vries 1971) and some inconsistency in the boundary condition used with the simplifications introduced, their analytical solution for degradation processes below dams was reported to be in fairly good agreement with their experimental results. It should be pointed out that Ashida and Michiue's solution is restricted to those cases in which the entire sediment load is retained at the dam and the sediment discharge in channels is proportional to the third power of the shear velocity.

De Vries $(1959,1965,1969,1971,1973)$ in his pioneering work showed in a rather general fashion that under the assumption of quasi-steady and quasiuniform flow, and some other suitable simplifications, the set of basic equations reduced to the linear parabolic heat-conduction equation. He attempted to solve the problem of degradation below dams and the case of degradation due to lowering of the base-level. However, due to inadequate establishment of the boundary conditions his solutions are of limited practical value. A somewhat similar comment applies to the analytical solutions presented by Vittal and Mittal (1980), for the case of degradation below dams, and by Begin, Meyer and Schumm (1980, 1981) for the case of degradation due to base-level lowering. 


\section{Numerical Models}

With the improvement in high speed electronic computers and numerical methods for solving partial differential equations, a substantial part of the research efforts concerning nonequilibrium flows has been concentrated on numerical modelling. As a result there exist a wide variety of numerical models. A brief summary of the pertinent literature is given as follows.

Tinney (1962) presented an analysis of the process of degradation, which consisted in the combination of the sediment continuity equation, Duboys' sediment-transport equation, and Manning's resistance relation. He obtained a differential equation for the rate of degradation which was solved by a stepby-step procedure. In his pioneering work on long-term morphological processes, de Vries $(1965,1969)$ showed that for low Froude numbers, the five basic governing equations for morphological processes could be reduced to two: the backwater curve and sediment-continuity equations. Both equations were initially solved by using the method of characteristics and later by means of a finite-difference method (pseudo-viscosity) that automatically takes care of the shock fitting. The method was initially applied to a bed-aggradation process induced by the withdrawal of clear water. Tsuchiya and Tshizaki (1969) manipulated the sediment continuity equation and the sediment-transport relation of Sato, Kikkawa and Ashida (1958) and assumed that the bed slope equals the energy slope. They obtained a linear parabolic equation which was solved by means of an explicit numerical scheme. Good agreement between the numerical results and measured field data was reported.

Chang (1969) and Chang and Richards (1971), by assuming quasi-steady flow conditions and neglecting the change in bed slope within a short time interval, reduced the number of basic equations to two (backwater and sediment-continuity) and solved them by the method of characteristics with an explicit rectangular grid scheme. A simple explicit numerical model was presented by Gessler (1971). He used the sediment-continuity equation together with Meyer-Peter and Muller (1948) bed-load equation to solve problems of aggradation due to sediment overloading and degradation below dams. In spite of the simplicity of the model, the need of special care in the determination of the time interval deserves mention. Simons and Komura (1967) and Komura (1971) obtained a differential equation for the rate of river-bed degradation based on a combination of sediment-continuity equation 
and one of the several possible sediment-discharge equations. Armoring due to nonuniformity of the bed material was included in the analysis. Sequential numerical integration of the differential equation provide a means for predicting time-dependent degradation processes below dams. A numerical procedure to compute the final equilibrium profile of the river bed was also described.

Miloradov and Muskatirovic (1971) and Miloradov and Radojkovic (1975) developed a model for unsteady, nonuniform flow in alluvial rivers with complex cross-sections and meanders. The model has capability to account for lateral inflows. The backwater curve and sediment continuity equations were solved by an implicit finite difference scheme. Some of the assumptons included in the model (e.g., horizontal water level, neglect of transverse flow in momentum equation and same propagation speed in the main channel and flood plane) were reported as cause of disagreement with field data.

Cunge and Pedreau (1973) solved the backwater and the sediment continuity equations coupled with Meyer-Peter and Muller sediment-transport equation by resorting to an implicit numerical scheme. The model was used to study the bed evolution of a hypothetical river reach subject to aggradation due to overloading. Its usage is recommended for long-term bed evolutions if discharge versus time variations are slow. Chen et al. (1975) developed a one-dimensional numerical model that solves the continuity and momentum equation for water and the sediment-continuity equation by means of a linear implicit scheme. Manning's or Chezy's resistance relation, and the modified Einstein formulation (Colby and Hembree 1955), to estimate the suspended-load and bed-load discharges based on measured sediment-transport data are also included in the analysis. The model was found to be accurate for gradually varied unsteady subcritical flows with irregular shape of the channel crosssection.

Mahmood (1975) and Mahmood and Ponce (1976) reported a mathematical model for the study of sedimentation transients in straight alluvial channels with subcritical flow. Bed and suspended load were separately accounted for in the computations. The model couples the water momentum equation and the sedimentcontinuity equation and solves them by means of a linear implicit scheme. Cunge and Simons (1975) developed an implicit numerical scheme which accounts for varying roughness. The usual single-valued Manning-like relationships 
between the energy slope and the flow variables was replaced by two equations, one for dunes and ripples and the remaining for flat bed, obtained from the Engelund-Hansen (1967) approach. The coincidence of computed results and available laboratory flume data was found encouraging. Hwang (1975) presented a numerical procedure to compute degradation processes below dams which is basically equal to the one developed by Komura (1971).

Stantchev et al. (1975) used an uncoupled explicit scheme to solve the backwater curve and sediment continuity equations. Sediment concentrations required for the computations were obtained from curves based on actual records. Brown and Li (1979) developed a known-discharge, uncoupled water and sediment routing model that uses an analytical Newton-Raphson solution to the backwater curve equation and an explicit finite difference scheme for the sediment-continuity equation. The model can handle lateral sediment inputs due to tributaries. The computer time required for the model was reported to be minimal, and it was recommended for modelling large systems for long periods. Puls et al. (1977) built a two-dimensional mathematical model that solves the common hydrodynamic equations and two additional turbulence equations resorting in an implicit finite-difference scheme. The shear and transport velocity were computed from the velocities near the bottom. An additional sediment-transport equation was used to determine the local sediment transport rate and the bed deformation. Bouvard et al. (1977) extended Cunge and Simons (1975) model and incorporated a varying friction factor given by either Engelund-Hansen or Einstein approach. The possibility of modelling natural alluvial rivers where the flow velocity is not a singlevalued function of the energy slope, water depth, and sediment size is the relevant feature of this contribution. Henriques (1977) formulated a numerical mode which may be considered similar to the Bouvard et al. (1977) model.

Thomas and Prasuhn (1977) presented a model (HEC-6) which solves iteratively the energy equation and allows the use of constant or water depth dependent friction factor. The sediment-transport capacity is computed by using one of the five options available. The model accounts for armoring effects and uses Gessler's (1971) armor stability procedure. The channel bed deformation is determined through the application of the sediment-continuity equation. The model was verified by reconstituting hydraulic model and field 
data under both armoring and non-armoring conditions. Chang and Hill (1977) and Chang (1982) advanced a one-dimensional model whose main feature is its capability to predict changes in river width on the principle of minimum total stream power.

A two-dimensional model which combines the finite-difference and finiteelement techniques to simulate morphological processes in alluvial channels composed by fine uniform sediments has been developed by Ariathurai (1974). Simons et al. (1980) developed a numerical model for simulating watershed sediment yield and subsequent aggradation/ degradation in a river system. The model accounts separately for bed and suspended sediment loads by making use of the Meyer-Peter and Muller equation and Einstein formula for bed- and suspended-load discharges, respectively. A model for rapidly changing flows which is intended to predict river stage, bed elevation and sediment discharge over the course of a flood is being developed by Brownlie (1981). The model accounts for varying friction factor and retains all the time derivatives included in the basic governing equations. 


\section{LINEAR AND NONLINEAR PARABOLIC MODELS}

FOR MORPHOLOGICAL PROCESSES

The classic parabolic model as well as an alternate parabolic model for morphological processes in alluvial rivers, referred to as Z-model and Gmodel, respectively, are derived in detail in this Chapter. The application of these models to several important nonequilibrium processes in rivers is undertaken in subsequent chapters.

\section{A. Theoretical Basis}

The basic one-dimensional equations that govern the flow over a deformable river bed undergoing a nonequilibrium process are:

Momentum equation for water

$$
\frac{\partial U}{\partial t}+U \frac{\partial U}{\partial x}+g \frac{\partial H}{\partial x}+g \frac{\partial z}{\partial x}+g S_{f}=0
$$

Continuity equation for water

$$
\frac{\partial H}{\partial t}+U \frac{\partial H}{\partial x}+H \frac{\partial U}{\partial x}=0
$$

Continuity equation for sediment

$$
\frac{\partial z}{\partial t}+\frac{1}{(1-\lambda)} \frac{\partial G}{\partial x}=0
$$

Sediment transport relation

$$
G=G\left(U, H, d, g, w, S_{f}, v, \ldots\right)
$$

Resistance relation

$$
f=f(U, H, G, d, v, \ldots)
$$


in which: $d=$ mean sediment diameter; $f=$ Darcy-Weisbach friction factor; $G=$ sediment discharge per unit width; $g=$ gravitational acceleration; $H=$ mean water depth; $S_{f}=$ energy slope; $t=$ time; $U=$ mean flow velocity; $w=$ sediment fall velocity; $x=$ longitudinal coordinate measured along the channel bed; $z=$ bed elevation with respect to an arbitrary horizontal reference level; $\lambda=$ porosity of the bed sediment; $\nu=$ kinematic viscosity of water.

1. Assumptions. The main assumptions introduced in the derivation of equations (3.1) through (3.5) are:

1. The alluvial channel is sufficiently straight and uniform so that the flow characteristics may be adequately represented by a onedimensional model.

2. The flow velocity is uniform over the entire cross-section.

3. Hydrostatic pressure distribution prevails at any point in the channel.

4. The water surface slope is small.

5. The density of sediment-laden water is constant over the entire cross section.

6. The sediment size distribution is rather uniform so that no bedarmoring will take place.

2. Basic considerations. Equations (3.4) and (3.5) are empirical relations based on laboratory and field measurements under steady, uniform flow conditions. Their use in nonequilibrium flows at first appears unwarranted; nevertheless, the insight gained in the process of modelling far outweighs the inability of the equations to properly account for all the physical details. An interesting feature in (3.5) is the dependance of the Darcy-Weisbach friction factor $f$ on the sediment discharge $G$. "It is believed that this reflects far more accurately the way streams operate. That is, streams adjust their bed roughness (and thereby their friction factor) to produce the flow depth-velocity combination for a given water discharge that brings the sediment transport capacity of the stream into conformity with the sediment discharge being imposed on the reach of the stream" (Karim, 1981). 


\section{B. The Classical Parabolic Model (Z-Model)}

de Vries (1965) showed that the celerity of propagation of bed disturbances is considerably smaller than the celerities of the water surface disturbances if the Froude number is not too close to unity. This mathematically implies that the local acceleration term $\left(\frac{\partial U}{\partial t}\right)$ and the time derivative of the water depth $\left(\frac{\partial H}{\partial t}\right)$ in (3.1) and (3.2) can be neglected in comparison to the other terms. Elimination of the convective acceleration term $\left(U \frac{\partial U}{\partial x}\right)$ between (3.1) and (3.2) yields

where

$$
\left(1-F r^{2}\right) \frac{\partial H}{\partial x}+\frac{\partial z}{\partial x}+S_{f}=0
$$

$$
\mathrm{Fr}=\mathrm{U} /(\mathrm{gH})^{1 / 2}
$$

Earlier investigators neglected the terms corresponding to the convective acceleration $\left(U \frac{\partial U}{\partial x}\right)$ and the spatial variation of the water depth $\left(\frac{\partial H}{\partial x}\right)$ at the beginning of the derivation of the governing equation for the parabolic model. In order to evaluate the effect of disregarding these two terms in the analytical solution, they are not dropped in the beginning. In the present study it is assumed that for small changes in sediment discharge, the first term in (3.6) can be linearized, which implies $\mathrm{Fr}=\mathrm{Fr}_{0}=\mathrm{U}_{0} /\left(\mathrm{gH}_{0}\right)^{1 / 2}$. Furthermore, by recalling that by definition, $S_{f}=f U^{3} /(8 g q)$, and that for constant water discharge $q$, and constant water and sediment properties (3.4) and $(3.5)$ can be written as

$$
G=G(U, f)
$$

and

$$
f=f(U)
$$

The spatial derivative of (3.6) gives

$$
\left(1-F r_{0}^{2}\right) \frac{\partial^{2} H}{\partial x^{2}}+\frac{\partial^{2} z}{\partial x^{2}}+\frac{1}{8 g q}\left(3 f U^{2}+U^{3} \frac{d f}{d U}\right) \frac{d U}{d x}=0
$$

After introduction of $(3.8)$ and $(3.10)$, the sediment continuity relation, (3.3), becomes

$$
\frac{\partial z}{\partial \tau}-K\left[\frac{\partial^{2} z}{\partial x^{2}}+\left(1-F r_{0}^{2}\right) \frac{\partial^{2} H}{\partial x^{2}}\right]=0
$$


where

$$
K=\frac{U \frac{\partial G}{\partial U}}{S_{f}(1-\lambda)\left(3+\frac{U}{f} \frac{d f}{d U}\right)}
$$

Equation (3.11) can be further simplified by assuming that the second term inside the brackets is negligible and linearizing the coefficient $K$. The result is

$$
\frac{\partial z}{\partial t}-k_{0} \frac{\partial^{2} z}{\partial x^{2}}=0
$$

where

$$
K_{0}=\left[\frac{U \frac{\partial G}{\partial U}}{S_{f}(1-\lambda)\left(3+\frac{U}{f} \frac{d f}{d U}\right)}\right]_{0} \equiv \text { value of } K \text { for uniform flow }
$$

The effects of neglecting the third term in (3.11) and of the linearization of $K$ on the analytical solution will be analyzed later in this study.

For the case of a plane initial bed profile it is advantageous to define a new dependent variable $Z$, as

$$
z=z-z_{b}
$$

where $z_{b}=z_{b}(x)$ is the vertical coordinate measured from a horizontal reference level up to the initial bed profile, and $z$ is the vertical coordinate measured from the initial bed profile. With the above transformation the governing equation becomes

$$
\frac{\partial z}{\partial t}-k_{0} \frac{\partial^{2} z}{\partial x^{2}}=0
$$

Equation (3.13) or (3.16) constitute the linear Z-model which was initially proposed, in a heuristic manner, by Culling (1960). 
C. The Alternate Parabolic Model (G-Model)

As shown in the preceeding section, in all the previous analytical treatments dealing with morphological processes the set of basic governing equations (3.1) through (3.5), after some suitable simplifications, is reduced to a single linear partial differential equation (3.13) or (3.16). From previous and forthcoming discussions it will become evident that further developments are needed in order to enable a reliable determination of the characteristic parameters of morphological processes by analytical means. In an attempt to overcome some of the limitations of the classical linear parabolic model, an alternate parabolic model (the G-model) is developed in the remainder of this chapter.

For a constant water discharge $q$ and constant water and sediment properties $(\nu, d, w),(3.4)$ and (3.5), without lack of rigor, can be expressed as

and

$$
G=G\left(S_{f}, f\right)
$$

$$
f=f\left(S_{f}\right)
$$

The spatial derivative of (3.3) yields

$$
\frac{\partial S}{\partial t}-\frac{1}{(1-\lambda)} \frac{\partial^{2} G}{\partial x^{2}}=0
$$

After substitution of the friction factor relation (3.18) into the sediment transport equation (3.17), the time derivative of the latter gives

where

$$
\frac{\partial G}{\partial t}=F(G) \frac{\partial S_{f}}{\partial t}
$$

$$
F(G)=\frac{d G}{d S_{f}}
$$

The time derivative of the momentum equation, (3.1), yields

$$
\frac{\partial S}{\partial t}=\frac{\partial S_{f}}{\partial t}+\frac{1}{g} \frac{\partial^{2} U}{\partial t^{2}}+\frac{1}{g} \frac{\partial U}{\partial x} \frac{\partial U}{\partial t}+\frac{U}{g} \frac{\partial^{2} U}{\partial x \partial t}+\frac{\partial^{2} H}{\partial x \partial t}
$$

Combining (3.19), (3.20) and (3.22) one obtains 


$$
\frac{1}{F(G)} \frac{\partial G}{\partial t}-\frac{1}{(1-\lambda)} \frac{\partial^{2} G}{\partial x^{2}}+\frac{1}{g} \frac{\partial^{2} U}{\partial t^{2}}+\frac{1}{g} \frac{\partial U}{\partial x} \frac{\partial U}{\partial t}+\frac{U}{g} \frac{\partial^{2} U}{\partial x \partial t}+\frac{\partial^{2} H}{\partial x \partial t}=0
$$

Considering that for all practical applications, $\frac{1}{F(G)} \frac{\partial G}{\partial t}$ is the dominant term in (3.23), and recalling that for studying bed or sediment transients the water flow can be considered quasi-steady, which implies $\frac{\partial U}{\partial t} \equiv \frac{\partial H}{\partial t}=0$, equation (3.23) can be simplified to give

where

$$
\frac{\partial G}{\partial t}-\bar{k} \frac{\partial^{2} G}{\partial x^{2}}=0
$$

$$
\bar{K}=\frac{F(G)}{(1-\lambda)}
$$

Introducing a dimensionless sediment transport parameter $G^{\star}$ defined as

$$
G^{\star}=\left(G-G_{0}\right) / \Delta G_{0}
$$

where $G_{0}$ is the total sediment discharge for uniform flow conditions and $\Delta G_{0}$ is the change (constant) in sediment discharge at $x=0,(3.24)$ and the sediment continuity equation (3.3) become

$$
\frac{\partial G^{*}}{\partial t}-\bar{K} \frac{\partial^{2} G^{*}}{\partial x^{2}}=0
$$

and

$$
\frac{\partial z}{\partial t}+\frac{\Delta G_{0}}{(1-\lambda)} \frac{\partial G^{\star}}{\partial x}=0
$$

The nonlinear sediment-diffusion equation (3.27) is the alternate nonlinear p*rabolic model which, in concert with the sediment continuity relation, (3.28), can be used for predicting bed transients in alluvial channels.

The linear version of the model derived above is

and

$$
\frac{\partial G^{*}}{\partial t}-\bar{K}_{0} \frac{\partial^{2} G^{\star}}{\partial x^{2}}=0
$$

$$
\frac{\partial z}{\partial t}+\frac{\Delta G_{0}}{(1-\lambda)} \frac{\partial G^{\star}}{\partial x}=0
$$

where 
$\bar{K}_{0}=\frac{F\left(G_{0}\right)}{(1-\lambda)}=$ value of $\bar{K}$ for the initial uniform flow

It is easy to prove that for a plane initial bed profile

$$
\bar{K}_{0}=K_{0}
$$

where $k_{0}$ is given by (3.14). A list of expressions for $k_{0}$ for several sediment-transport and friction-factor relations is given in Appendix $I$. When dealing with a time-dependent change in sediment discharge at $x=0$ (i.e., $\Delta G=\Delta G(t)$ ), it is preferable to define a new sediment parameter $G^{\prime}$ as

$$
G^{\prime}=G-G_{0}
$$

Use of the transformation (3.33) in the linearized sediment-diffusion equation and the sediment-continuity equation reduces them to

and

$$
\frac{\partial G^{\prime}}{\partial t}-K_{0} \frac{\partial^{2} G^{\prime}}{\partial x^{2}}=0
$$

$$
\frac{\partial z}{\partial t}+\frac{1}{(1-\lambda)} \frac{\partial G^{\prime}}{\partial x}=0
$$

The strategy to solve any one-dimensional morphological process will consist in solving, firstly, the sediment diffusion (transport) equation (3.27) or (3.29) or (3.34) for the appropriate initial and boundary conditions and, subsequently, use this information to integrate the sediment continuity equation to obtain the time dependent bed profiles. 


\section{LINEAR PARABOLIC MODEL FOR MORPHOLOGICAL PROCESSES}

IN CHANNELS OF SEMI-INFINITE LENGTH

This chapter presents the application of the linear models, introduced in Chapter III, to quantitatively estimate the relevant parameters of nonequilibrium processes of primary importance in river-engineering. The nonequilibrium processes of aggradation due to sediment augmentation and degradation due to sediment diminution in alluvial channels of semi-infinite length is introduced in the first section. The degradation process due to a lowering in the base level of a semi-infinite long channel is given in the later part of this chapter.

A. Aggradation due to Sediment Augmentation and Degradation due to Sediment Diminution

Consider a wide rectangular alluvial channel of semi-infinite length, subject to a constant discharge per unit width $q$, with the mean flow velocity $U_{0}$ and the mean flow depth $H_{0}$, as is shown in figure 4.1. The equilibrium sediment-transport rate under the initial uniform flow condition is $G_{0}$. Let the sediment load at the upstream end of the channel $(x=0)$ be varied by $-G(t)$ so that the total sediment-transport rate at $x=0$ becomes $G_{0}$ $+\Delta G(t)$. As a result the equilibrium between the water and sediment discharges is disturbed. If $\Delta G(t)$ is positive, the bed slope must increase to transport the additional imposed sediment load which is deposited on the bed causing it to aggrade. On the contrary, for a negative value of $\Delta G(t)$, the bed will degrade and the bed slope will decrease.

1. Analytical solution by linear G-model. From the statement of the problem it becomes evident that the initial and boundary conditions can be formulated in a rather simple and accurate manner in terms of the sedimenttransport rate. Hence, the use of the linear parabolic model constituted by (3.34) and (3.35) is the better alternative in the present case. The initial condition applicable to the nonequilibrium processes under consideration is 


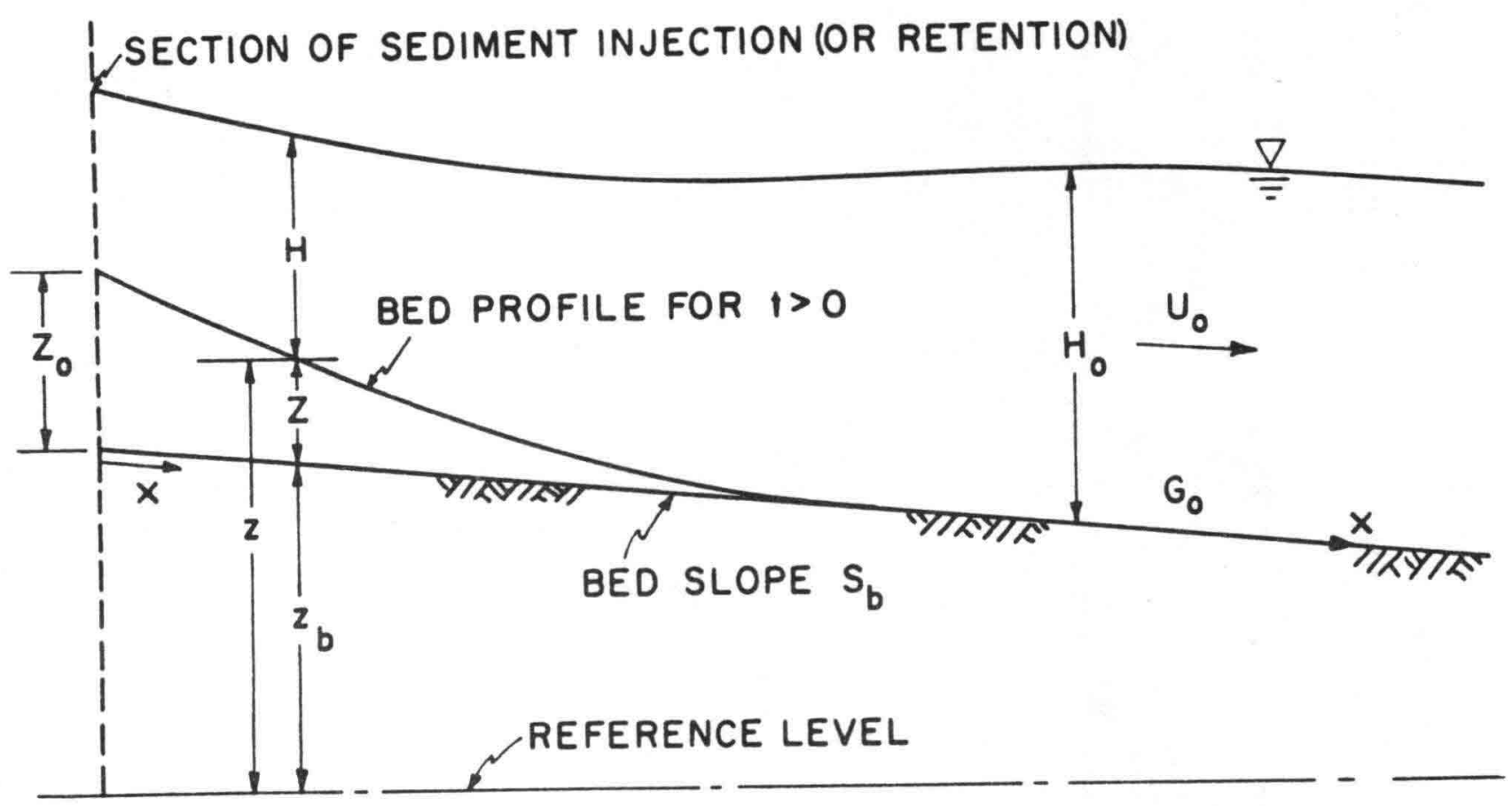

Figure 4.1 Morphological Processes in a Semi-Infinite Alluvial 


$$
G^{\prime}(x, 0)=0 \text {, for } x \geq 0
$$

The boundary conditions for the case in which the imposed sediment discharge at $x=0$ differs by $\Delta G(t)$ from the equilibrium sediment discharge $\left(G_{0}\right)$ are simply

and

$$
G^{\prime}(0, t)=\Delta G(t) \text {, for } t>0
$$

$$
\lim _{x \rightarrow \infty} G^{\prime}(x, t)=0
$$

The sediment-diffusion equation (3.34) and its corresponding initial and boundary conditions $(4.1),(4.2)$, and (4.3), respectively, constitute a classical boundary-value problem in heat conduction in solids with constant properties (Carslaw and Jaeger, 1978). Its general solution is

$$
G^{\prime}(x, t)=\frac{2}{\sqrt{\pi}} \int_{n}^{\infty} \Delta G\left(t-\frac{x^{2}}{2 k_{0} \zeta^{2}}\right) \exp \left(-\zeta^{2}\right) d \zeta
$$

where

$$
n=\frac{x}{2 \sqrt{K_{0} t}}
$$

Although the entire research on the subject has been restricted, so far, to the case in which the variation in total sediment load at $x=0$ is a constant, it is evident that (4.4) enables the solution for several other interesting cases in which the variation in sediment load is a function of time. Analytical solutions for two cases are given in the following.

Case 1

$$
\Delta G(t)=\Delta G_{0}=\text { constant }
$$

For illustrative purposes, and due to its importance in practical applications, this case will be solved in detail.

Placing (4.6) into the general solution (4.4), gives

$$
G^{\prime}(x, t)=\frac{2 \Delta G_{0}}{\sqrt{\pi}} \int_{n}^{\infty} \exp \left(-\zeta^{2}\right) d \zeta
$$


which can be rewritten

$$
G(x, t)=G_{0}+\Delta G_{0} \operatorname{erfc}(n)=G_{0}+\Delta G_{0} \operatorname{erfc}\left(\frac{x}{2 \sqrt{K_{0} t}}\right)
$$

Once the solution to the sediment-diffusion equation (3.34) has been obtained, the bed profile is obtained from the sediment-continuity equation (3.35). Substitution of $\frac{\partial G^{\prime}}{\partial x}$ from equation (4.7) into (3.35), and subsequent integration with respect to time yields

$z=\frac{2 \Delta G_{0}}{K_{0}(1-\lambda)}\left[\left(\frac{K_{0} t}{\pi}\right){ }^{1 / 2} \exp \left(-\frac{x^{2}}{4 K_{0} t}\right)-\frac{x}{2} \operatorname{erfc}\left(\frac{x}{2 \sqrt{K_{0} t}}\right)\right]+C(x)$

The constant of integration $C(x)$ is evaluated from the known initial bed profile, that is

$$
z(x, 0)=z_{b}(x)
$$

hence, the final expression for the time-dependent bed profile becomes

$$
z=\frac{2 \Delta G_{0}}{K_{0}(1-\lambda)}\left[\left(\frac{K_{0} t}{\pi}\right){ }^{1 / 2} \exp \left(-\frac{x^{2}}{4 K_{0} t}\right)-\frac{x}{2} \operatorname{erfc}\left(\frac{x}{2 \sqrt{K_{0} t}}\right)\right]+z_{b}(x)
$$

Though (4.11) provides a general solution which is valid for any arbitrary initial bed profile $z_{b}(x)$, its applicability to initial curved bed profiles requires the fulfillment of the condition

$$
G(x, 0)=G_{0}=G\left(S_{f}(x, 0), f(x, 0)\right)
$$

as well as the estimation of a suitable value for either the bed slope or the friction factor in the evaluation of the coefficient $K_{0}$.

For the case of a plane initial bed profile, substitution of the transformation defined by (3.15) into (4.11) yields

$$
z(x, t)=\frac{2 \Delta G_{0}}{K_{0}(1-\lambda)}\left[\left(\frac{K_{0} t}{\pi}\right)^{1 / 2} \exp \left(\frac{-x^{2}}{4 K_{0} t}\right)-\frac{x}{2} \operatorname{erfc}\left(\frac{x}{2 \sqrt{K_{0} t}}\right)\right]
$$

The bed elevation at $x=0$, for any time $t$, is given by 


$$
Z_{0}=\frac{2 \Delta G_{0}}{K_{0}(1-\lambda)}\left(\frac{K_{0} t}{\pi}\right)^{1 / 2}
$$

which may be expressed in dimensionless form as

$$
\frac{z_{0}}{\left(K_{0} t\right)^{1 / 2}}=\frac{2 \Delta G_{0}}{(\pi)^{1 / 2} K_{0}(1-\lambda)}
$$

The dimensionless or normalized bed profile can be written

$$
z / z_{0}=\exp \left(-n^{2}\right)-n(\pi)^{1 / 2} \operatorname{erfc}(n)
$$

where $n$ is given by (4.5): A characteristic length $L$ for the morphological processes under consideration can be obtained by assuming, as is usual in phenomena of asymptotic nature, that the process ends where $z / Z_{0}=0.01$. By doing so, (4.16) yields

$$
L=3.20\left(K_{0} t\right)^{1 / 2}
$$

The bed slope at any section and time can be obtained from (4.13) and (3.15) and is given by

$$
S=S_{0}+\frac{\Delta G_{0}}{K_{0}(1-\lambda)} \operatorname{erfc}(n)
$$

where $S_{0}$ is the initial constant bed slope.

The curvature of the bed profile is

$$
C=\frac{\partial^{2} z}{\partial x^{2}}=-\frac{\Delta G_{0}}{K_{0}(1-\lambda) \sqrt{\pi K_{0} t}} \exp \left(\frac{-x^{2}}{4 K_{0} t}\right)
$$

This last equation leads to the following general conclusions:

1. At any given time $t$, the curvature is maximum at $x=0$ (i.e., the place at which the increase or withdrawal of sediment is being imposed) and decreases asymptotically as $x$ grows. This implies that the error introduced in the solution due to the quasi-uniform flow assumption will be larger as $x$ tends to zero and will become smaller as $x$ increases. 
2. As time progresses, the bed-profile curvature lessens so that better agreement between theoretical and experimental values should be expected at relatively large times $t$.

3. The bed-profile concavity depends on the magnitude of $\Delta G_{0}$ and on the nature of the process (aggradation or degradation). It will be concave downward for degradation processes, where $\Delta G_{0}$ is negative. On the contrary, a bed profile concave upward should be expected in aggradation processes, where $\Delta G_{0}$ is positive.

4. By equating to zero the time derivative of (4.19) it can be shown that the rate of change of curvature is a maximum at $x(\max )=$ $\left(2 K_{0} t\right)^{1 / 2}$.

Case 2

$$
\Delta G(t)=C_{0} t^{m / 2}
$$

where $m$ is any positive integer. The solution for this case is (Carslaw and Jaeger 1978)

$$
G^{\prime}(x, t)=C_{0} \Gamma\left(\frac{m}{2}+1\right)(4 t)^{m / 2} i^{m} \operatorname{erfc}\left(\frac{x}{2 \sqrt{K_{0} t}}\right)
$$

or

$$
G(x, t)=G_{0}+C_{0} \Gamma\left(\frac{m}{2}+1\right)(4 t)^{m / 2} i^{m} \operatorname{erfc}(n)
$$

and

$z(x, t)=\frac{c_{0} \Gamma\left(\frac{m}{2}+1\right)}{k_{0}^{1 / 2}(1-\lambda)}(4 t)^{(m+1) / 2} i^{m+1} \operatorname{erfc}\left(\frac{x}{2 \sqrt{k_{0} t}}\right)+z_{b}(x)$

where $\Gamma$ is the gamma function and $i^{m} \operatorname{erfc} x$ is the repeated integral of the error function defined as

with

$$
i^{m} \operatorname{erfc} x=\int_{x}^{\infty} i^{m-1} \operatorname{erfc} u d u, m=1,2, \ldots
$$




$$
i^{0} \operatorname{erfc}=\operatorname{erfc} x
$$

The analytical solution for bed profiles corresponding to the case of a time-dependent variation in total sediment discharge at $x=0$ (i.e., $\Delta G=C_{0} t^{m / 2} ; m=-1,0,1,2,3, \ldots$ ) and plane initial bed is shown in figure 4.2. It is interesting to point out that the bed slope at any location $x$ increases as the exponent $m$ grows. Hence, both the aggradation and the degradation lengths decrease as the exponent $m$ increases. Consistent with the above observations, (4.23) indicates that the bed elevation at $x=0$ increases in an aggradation process and diminishes during a degradation process with $t(m+1) / 2$.

It seems useful and timely to point out the main features of the analytical solution presented above:

a) A general and unified treatment has been given to both aggradation and degradation processes in alluvial streams.

b) The analytical solution is valid for constant as well as for time dependent variations in total sediment discharge (at $x=0$ ).

c) the derivation has been kept sufficiently general as to enable its usage in conjunction with almost any of the sediment-transport and friction-factor relations available.

2. Analytical solution by linear Z-model. In order to assess the similarities and differences between the G- and Z-models, the solution to the morphological problem formulated above by the Z-model is presented in the following.

The governing equation is

$$
\frac{\partial z}{\partial t}-k_{0} \frac{\partial^{2} z}{\partial x^{2}}=0
$$

The initial condition applicable to the nonequilibrium processes under consideration is 


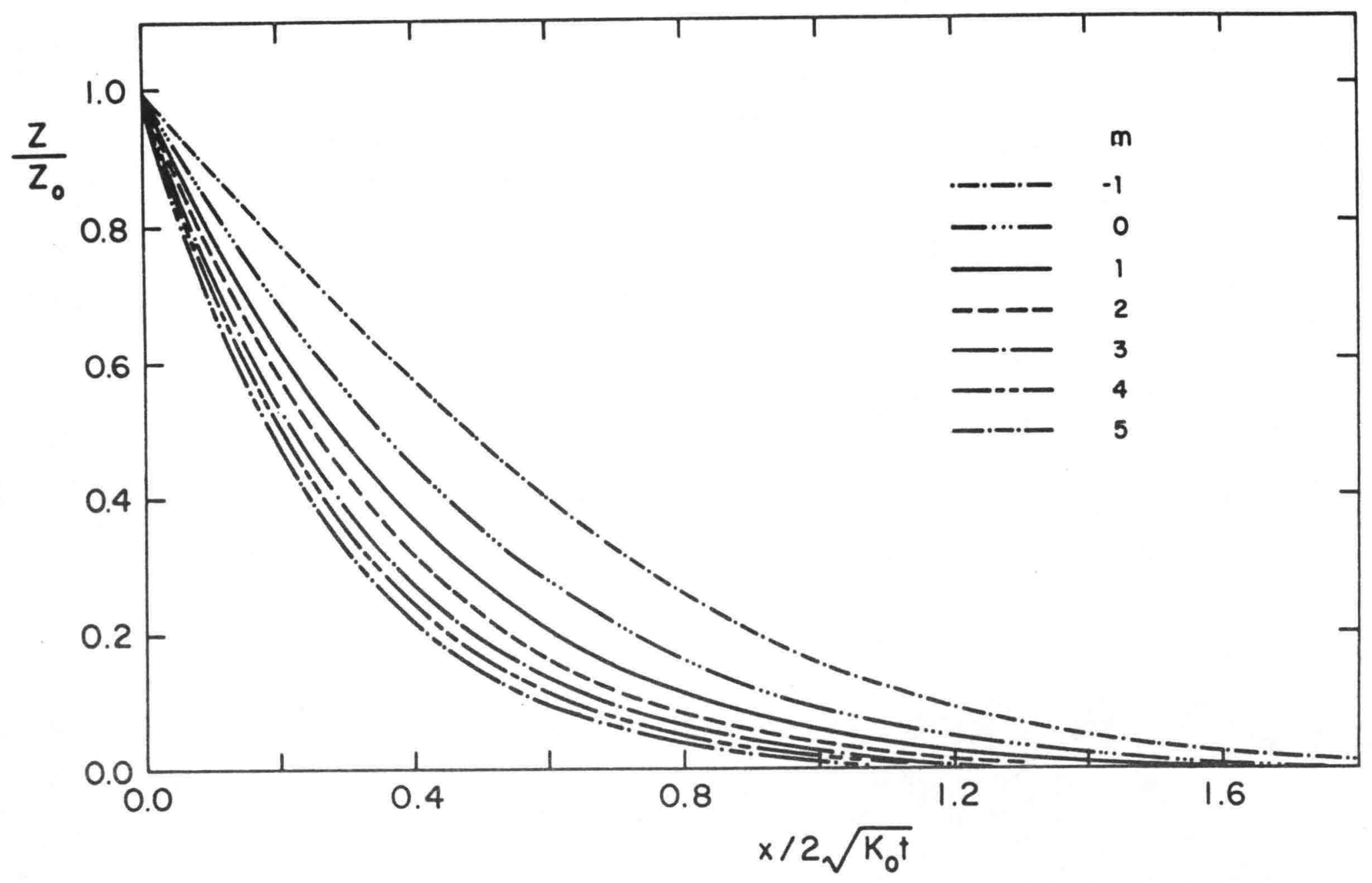

Figure 4.2 Normalized Bed-Profile $\left(Z / Z_{0}\right.$ versus $\left.\eta\right)$ for Various Sediment Discharge
Variations $\left(\Delta G=C t^{m / 2}\right)$ Variations $\left(\Delta G=C_{0} t^{m / 2}\right)$ 


$$
z(x, 0)=z_{b}(x)
$$

The downstream boundary condition is

$$
z(x, t)=\operatorname{limit}_{x \rightarrow \infty} z_{b}(x)
$$

The upstream boundary condition at $x=0$ which is known in terms of $G$ (see $(4.2))$ is, however, not readily evident as a function of the dependent variable, z. In fact this boundary condition has been subject of controversy among earlier investigators (de Vries 1973; Ashida and Michiue 1971; Soni et al. 1980; Mehta et al. 1981; Jain 1981). The derivation of the upstream boundary condition in terms of $z$ is given below.

Equating the values of $\frac{\partial z}{\partial t}$ from (3.13) and the sediment-continuity equation (3.3) and integrating the resulting equation yields

$$
G(x, t)=G_{0}+K_{0}(1-\lambda)\left(\frac{\partial z b}{\partial x}-\frac{\partial z}{\partial x}\right)
$$

The constant of integration is determined from the condition

$$
G=G_{0} \text { when } \frac{\partial z}{\partial x}=\frac{\partial z}{\partial x}
$$

Equation (4.28) is the modified sediment-transport equation that replaces (3.4) as a result of the simplifications introduced in the analysis. From the fact that for $t>0, G(0, t)=G_{0}+\Delta G(t),(4.28)$ gives

$$
\frac{\partial z}{\partial x}(0, t)=\frac{\partial z b}{\partial x}-\frac{\Delta G(t)}{K_{0}(1-\lambda)}
$$

which is the boundary condition required to solve (3.13).

It is apparent that the solution of (3.13) subject to $(4.26),(4.27)$ and (4.29) requires the specification of the initial bed profile $z_{b}(x)$. Hence, no general solution (as the one obtained by means of the G-model, namely, (4.23)) can be obtained. Moreover, the analytical solution, depending on the particular initial bed profile, may become complex. It is interesting to note that for the initial curved bed profiles, the general explicit solution obtained from the G-parabolic model and the ad-hoc solution provided by the Z- 
model are different. The reason for this difference is the different assumptions upon which the models are based.

Due to its practical applications, the solution for a plane initial bed is of particular interest and is presented below.

On introducing the new independent variable $Z$, defined by (3.15), the governing equation and the initial and boundary conditions are transformed to

$$
\begin{gathered}
\frac{\partial Z}{\partial t}-k_{0} \frac{\partial^{2} Z}{\partial x^{2}}=0 \\
Z(x, 0)=0 \\
\lim _{x \rightarrow \infty} Z(x, t)=0
\end{gathered}
$$

and

$$
\frac{\partial Z}{\partial x}(0, t)=-\frac{\Delta G(t)}{K_{0}(1-\lambda)}
$$

The governing equation (3.16) with the initial and boundary conditions (4.30), (4.31) and (4.32) constitute a classical boundary-value problem in heat conduction in solids (Carslaw and Jaeger 1978). Its general solution is

$$
Z(x, t)=\frac{x}{K_{0} \sqrt{\pi}} \int_{x / 2 \sqrt{K_{0} t}}^{\infty} \Delta G\left(t-\frac{x^{2}}{4 K_{0} \mu^{2}}\right) \frac{\exp \left(-\mu^{2}\right)}{\mu^{2}} d \mu
$$

Solutions for two choices of the variation in total sediment discharge $\Delta G(t)$ at $x=0$, obtained by integrating $(4.33)$ by parts are written down in the following.

Case 1

$$
\begin{gathered}
\Delta G(t)=\Delta G_{0}=\text { constant } \\
Z(x, t)=\frac{2 \Delta G_{0}}{K_{0}(1-\lambda)}\left[\left(\frac{K_{0} t}{\pi}\right)^{1 / 2} \exp \left(\frac{-x^{2}}{4 K_{0} t}\right)-\frac{x}{2} \operatorname{erfc}\left(\frac{x}{2 \sqrt{K_{0} t}}\right)\right]
\end{gathered}
$$


Case 2

$$
\Delta G(t)=C_{0} t^{m / 2}
$$

where $m$ is an integer greater or equal to -1 (i.e., $m \geq-1$ )

$$
Z(x, t)=\frac{c_{0} \Gamma\left(\frac{m}{2}+1\right)}{k_{0}^{1 / 2}(1-\lambda)}(4 t)^{(m+1) / 2} i^{m+1} \operatorname{erfc}\left(\frac{x}{2 \sqrt{k_{0} t}}\right)
$$

It is evident that for this condition (plane initial bed profile) both the Gand the Z-model give identical solutions. This stems from the fact that in such a case, the assumptions contained in both linear parabolic models are the same, namely, the flow is considered to be quasi-steady and quasi-uniform. This special feature of the models proved to be useful in the solution of other morphological processes which are discussed in the next chapter.

B. Degradation Due to Base-Level Lowering

The degradation of alluvial channels in response to base-level lowering has attracted the attention of geologists for many years. The initiation and development of gullies due to a lowering in base-level is of primary importance to agricultural interests and to conservationists because of its undesirable effects. Some of the practical examples of degradation processes initiated by a lowering in base level which may be relevant to hydraulic engineers are:

a) Rapid drawdown of a reservoir located at the downstream end of the alluvial river.

b) Meander loop cutoff.

c) Road-cut at the toe of a slope.

d) Enlargement of the channel cross section.

Nevertheless, it apears that hydraulic engineers have devoted little attention to this interesting type of morphological process.

Holland and Pickup (1976) reported laboratory flume experiments simulating the rapid drawdown of a reservoir located downstream. The 
diminution in reservoir level was such that it created critical flow conditions at the downstream end of the alluvial channel throughout the process. Begin et al. $(1980,1981)$ performed similar experiments; however, during their tests the downstream critical flow condition was attained only during the initial stages of the morphological process. Begin and coworkers developed a linear parabolic model (Z-model), valid for the case in which the sediment-transport rate is proportional to the third power of the mean flow velocity, and obtained an analytical solution. The downstream boundary condition they used, namely, the bed elevation at the downstream end decreases instantaneously by an amount equal to the diminution in reservoir level and remains unchanged throughout the process, is neither supported by Holland and Pickup's experiments nor by physical reasoning. The poor agreement between the analytical and experimental results, which forced the authors to empirically modify the diffusion coefficient, may be to some extent explained by the inappropriate statement of the downstream boundary condition.

The purpose of this section is to obtain an analytical solution for a degradation process due to base-level lowering by using a more appropriate downstream boundary condition.

1. Statement of the Problem. Consider, as in the previous case, a wide, semi-infinite-long, alluvial channel subject to an initial steady uniform flow. The degradation process initiated by a lowering of base level, as a result of a rapid drawdown of a reservoir located at the downstream end of the river $(x=0)$ is depicted in figure 4.3 .

The assumptions introduced in the analysis are:

(i) The process can be adequately described by the linear models derived previously.

(ii) The bed material can stand on steep slopes.

(iii) At time $t=0$, the water level at the downstream end is lowered enough to create a critical flow condition at $x=0$.

(iv) The downstream pool or channel disposes the entire sediment load that is transported from the upstream channel.

(v) The degradation process is eventually limited by the thickness ( $Z_{L}$ ) of the alluvial stratum, as shown in figure 4.3 . 


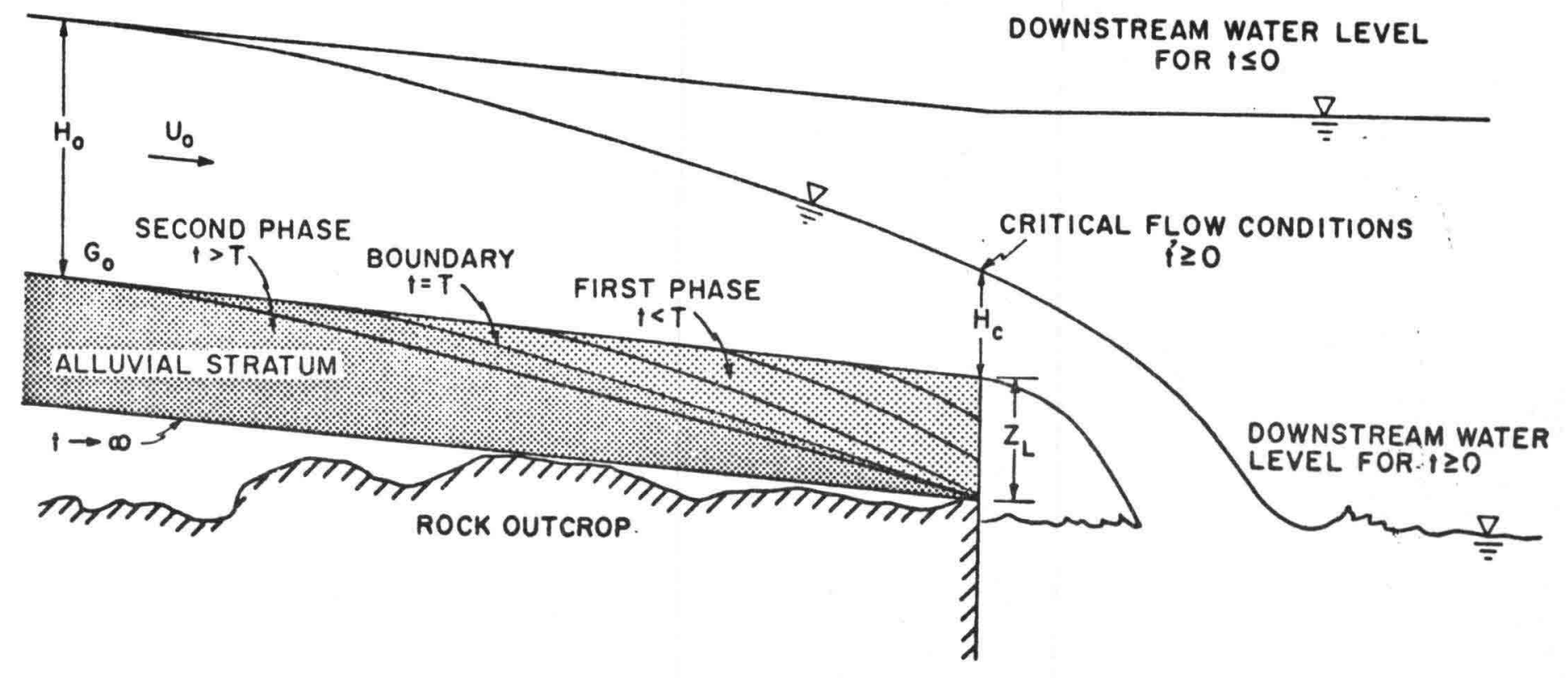

Figure 4.3 Schematic Illustrating a Degradation Process Due to Base Level-Lowering 
(vi) The initial bed is plane.

2. Schematization of the problem. In spite of the simplifications cited above, the present problem is still too complex and a further schematization is required to solve it.

The process is divided in two phases. Within the first phase, the bed level throughout the channel decreases gradually until the bed level at $x=0$ at $t=T$ reaches the new imposed bed level $Z_{L}$ (i.e., the rock outcrop). During the second phase of the process the bed level at the downstream end remains constant at $Z_{L}$ and the rest of the stream degrades.

3. First phase. From the fact that the initial and boundary conditions required to solve the problem are easier to formulate in terms of the sediment transport rate, the G-parabolic model (3.29) should be used during this initial part. The initial and boundary conditions may be written

$$
\begin{aligned}
& G *(x, 0)=0 \\
& G *(0, t)=1
\end{aligned}
$$

and

$$
\operatorname{limit}_{x \rightarrow \infty} G^{*}(x, t)=0
$$

where $G^{*}$ is defined as in (3.26) and

$$
\Delta G_{0}=G_{C}-G_{0}
$$

in which $G_{C}$ is the sediment discharge at critical-flow conditions. The solution to the governing equation (3.29) under the initial and boundary conditions prescribed by $(4.38),(4.39)$ and $(4.40)$ is

$$
Z(x, t)=\frac{2 \Delta G_{0}}{K_{0}(1-\lambda)}\left[\left(\frac{K_{0} t}{\pi}\right)^{1 / 2} \exp \left(-\frac{x^{2}}{4 K_{0} t}\right)-\frac{x}{2} \operatorname{erfc}\left(\frac{x}{2 \sqrt{K_{0} t}}\right)\right]
$$

Note that (4.13) through (4.19) are valid for this phase. The end of this initial phase occurs at time $T$, when $Z(0, T)=Z_{L}$; hence, from $(4.14)$ one obtains 


$$
T=\pi K_{0} Z_{L}^{2}(1-\lambda)^{2} /\left(4 \Delta G_{0}^{2}\right)
$$

4. Second phase. The Z-model is more suitable for the second phase, because the initial and boundary conditions are known in terms or $z$. The initial condition in terms of $Z$ at the end of the first phase is given by (4.13) on substituting $t=T$, that is

$Z(x, 0)=\frac{2 \Delta G_{0}}{K_{0}(1-\lambda)}\left[\left(\frac{K_{0} T}{\pi}\right)^{1 / 2} \exp \left(-\frac{x^{2}}{4 K_{0} T}\right)-\frac{x}{2} \operatorname{erfc}\left(\frac{x}{2 \sqrt{K_{0} T}}\right)\right]$

The boundary condition is

$$
Z(0, t)=Z_{L} \text { for } t>0
$$

The introduction of a new dependent variable $\bar{Z}$ as

$$
\bar{Z}(x, t)=Z(x, t)-Z_{L}
$$

transforms the initial problem to the simpler one given below. Governing equation

Initial condition:

$$
\frac{\partial \bar{z}}{\partial t}-k_{0} \frac{\partial^{2} \bar{z}}{\partial x^{2}}=0
$$

$$
\bar{Z}(x, 0)=Z(x, 0)-Z_{L}=F(x)
$$

Boundary condition

$$
\bar{z}(0, t)=0 \text { for } t \geq 0
$$

The solution to (4.46) subject to (4.47) and (4.48) is (Carslaw and Jaeger 1978)

$$
\begin{gathered}
\bar{Z}(x, t)=\frac{1}{2 \sqrt{\pi K_{0} t}} \int_{0}^{\infty}\left\{\exp \left[-\frac{(x-u)^{2}}{4 K_{0} t}\right]-\right. \\
\left.\exp \left[-\frac{(x+u)^{2}}{4 K_{0} t}\right]\right\} F(u) d u
\end{gathered}
$$


The analytical integration of $(4.49)$ is given in appendix II. The final result reads

$$
\begin{gathered}
\frac{Z(x, t)}{Z_{L}}=1-\operatorname{erf}\left(\frac{x}{\sqrt{K_{0} t}}\right)+\sqrt{1+\frac{t}{T}} \exp \left[-\frac{x^{2}}{4 K_{0} T\left(1+\frac{t}{T}\right)}\right] \\
\operatorname{erf}\left[\frac{x}{2 \sqrt{K_{0} t\left(1+\frac{t}{T}\right)}}\right]
\end{gathered}
$$

$-\frac{\sqrt{\pi}}{2 \sqrt{K_{0} T}}\left(1-\frac{2}{\pi} \operatorname{arctg} \sqrt{\frac{t}{T}}\right)+\frac{4}{\sqrt{\pi}}\left(\frac{x}{2 \sqrt{K_{0} T}}\right)^{2} \sum_{n=0}^{\infty} \frac{1}{[2(n+1)] !}\left(\frac{x}{2 \sqrt{K_{0} t}}\right)^{2(n+1)} H_{2 n+1}(\gamma)$

where $\mathrm{H}_{2 n+1}$ is a special polynomial whose coefficients are given by those corresponding to the Hermite polynomial of order $2 n+1$, and the argument $\gamma$ follows the rule

$$
r^{n}=\frac{\Gamma(n)}{2\left(1+\frac{t}{T}\right)^{n}}, \quad n>0
$$

in which $\Gamma(n)$ is the gamma function of $n$.

From the analytical solution as well as from, physical considerations, it becomes apparent that the final equilibrium condition will be asymptotically attained when the bed slope equals the original bed slope $S_{0}$. A useful time scale $\left(T^{*}\right)$ for the process under study can be obtained by considering that the end of the process will be reached when the slope at $x=0$, fulfills the condition

$$
S(0, t)=1.01 S_{0}
$$

After manipulating (4.50), (4.51) and (4.52) the analytical time scale for the process becomes

$$
\sqrt{\frac{T^{\star}}{T}}=\operatorname{tg}\left\{\frac{\pi}{2}\left[1-\frac{0.1 S_{0} K_{0}(1-\lambda)}{\Delta G_{0}}\right]\right\}
$$

The above example illustrates the application of both linear G- and Z-models to the same morphological process. 


\section{LINEAR PARABOLIC MODELS FOR MORPHOLOGICAL PROCESSES IN ALLUVIAL CHANNELS OF FINITE LENGTH}

The analytical solution for the processes of aggradation resulting from sediment augmentation and degradation due to sediment curtailment in alluvial channels of finite length is presented in this chapter.

\section{A. Statement of the Problem}

Consider a wide rectangular alluvial channel of finite length $L$, subject to a constant discharge per unit width $q$, with mean flow velocity $U_{0}$ and mean flow depth $H_{0}$, as shown in figure 5.1. The equilibrium sediment-transport rate under the uniform-flow condition is $G_{0}$ and the bed slope is $S_{0}$. Let the sediment discharge at the upstream end of the channel $(x=0)$ be varied by $\Delta G$, so that the total sediment-transport rate at $x=0$ becomes $G_{0}+\Delta G$. As a result, the equilibrium between the water and sediment discharges is disturbed. If $\Delta G$ is positive, the bed slope must increase to transport the additional imposed load which is deposited on the bed causing it to aggrade. On the contrary, for a negative value of $\Delta G$, the bed will degrade and the bed slope will decrease. At the downstream end of the channel $(x=L)$, the bed elevation remains unchanged due to the presence of a rock outcrop or control structure. The process of aggradation (or degradation) will continue until the entire channel bed attains a new equilibrium slope for which the balance between the water discharge and the new sediment load is re-established.

\section{B. Model Selection}

The choice between the Z- and G-models depend on the initial and boundary conditions. The initial condition is known in terms of both $Z$ and $G$; that is

or

$$
Z(x, 0)=0 \quad 0 \leq x \leq L
$$

$$
G^{\prime}(x, 0)=0 \quad 0 \leq x \leq L
$$




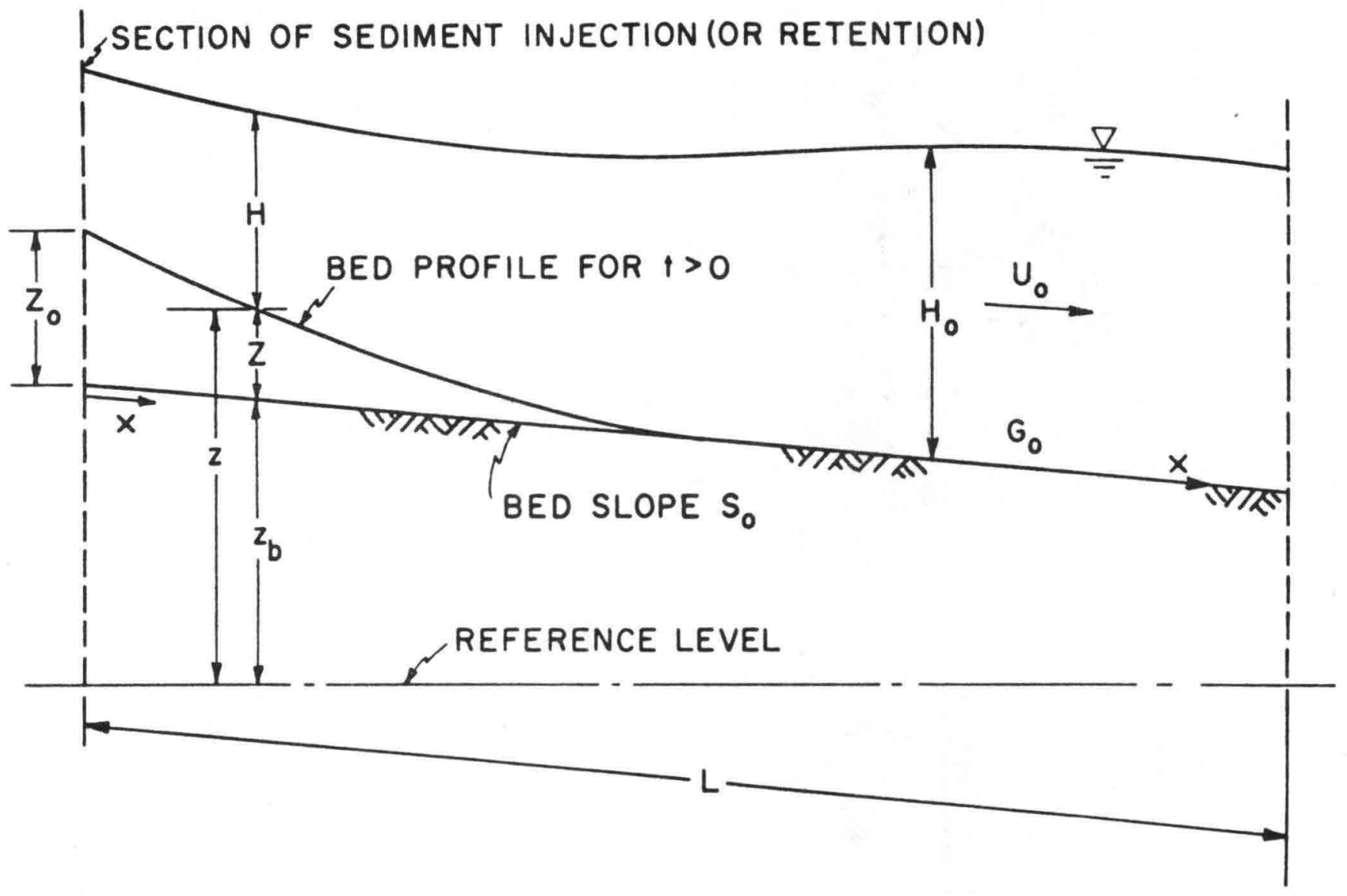

Figure 5.1 Definition Sketch for Morphological Processes in Finite Length Channels 
The upstream and downstream boundary conditions are known in terms of $G^{\prime}$ and $Z$, respectively. They read

$$
G^{\prime}(0, t)=\Delta G
$$

and

$$
Z(L, t)=0
$$

The transformation of the downstream boundary condition (5.2a) in terms of $G$ is not apparent. The upstream boundary condition (5.2) is transformed in terms of $Z$ using $(4.28)$ and $(3.15)$ to

$$
\frac{\partial Z}{\partial x}(0, t)=-\frac{\Delta G}{K_{0}(1-\lambda)}
$$

From the above discussion it becomes obvious that the Z-model is the proper selection for studying the morphological processes under consideration.

C. Analytical Solution for a Constant Variation

in Total Sediment Discharge

The solution for the case in which $\Delta G=\Delta G_{0}$ is

$$
\begin{aligned}
& Z(x, t)=\frac{\Delta G_{0} L}{K_{0}(1-\lambda)}\left\{\left(1-\frac{x}{L}\right)-\frac{8}{\pi^{2}} \sum_{n=0}^{\infty} \frac{(-1)^{n+1}}{(2 n+1)^{2}}\right. \\
& \left.\exp \left[-\frac{(2 n+1)^{2}}{4} \pi^{2} t \star^{2}\right] \sin \left[\left(\frac{2 n+1}{2}\right)\left(1-\frac{x}{[}\right) \pi\right]\right\}
\end{aligned}
$$

where

$$
t *=\sqrt{K_{0} t} / L
$$

The bed elevation $Z_{0}$, at $x=0$ is given by

$$
\begin{aligned}
Z_{0}= & \frac{\Delta G_{0} L}{K_{0}(1-\lambda)}\left\{1-\frac{8}{\pi^{2}} \sum_{n=0}^{\infty} \frac{(-1)}{(2 n+1)^{2}}\right. \\
& \left.\exp \left[-\frac{(2 n+1)^{2}}{4} \pi^{2} t^{2}\right]\right\}
\end{aligned}
$$


The variation of the sediment-transport rate with distance and time can be obtained on substituting for $\partial Z / \partial x$ from $(5.4)$ into the sediment-continuity equation (4.28) as

$$
\begin{aligned}
G^{*}=1+\frac{4}{\pi} & \sum_{n=0}^{\infty} \frac{(-1)^{n}}{(2 n+1)} \exp \left[-\frac{(2 n+1)^{2} \pi^{2} t_{*}^{2}}{4}\right] \\
& \exp \left[\frac{\pi(2 n+1)}{2}\left(1-\frac{x}{L}\right)\right]
\end{aligned}
$$

The new equilibrium condition is attained when the change in the bed elevation at $x=0$ equals $\Delta G_{0} L /\left[K_{0}(1-\lambda)\right]$. The time required to change the bed elevation at $x=0$ to 99 percent of its final value is obtained from (5.6) as

$$
t=1.77 \mathrm{~L}^{2} / \mathrm{K}_{0}
$$

The time required to attain the new equilibrium condition is independent of $\Delta G_{0}$ and is the same for aggradation and degradation.

1. Discussion of results. The normalized bed profiles, $z / Z_{0},((5.4)$ and (5.6) as functions of $x / L$ for several values of the dimensionless time $t$ * are presented in figure 5.2. It is interesting to note that the aggrading (or degrading) front for values of $t$ * less than about 0.312 does not reach the downstream end of the channel. This suggests that for small values of $t^{*}$, the channel can be treated as semi-infinite in length. The solution for the semiinfinite reach presented in Chapter IV suggests introduction of a new dimensionless length scale,

$$
n=\frac{x}{2 \sqrt{K_{0} t}}=\frac{x}{2 t \star L}
$$

The normalized bed profiles plotted against $n$ for several values of $t$ * are shown in figure 5.3. The bed profiles for $t *$ less than about 0.312 coalesce into a single curve which coincides with the semi-infinite reach solution. The variation of the dimensionless sediment transport with $x / L$ and $n$ are shown, respectively, in figures 5.4 and 5.5. As time increases, the sedimenttransport rate along the channel tends to attain the imposed sediment discharge. The curves corresponding to $t *$ less than about 0.274 coalesce into a single curve which coincides with the solution for the semi-infinite reach 


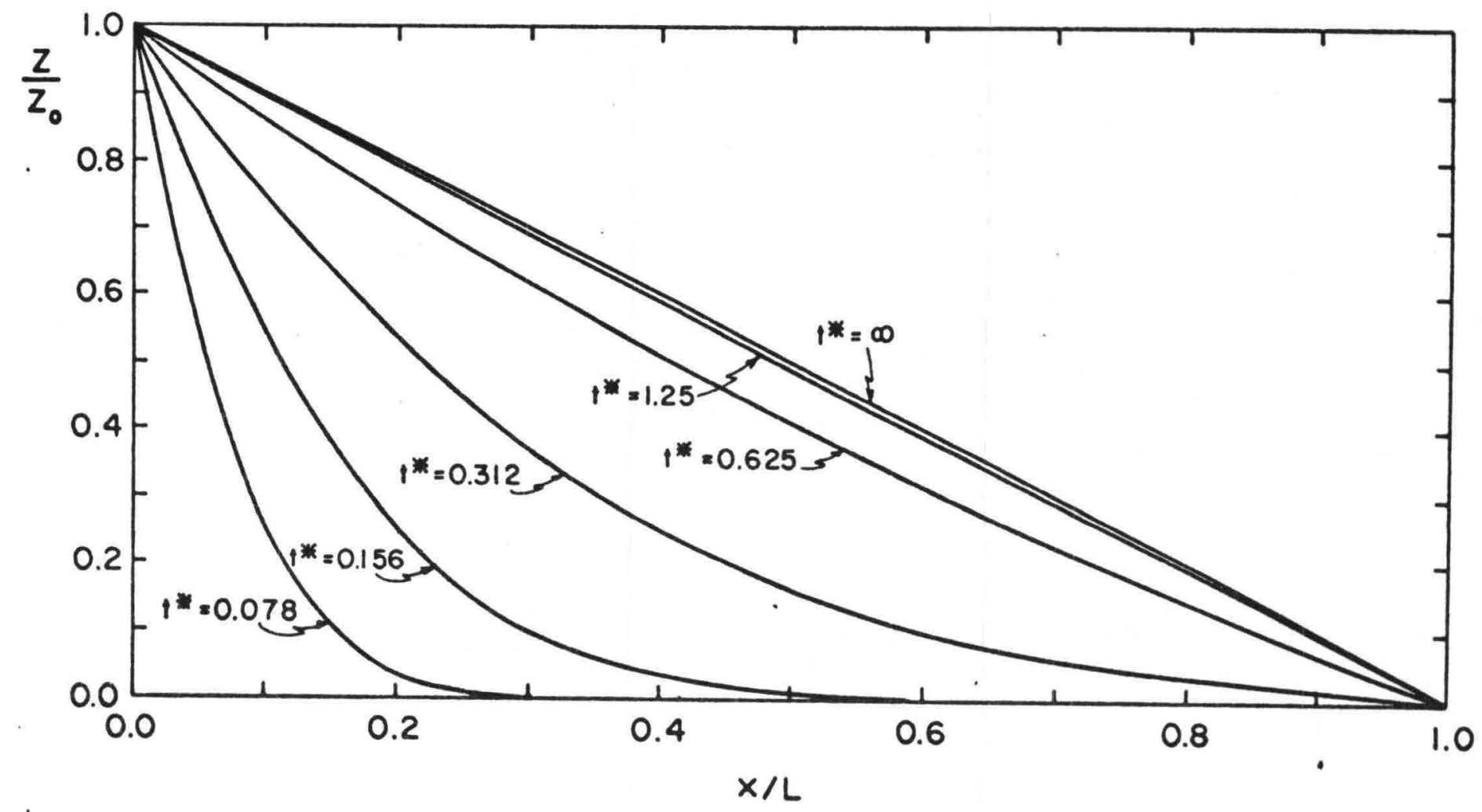

Figure 5.2 Normalized Bed Profiles $\left(Z / Z_{0}\right.$ versus $\left.x / L\right)$ for Various Normalized Times 


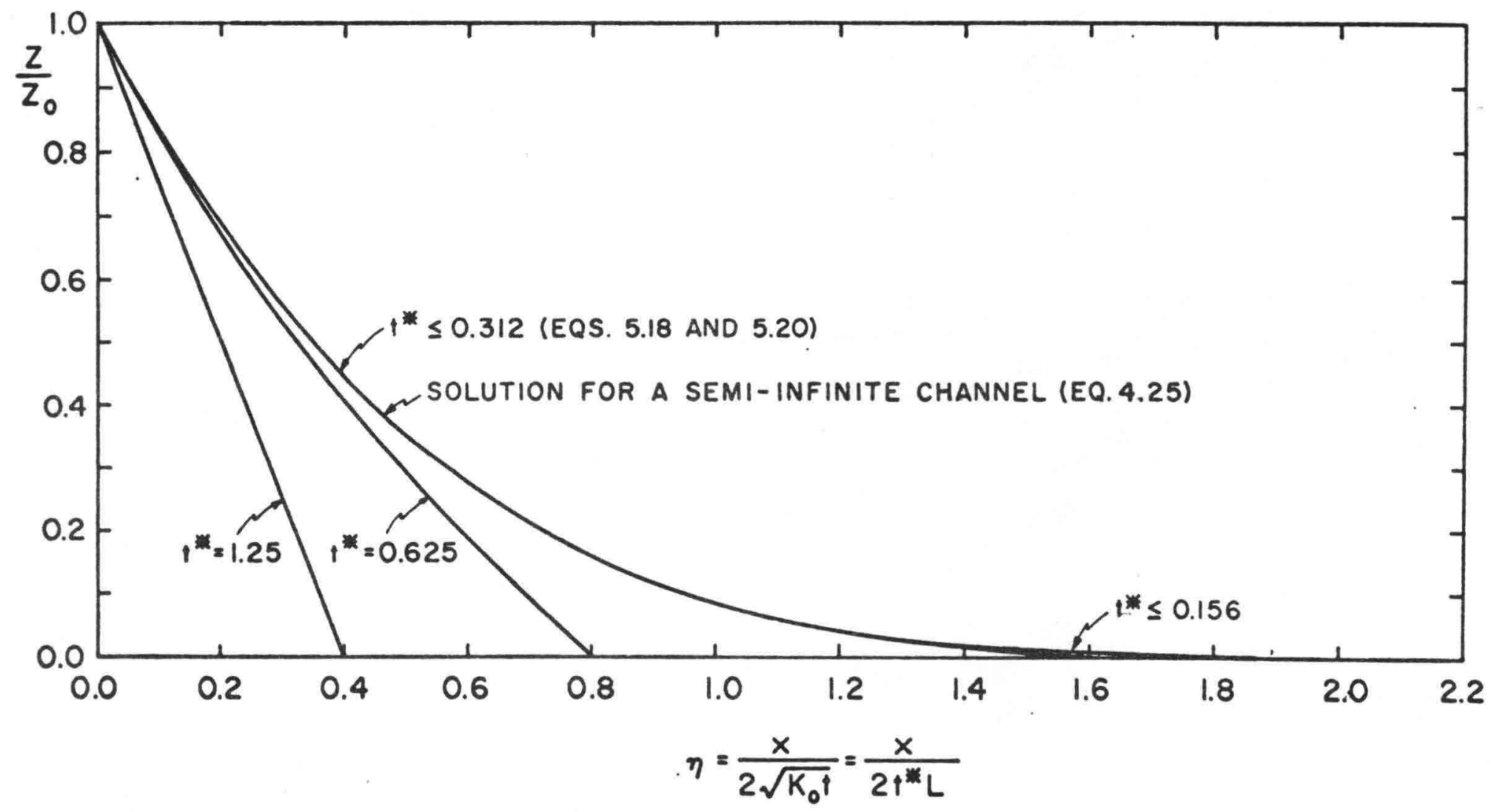

Figure 5.3 Normalized Bed Profiles $\left(Z / Z_{0}\right.$ versus $\left.\eta\right)$ for Various Normalized Times 


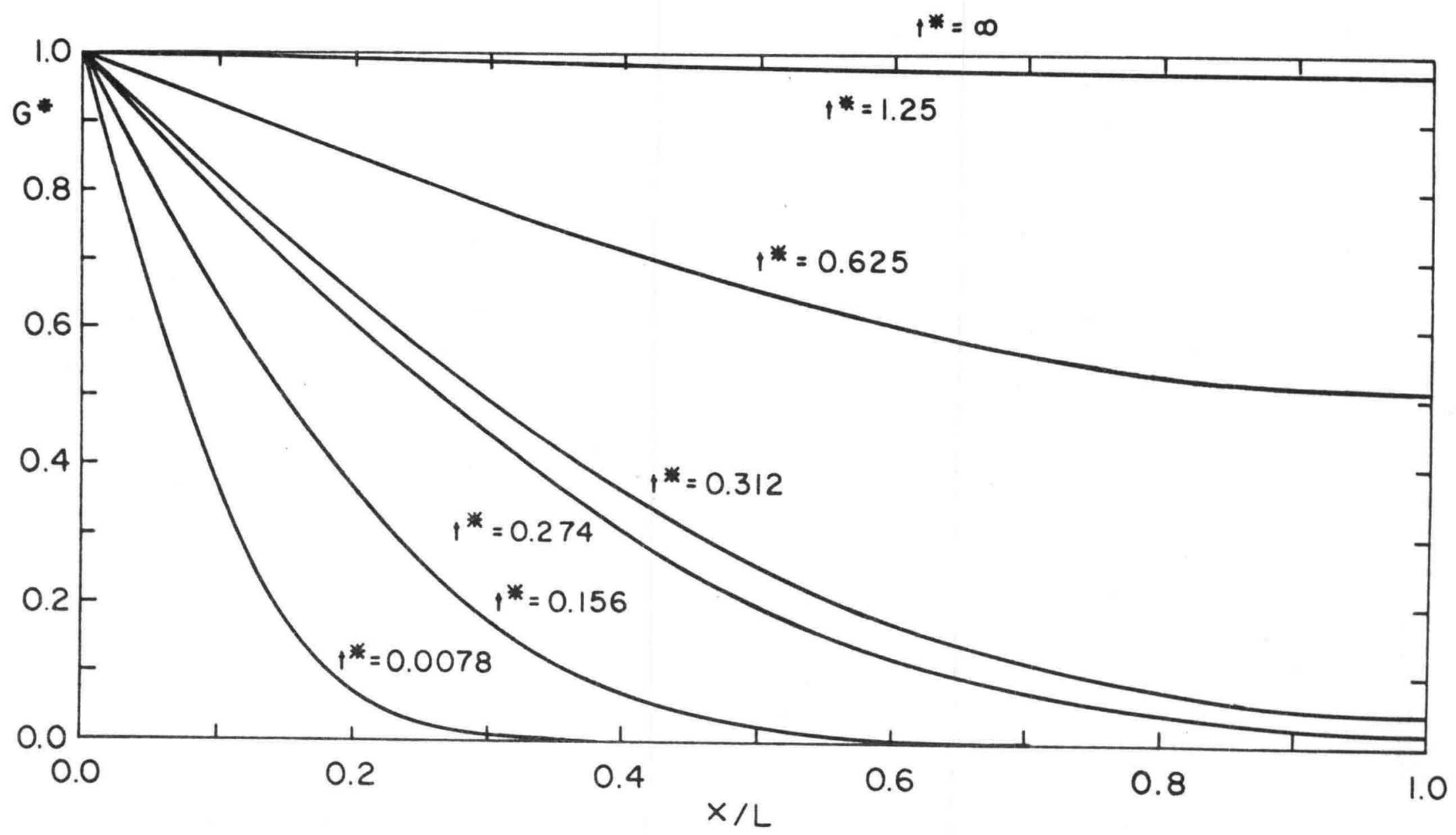

Figure 5.4 Normalized Total Sediment-Transport Rate $\left(G^{*}\right.$ versus $\left.\times / L\right)$ for Various Normalized Times 


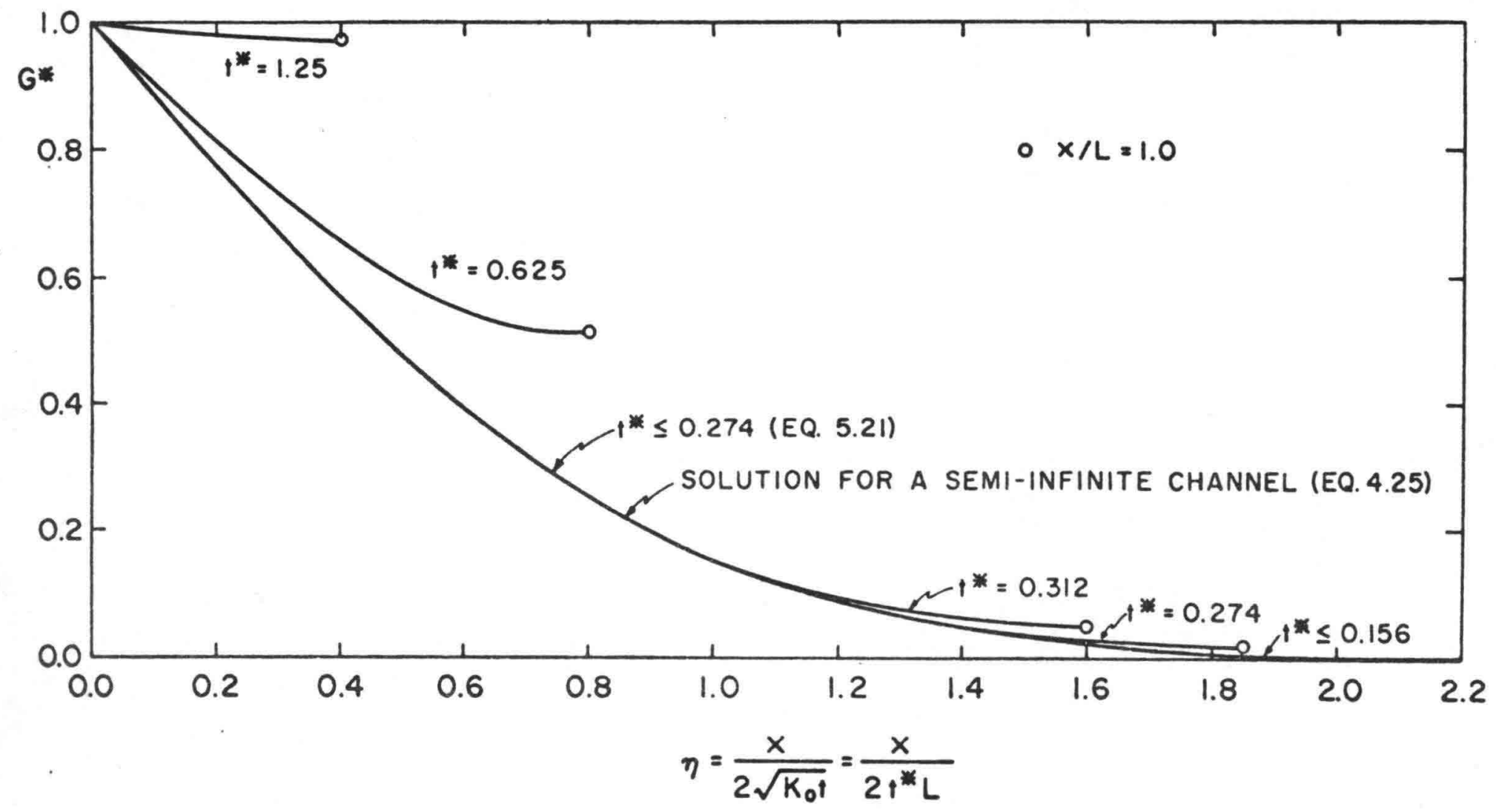

Figure 5.5 Normalized Total Sediment Discharge ( $G^{*}$ versus $\eta$ ) for Various Normalized Times 
presented in Chapter IV. The limiting value of $t^{*}$ equal to 0.312 for $\mathrm{Z} / \mathrm{Z}_{0}$ and 0.274 for $G *$ were obtained from the solutions for the semi-infinite reach assuming the end of the process where $Z / Z_{0}$ or $G^{\star}$ is 0.01 .

D. Solution for a Time Dependent Variation in

Total Sediment Discharge

The solution for this process is obtained by using Duhamel's theorem, which as applied to the present problem may be stated as follows: If $v=$ $F(x, t)$ represents the slope of an alluvial channel subjected to a sudden change in sediment discharge at $x=0$ which would yield a change in bed slope (at $x=0$ ) equal to unity, then the solution of the problem where the change in sediment discharge produces a change in bed slope at $x=0$ of $\phi(t)$, is given by

$$
v=\int_{0}^{t} \phi(u) \frac{\partial}{\partial t} F(x, t-u) d u
$$

On recalling the definition of bed slope (i.e., $S=-\frac{\partial z}{\partial x}$ ), using equations (4.29), (5.4) and applying the Duhamel's theorem, one obtains

$$
\begin{gathered}
Z(x, t)=\int_{v=L}^{x} \int_{u=0}^{t} \frac{\Delta G(u)}{K_{0}(1-\lambda)} \frac{\partial^{2}}{\partial \operatorname{tax}}\left(1-\frac{x}{L}\right)-\frac{8}{\pi^{2}} \sum_{n=0}^{\infty} \\
\left.\left.\frac{(-1)^{n}}{(2 n+1)^{2}} \exp \left[-\frac{(2 n+1)^{2}}{4 L^{2}} \pi^{2} K_{0}(t-u)\right] \sin \left[\frac{(2 n+1)}{2} \pi\left(1-\frac{x}{L}\right)\right]\right\}\right\} d u d v
\end{gathered}
$$

which may be written

$$
\begin{gathered}
Z(x, t)=\frac{2}{L(1-\lambda)} \int_{0}^{t} \Delta G(t-u) \sum_{n=0}^{\infty}(-1)^{n} \exp \left[-\frac{(2 n+1)^{2}}{4 L^{2}} \pi^{2} K_{0} t\right] \\
\sin \left[\frac{(2 n+1)}{2} \pi\left(1-\frac{x}{\tau}\right)\right] d u
\end{gathered}
$$

For

$$
\Delta G(t)=C_{0} t^{m / 2}
$$

where: $m=-1,0,1,2,3, \ldots$, the integration by parts of (5.12) leads to the following solution (Carslaw and Jaeger 1978). 


$$
\begin{gathered}
Z(x, t)=\frac{2^{m+1} C_{0} t^{(m+1) / 2} \Gamma(m / 2+1)}{K_{0}(1-\lambda)} \sum_{n=0}^{\infty}(-1)^{n}\left\{i^{m+1} \operatorname{erfc}\left[\frac{2 n L+x}{2 \sqrt{K_{0} t}}\right]-\right. \\
\left.i^{m+1} \operatorname{erfc}\left[\frac{2(n+1) L-x}{2 \sqrt{K_{0} t}}\right]\right\}
\end{gathered}
$$

E. Comparison of Analytical Results with Experimental Data

The validity of any mathematical model can only be assessed by comparison with experimental evidence. In the present study the analytical solution is compared with flume experimental data by Soni et al. (1980) and Mehta et al. (1981) for the case of aggradation; and by Newton (1951) for the degradation case. In all of the above cited investigations, the variation in total sediment transport rate was kept constant (i.e., $\Delta G=\Delta G_{0}$ ).

In the preceeding paragraphs it has been shown that the analytical solutions for bed profile and sediment transport rates in an alluvial channel of finite length for small times $t *$ is, for all practical purposes, identical to that in a semi-infinite channel. Most of the available laboratory data from experimental flumes of finite length correspond to the early stages, before the bed wave reached the downstream end; hence, the comparative study will apply equally to both cases. The experimental data are, therefore, compared with the analytical solution for a semi-infinite channel subject to a constant variation in total sediment load.

The bed profile data of Soni et al. (1980) and Mehta et al. (1981) for the process of aggradation due to sediment overloading at constant rates is compared with the analytical solution (i.e., (4.16)) in figure 5.6. The comparison between the analytical result and the flume data of Newton (1951) for the process of degradation is presented in figure 5.7. Equation (4.8) for $G$ is compared with the data of Soni (1981) in figure 5.8. The dimensionless bed elevation at $x=0$, as given by (4.15) is compared with the data for aggradation and degradation in figure 5.9. The experimental data, except that of Newton, were available in terms of $n$. For Newton's data, it was assumed that the sediment transport rate $G$ is proportional to $U^{b}$, and the value of $K_{0}$ 


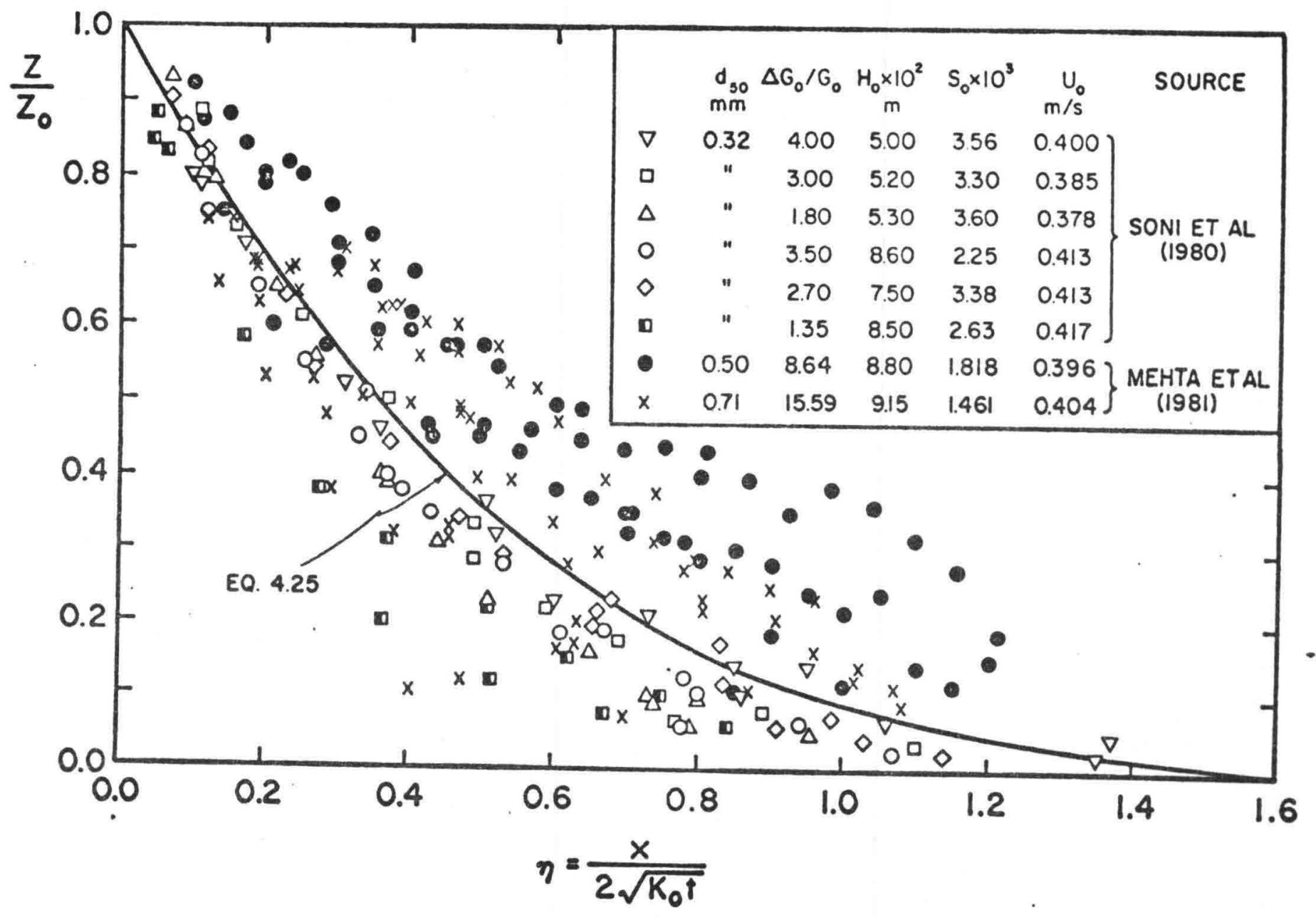

Figure 5.6 Comparison Between Analytical Solution and Experimental Data for Bed Aggradation 


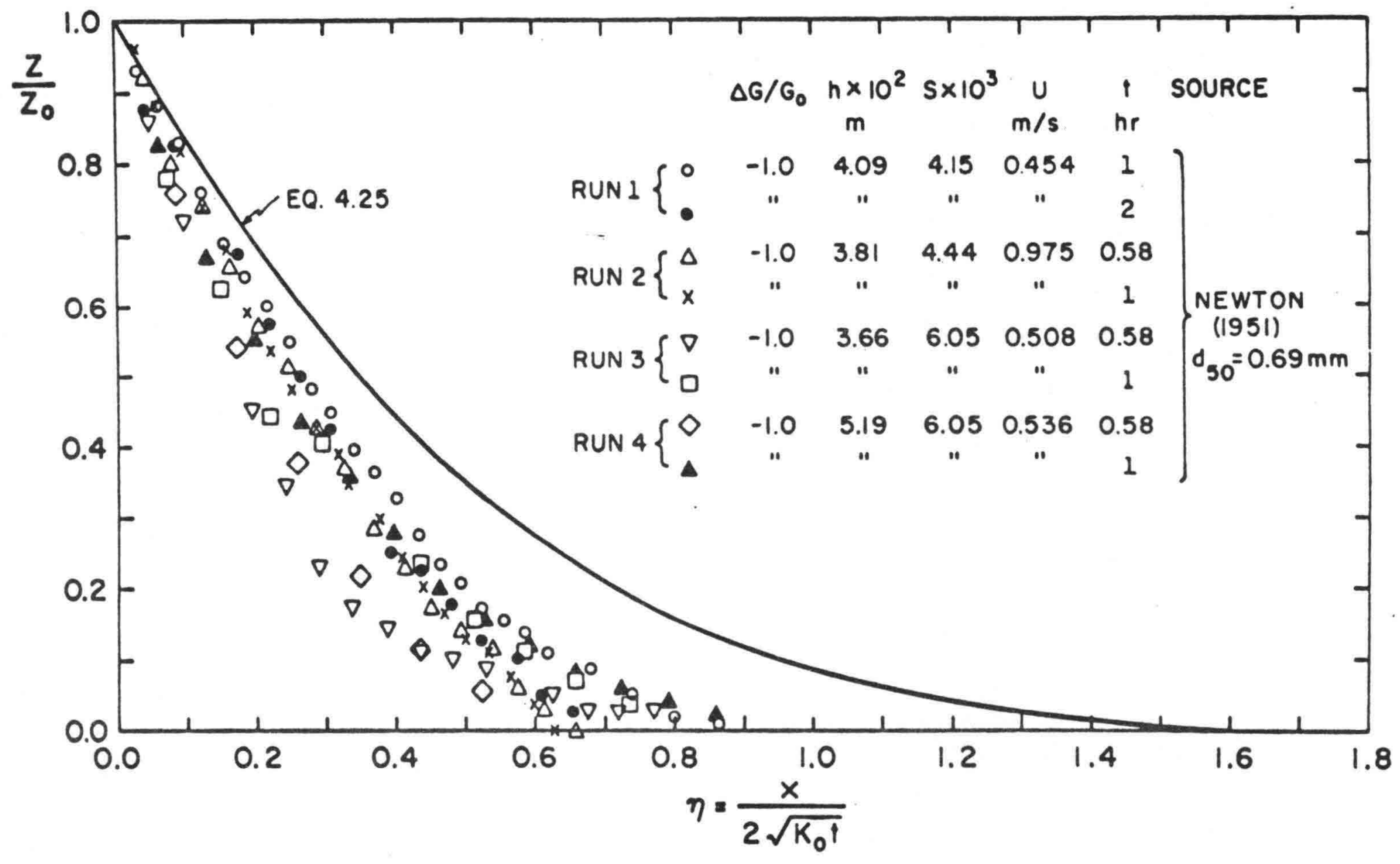

Figure 5.7 Comparison Between Analytical Solution and Experimental Data for Bed Degradation 


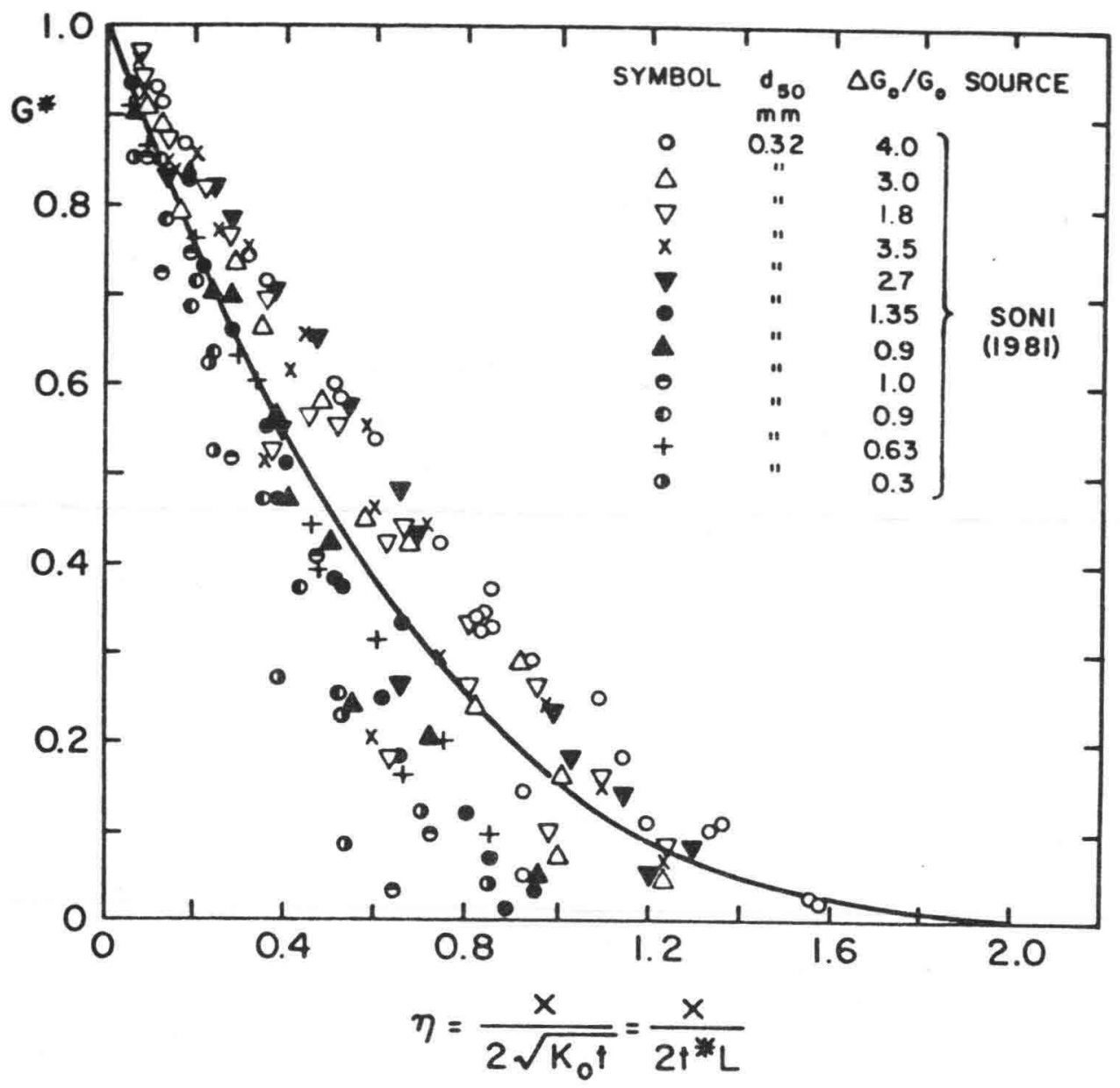

Figure 5.8 Comparison of the Analytical Solution for Total Sediment-Transport Rate and Experimental Data for Aggradation 


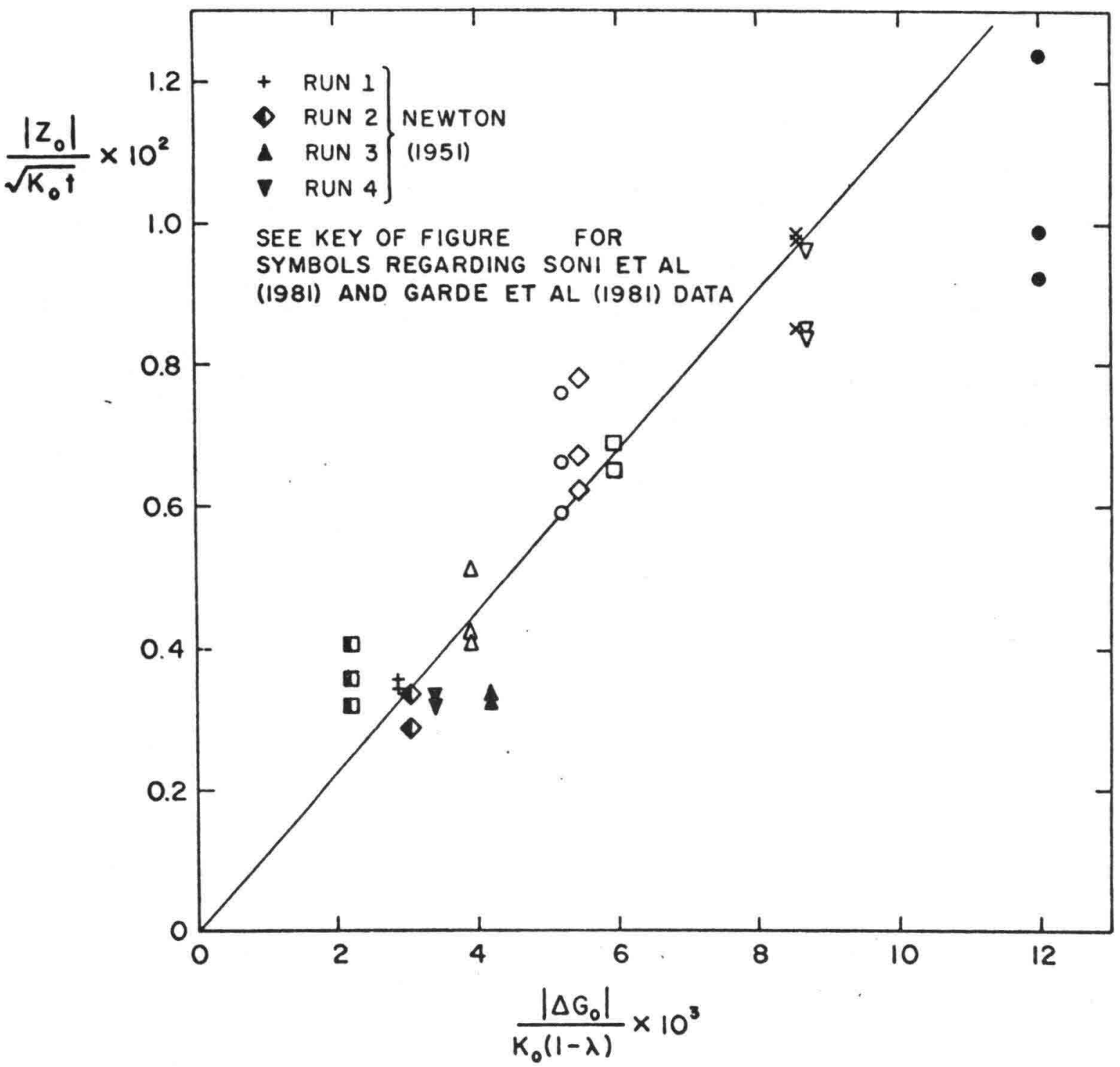

Figure 5.9 Normalized Bed Elevation at $x=0$ versus Normalized Total Sediment Transport Rate Variation 
was computed from (3.14). The value of the exponent $b$ was determined to be 4.4 from the data.

The analytical solution overestimates the relative depth, $z / Z_{0}$, for all values of $\Delta G_{0} / G_{0}$ in the case of degradation (figure 5.7) and for only smaller values of $\Delta G_{0} / G_{0}$ in the case of aggradation (figure 5.6). The agreement between the analytical results and the experimental data seems better as $\Delta G_{0} / G_{0}$ increases to about 4 . The analytical solution underestimates the relative depth for higher values of sediment overloading. It is believed that such behavior arises from the two simplifications introduced in the analytical model; the neglect of the last term in (3.11) and the linearization of (3.12) to (3.14). The spatial-derivative terms in (3.11) are of the same signs; the error introduced by neglecting the first terms may be interpreted as overestimation of the coefficient $\mathrm{K}_{0}$. Due to the linearization of $k$, its value is underestimated for aggradation and overestimated for degradation. The two corrections are additive for degradation and the analytical solution overpredicts for all values of $\Delta G_{0} / G_{0}$, as is shown in figure 5.7, for $\Delta G_{0} / G_{0}=-1$. The two errors are of opposite nature for aggradation process and happens to annul each other as $\Delta G_{0} / G_{0}$ of about 4 for the data presented in figure 5.6. 
VI. NONLINEAR PARABOLIC MODEL FOR MORPHOLOGICAL PROCESSES

IN A SEMI-INFINITE ALLUVIAL CHANNEL

The purpose of the present chapter is to solve the nonlinear parabolic model introduced in Chapter 3 by the method of weighted residuals.

A. Analytical Solution

The nonlinear parabolic model under consideration consists of the sediment-diffusion (transport) equation,

$$
\frac{\partial G^{*}}{\partial t}-\bar{k} \frac{\partial^{2} G^{*}}{\partial x^{2}}=0
$$

and the sediment-continuity equation,

$$
\frac{\partial z}{\partial t}+\frac{\Delta G_{0}}{(1-\lambda)} \frac{\partial G^{*}}{\partial x}=0
$$

By using the coordinate transformation defined by (3.15), (3.28) becomes

$$
\frac{\partial Z}{\partial t}+\frac{\Delta G_{0}}{(1-\lambda)} \frac{\partial G^{*}}{\partial x}=0
$$

which is the version of the sediment-continuity relation utilized in the following. The initial and boundary conditions needed to solve (3.27) and (6.1) are:

$$
\begin{aligned}
& G \star(x, 0)=0 \\
& G \star(0, t)=1
\end{aligned}
$$

and

$$
Z(x, 0)=0
$$

As stated before, the procedure followed involved solving, first, (3.27) for the corresponding initial and boundary conditions (6.2) and (6.3); and 
subsequent use this solution to obtain the solution of (6.1) subject to (6.4). The solution to the nonlinear sediment transport equation (3.27) will be obtained by means of the method of weighted residuals (Ames, 1965), which is briefly outlined in the next section.

1. The method of weighted residuals. The method of weighted residuals, in its several versions, has been widely used for the solution of ordinary and linear partial differential equations by mathematicians like Galerkin (1915), Landhal (1953), Crandall (1958), and Collatz (1960), among others. Several engineers have also applied this method in connection with elasticity and structure stability and deformation problems (NASA 1962; Budiansky and Roth 1962; Mushtari and Galimov 1957), gas dynamics (Jain 1962; Frederiksen 1957), heat transfer (Goodman 1964; Smith 1956), viscous flow and boundary layer problems (von Karman 1921; Polhausen 1921; Tani 1954; Schetz 1963 and many others). Yamada (1947) and Fujita (1951) applied this method to the solution of a nonlinear diffusion problem. There is no indication of the utilization of the method of weighted residuals to solve sediment transport processes. This study constitutes the first attempt in this direction.

The method of weighted residuals comprises various techniques that can be applied when the nonlinearities appear in either the governing equation, the boundary conditions, or both. The details of these techniques can become rather involved and lengthy; therefore, only a broad outline will be given in the following.

In general terms, all the techniques transform a continuous problem (partial differential equation) into an approximately equivalent lumped parameter system whose form is obtained by the solution of a set or ordinary differential equations.

Consider the governing equation (3.27) described by the nonlinear operator $L\left(G^{*}\right)$

$$
L\left(G^{*}\right)=0
$$

An approximate solution, $G_{n}^{*}$, when substituted into the left-hand side of (3.27) will result in a residual $E_{n}$, 


$$
L\left(G_{n}^{*}\right)=E_{n}
$$

In order to find a solution which makes $E_{n}$ small in some well defined sense, (6.5) is multiplied by a weighting factor $W_{j}$, and averaged over the entire space domain. Setting the average to zero gives

$$
\int W_{j} L\left(G_{n}^{*}\right) d x=0 \quad j=1,2, \ldots, n
$$

The required solution will be made to satisfy (6.6) instead of (3.27). The form of $G_{n}^{*}$ will be taken in such a way as to satisfy the boundary conditions and to contain unknown parameters $C_{j}$. By choosing $n$ different weighting factors, there will result precisely the same number of equations as unknowns.

For different selections of the forms of the weighting factor the method is known by different names. When $w_{j}=\Delta\left(x-x_{j}\right)$, where $\Delta$ is the Dirac delta function, the method is called collocation. If $G_{n}^{*}$ is a linear function of the parameters $C_{j}$, and $W_{j}=\partial G_{n}^{*} / \partial C_{j}$, the method is named Galerkin's method. When $W_{j}=x^{j}$, it is called the method of moments. This study will be primarily concerned with the application of the method of moments for solving the nonlinear parabolic partial differential equation (3.27), which, together with (6.1), constitute the mathematical representation of the morphological processes under consideration.

The analytical solutions presented in the previous chapters suggest the introduction of the penetration distance $\ell(t)$ such that for $x \geqslant \ell(t)$ the system is unaffected; $i . e .$, the alluvial channel is at the initial equilibrium condition; hence,

$$
G *(x, t)=0 \text { for } x \geqslant \ell(t)
$$

and

$$
Z(x, t)=0 \text { for } x \geqslant \ell(t)
$$

apply. It is interesting to point out that the above definition of the penetration distance parallels the concept of boundary layer thickness used in boundary-layer analyses.

A polynomial of nth degree is selected as an approximate solution, that is 


$$
G^{*} \simeq G_{n}^{*}=C_{0}+C_{1} x+C_{2} x^{2}+C_{3} x^{3}+\ldots+C_{n} x^{n}=\sum_{i=0}^{n} C_{i}(t) x^{i}
$$

There are $n+1$ constants $c_{0}, C_{1}, c_{2}, \ldots, C_{n}$ which must be determinend. Three of the $n+1$ constants can be obtained from the boundary conditions at $x=0$ and $x=\ell(t)$, namely

$$
\begin{aligned}
& G \star(0, t)=1 \\
& G \star(l, t)=0
\end{aligned}
$$

and

$$
\frac{\partial G^{*}}{\partial x}(\ell, t)=0
$$

The last two boundary conditions indicate that the process terminates at $x$ $=\ell(t)$. The remaining constants can be obtained by imposing additional boundary conditions. In the present case it is assumed that the remaining $n-2$ spatial derivatives of $G^{*}$ at $x=\ell(t)$ are zero. That is

$$
\frac{\partial^{i} G^{*}}{\partial x^{i}}(l, t)=0 \quad i=2,3,4, \ldots, n-1
$$

By substituting $(6.3),(6.7),(6.10)$ and $(6.11)$ into $(6.9)$ the following general expressions for $C_{n}(t)$ and $G^{*}$ are obtained:

$$
c_{n}(t)=(-1 / \ell)^{n}
$$

and

$$
G^{*}=(1-x / \ell)^{n}
$$

The penetration length $\ell(t)$ is the only unknown parameter in (6.13); therefore, only one weighting factor is required to determine it. For the sake of generality a weighting factor of the form

$$
w=x^{m}
$$


is used. By performing the required substitutions and integrating from $x=0$ to $x=\ell(t)$, the following version of $(6.6)$ is obtained:

$$
\int_{0}^{\ell(t)}\left[\frac{\partial G^{*}}{\partial t}-\bar{k} \frac{\partial^{2} G^{*}}{\partial x^{2}}\right] x^{m} d x=0
$$

By using the Leibnitz's rule $(6.15)$ becomes

$$
\frac{\partial}{\partial t} \int_{0}^{\ell(t)} G^{*} x^{m} d x=\int_{0}^{\ell(t)} \bar{k} x^{m} \frac{\partial^{2} G^{*}}{\partial x^{2}} d x
$$

In order to proceed with the solution and obtain an explicit expression for the penetration length $\ell(t)$, it is necessary to specify the coefficient $\bar{K}$, which requires the adoption of the appropriate sediment-transport and friction-factor relations $((3.4)$ and $(3.5))$. To keep the analysis as general and clear as possible, and in order to enable comparison of the analytical solution with existing experimental information, the following relations are adopted:

$$
G=a U^{b}
$$

and

$$
f=f_{0}=\text { constant }
$$

where $a$ and $b$ are constants that depend on the sediment and uniform flow characteristics, and $f_{0}$ is the value of the Darcy-Weisbach friction factor for the initial uniform flow condition. The last two equations together with (3.21) and (3.25) yield

$$
\bar{K}=\frac{b G_{0}}{3(1-\lambda) S_{0}}\left(1+\frac{\Delta G_{0}}{G_{0}} G^{\star}\right)^{1-3 / b}
$$

Substitution of (6.13) and (6.19) into (6.16) gives

$$
\begin{aligned}
\frac{\partial}{\partial t} \int_{0}^{\ell(t)}(1-x / \ell)^{n} x^{m} d x= & \frac{b G_{0} n(n-1)}{3(1-\lambda) S_{0} \ell^{2}} \int_{0}^{\ell(t)}\left[1+\frac{\Delta G_{0}}{G_{0}}\left(1-\frac{x}{\ell}\right)^{n}\right] \\
& \left(1-\frac{x}{\ell}\right)^{n-2} x^{m} d x
\end{aligned}
$$


Usage of the binomial series expansion and subsequent integration lead to

$$
\begin{gathered}
\frac{d}{d t}\left[l^{m+1} \sum_{j=0}^{n} \frac{n !(-1)^{n-j}}{j !(n-j) !(n+m+1-j)}\right]=\frac{b G_{0} n(n-1)}{3(1-\lambda) S_{0}} e^{m-1} \\
{\left[\sum_{j=0}^{n-2} \frac{(n-2) !(-1)^{n-2-j}}{j !(n-2-j) !(n+m-1-j)}+\alpha \frac{\Delta G_{0}}{G_{0}} \sum_{j=0}^{2 n-2} \frac{(2 n-2) !(-1)^{2 n-2-j}}{j !(2 n-2-j) !(2 n+m-1-j)}+\right.} \\
\frac{\alpha(\alpha-1)}{2 !}\left(\frac{\Delta G_{0}}{G_{0}}\right)^{2} \sum_{j=0}^{3 n-2} \frac{(3 n-2) !(-1)^{3 n-2-j}}{j !(3 n-2-j) !(3 n+m-1-j)}+\frac{\alpha(\alpha-1)(\alpha-2)}{3 !}\left(\frac{\Delta G_{0}}{G_{0}}\right)^{3} \\
\left.\sum_{j=0}^{4 n-2} \frac{(4 n-2) !(-1)^{4 n-2-j}}{j !(4 n-2-j) !(4 n+m-1-j)}+\ldots . .\right]
\end{gathered}
$$

where

$$
\alpha=1-3 / b
$$

Equation (6.21) is an ordinary differential equation, whose solution is

$$
\ell(t)=(K * t)^{1 / 2}
$$

where

$$
\begin{gathered}
K^{*}=\left\{\left[\frac{2 b G_{0} n(n-1)(m+1)^{-1}}{3(1-\lambda) S_{0} \sum_{j=0}^{n} \frac{n !(-1)^{n-j}}{j !(n-j) !(n+m+1-j)}}\right]\right. \\
\left.\left[\sum_{j=0}^{n-2} \frac{(n-2) !(-1)^{n-2-j}}{j !(n-2-j) !(n+m-1-j)}+\alpha \frac{\Delta G_{0}}{G_{0}} \sum_{j=0}^{2 n-2} \frac{(2 n-2) !(-1)^{2 n-2-j}}{j !(2 n-2-j) !(2 n+m-1-j)}+\ldots\right]\right\}
\end{gathered}
$$

By making use of the symmetry properties of the coefficients of the binomial series, $K^{*}$ can be rewritten as

$$
\begin{gathered}
K^{*}=\frac{2 b G_{0} n(n-1)(n+m+1)(n+m) \ldots(n+1)}{3(1-\lambda) S_{0}(m+1)}\left\{\frac{1}{(n+m-1)(n+m-2) \ldots(n-1)}+\right. \\
\alpha \frac{\left.\Delta G_{0}\right)}{\left(\frac{G_{0}}{2}\right)} \frac{1}{(2 n+m-1)(2 n+m-2) \ldots(2 n-1)}+\frac{\alpha(\alpha-1)}{2 !}\left(\frac{\Delta G_{0}}{G_{0}}\right)^{2} \\
\frac{1}{(3 n+m-1)(3 n+m-2) \ldots(3 n-1)}+\frac{\alpha(\alpha-1)(\alpha-2)}{3 !}\left(\frac{\Delta G_{0}}{G_{0}}\right) \\
\left.\frac{1}{(4 n+m-1)(4 n+m-2) \ldots(4 n-1)}+\ldots\right\}
\end{gathered}
$$


Equations (6.13), (6.23) and (6.25) provide a solution to the nonlinear parabolic equation (3.27) under the conditions imposed by (6.2) and (6.3) (i.e., initial and boundary conditions). Introducing the above solution into the sediment continuity equation (6.1) and subsequent integration with respect to time give

$$
\begin{gathered}
Z=\frac{\Delta G_{0} n}{(1-\lambda)}\left[\sum_{j=0}^{n-3} \frac{(n-1) !(-1)^{n-1-j} x^{n-1-j}}{j !(n-1-j) ![1-(n-j) / 2]\left(K^{\star} t\right)^{[(n-j) / 2-1]}-}\right. \\
\left.\quad(n-1) \frac{x}{K^{\star}} \text { \&n } t+\frac{2 t^{1 / 2}}{K^{\star} 1 / 2}+C\right]
\end{gathered}
$$

The constant of integration is evaluated from the definition of the penetration length $\ell(t)$, which requires $Z(\ell(t), t)=0$. The final result is

$$
\begin{aligned}
Z(x, t) & =\frac{2 \Delta G_{0} n}{(1-\lambda)^{\prime}} \sqrt{\frac{t}{K^{\star}}}\left\{1-\frac{x}{\sqrt{K^{\star} t}}+\frac{(n-1)}{2} \frac{x}{\sqrt{K^{\star} t}} \ln \frac{x^{2}}{K^{\star} t}+\sum_{j=0}^{n-3}\right. \\
& \frac{(n-1) !(-1)^{n-1-j}}{j !(n-1-j) !(2-n+j)}\left[\frac{x^{n-1-j}}{\left.\left.\left(K^{\star} t\right)^{(n-1-j) / 2}-\frac{x}{\sqrt{K^{\star} t}}\right]\right\}}\right.
\end{aligned}
$$

which provides the time dependent bed profile for nonequilibrium processes. The depth of aggradation or degradation at $x=0$ is

$$
Z_{0}=\frac{2 n \Delta G_{0}}{(1-\lambda)} \sqrt{\frac{t}{K^{\star}}}
$$

The dimensionless bed profile can be expressed

$$
\begin{aligned}
& \frac{Z}{Z_{0}}=1-\frac{x}{\sqrt{K^{\star} t}}+\frac{(n-1)}{2} \frac{x}{\sqrt{K^{\star} t}} \ln \frac{x^{2}}{K^{\star} t}+\sum_{j=0}^{n-3}\left\{\frac{(n-1) !(-1)^{n-1-j}}{j !(n-1-j) !(2-n+j)}\right. \\
& \left.\left[\frac{x^{n-1-j}}{\left(k^{\star} t\right)^{(n-1-j) / 2}}-\frac{x}{\sqrt{k^{\star} t}}\right]\right\}
\end{aligned}
$$

which completes the solution to morphological processes of aggradation due to augmentation of the sediment load and degradation due to curtailment of the sediment discharge.

Wieghardt (1948), Walz (1948) and Tani (1954) in studies on compressible and incompressible laminar and turbulent boundary layers introduced another possible way of applying the method of moments, which consists in using the 
dependent variable $\left(G^{*}\right)$ instead of the independent variable $(x)$ as a weighting function. The advantage that this method presents over the one developed above is that the differential equation (3.27) is weighted most where the sediment-transport-rate change with respect to the initial or equilibrium sediment transport rate is the greatest. Thereby, regions with larger changes in sediment load are considered to be more important than regions with a relatively small variation in sediment transport rate.

By defining $W=G *^{m},(6.6)$ becomes

$$
\int_{0}^{\ell(t)}\left[\frac{\partial G *}{\partial t}-\bar{K} \frac{\partial^{2} G \star}{\partial x^{2}}\right] G^{m} d x=0
$$

Substituting (6.13) and (6.19) into (6.30) one obtains

$$
\begin{aligned}
& \frac{\partial}{\partial t} \int_{0}^{\ell(t)}\left(1-\frac{x}{\ell}\right)^{n(1+m)} d x=\frac{b n G_{0}(n-1)}{3(1-\lambda) S_{0} \ell^{2}} \int_{0}^{\ell(t)} \\
& {\left[1+\frac{\Delta G_{0}}{G_{0}}\left(1-\frac{x}{\ell}\right)^{n}\right]^{1-3 / b}\left(1-\frac{x}{\ell}\right)^{n(1+m)-2} d x}
\end{aligned}
$$

Use of the binomial series expansion and subsequent integration lead to

$$
\begin{aligned}
& \frac{d}{d t}\left\{\ell \sum_{j=0}^{n(1+m)} \frac{[n(1+m)] !(-1)^{n(1+m)-j}}{j ![n(1+m)-j] ![n(1+m)+1-j]}\right\}=\frac{b n(n-1) G_{0}}{3(1-\lambda) \ell S_{0}}\left\{\sum_{j=0}^{n(1+m)-2}\right. \\
& \frac{[n(1+m)-2] !(-1)^{n(1+m)-2-j}}{j ![n(1+m)-2-j] ![n(1+m)-1-j]}+\frac{\Delta G_{0}}{G_{0}} \sum_{j=0}^{n(2+m)-2} \\
& \frac{[n(2+m)-2] !(-1)^{n(2+m)-2-j}}{j ![n(2+m)-2-j] ![n(2+m)-1-j]}+\frac{\alpha(\alpha-1)}{2 !}\left(\frac{\Delta G_{0}}{G_{0}}\right)^{2} \sum_{j=0}^{n(3+m)-2} \\
& \frac{[n(3+m)-2] !(-1)^{n(3+m)-2-j}}{j ![n(3+m)-2-j] ![n(3+m)-1-j]}+\frac{\alpha(\alpha-1)(\alpha-2)}{3 !}\left(\frac{\Delta G_{0}}{G_{0}}\right)^{3} \sum_{j=0}^{n(4+m)-2} \\
& \left.\frac{[n(4+m)-2] !(-1)^{n(4+m)-2-j}}{j ![n(4+m)-2-j] ![n(4+m)-1-j]}+\ldots . .\right\}
\end{aligned}
$$

where, as before

$$
\alpha=1-3 / b
$$


Equation (6.32) is an ordinary differential equation whose solution is as

$$
\ell(t)=(\bar{K} \star t)^{1 / 2}
$$

where:

$$
\begin{aligned}
& K^{*}=\left\{\frac{2 b n(n-1) G_{0}}{3(1-\lambda) S_{0} \sum_{j=0}^{n(1+m)} \frac{[n(1+m)] !(-1)^{n(1+m)-j}}{j ![n(1+m)-j] ![n(1+m)+1-j]}}\right\} \\
&\left\{\sum_{j=0}^{n(1+m)-2} \frac{[n(1+m)-2] !(-1)^{n(1+m)-2-j}}{j ![n(1+m)-2-j] ![n(1+m)-1-j]}+\alpha\left(\frac{\Delta G_{0}}{G_{0}}\right) \sum_{j=0}^{n(2+m)-2}\right. \\
& \\
&\left.\frac{[n(2+m)-2] !(-1)^{n(2+m)-2-j}}{j ![n(2+m)-2-j] ![n(2+m)-1-j]}+\ldots\right\}
\end{aligned}
$$

By using the symmetry properties of the binomial series coefficients, (6.34) can be rewritten

$$
\begin{gathered}
\bar{K}^{\star}=\left\{\frac{2 b G_{0} n(n-1)[n(1+m)+1]}{3 S_{0}(1-\lambda)}\right\}\left\{\frac{1}{n(1+m)-1}+\alpha\left(\frac{\Delta G_{0}}{G_{0}}\right) \frac{1}{[n(2+m)-1]}\right. \\
\left.+\frac{\alpha(\alpha-1)}{2 !}\left(\frac{\Delta G_{0}}{G_{0}}\right)^{2} \frac{1}{[n(3+m)-1]}+\frac{\alpha(\alpha-1)(\alpha-2)}{3 !}\left(\frac{\Delta G_{0}}{G_{0}}\right)^{3} \frac{1}{[n(4+m)-1]}+\ldots\right\}
\end{gathered}
$$

Equations (6.13), (6.33) and (6.35) constitute another solution to the nonlinear parabolic sediment transport (diffusion) equation (3.27) subject to the initial and boundary conditions given by $(6.2)$ and $(6.3)$, respectively.

Introducing the above solution into the sediment-continuity equation (6.1) and subsequent integration with respect to time yields

$$
\begin{aligned}
Z(x, t)= & \frac{2 n \Delta G_{0}}{(1-\lambda)} \sqrt{\frac{t}{\bar{K}^{\star}}}\left\{1-\frac{x}{\sqrt{K^{\star} t}}+\frac{(n-1)}{2} \frac{x}{\sqrt{K^{\star} t}} \ln \frac{x^{2}}{\bar{K} \star t}+\sum_{j=0}^{n-3}\right. \\
& \left\{\frac{(n-1) !(-1)^{n-1-j}}{j !(n-1-j) !(2-n+j)}\left[\frac{x^{n-1-j}}{\left(K^{\star} t\right)^{(n-1-j) / 2}}-\frac{x}{\sqrt{K^{\star} t}}\right]\right\}
\end{aligned}
$$


which enables the determination of the time dependent bed profiles for nonequilibrium processes.

The depth of aggradation or degradation at $x=0$ is

$$
Z_{0}=\frac{2 n \Delta G_{0}}{(1-\lambda)} \sqrt{\frac{t}{R^{*}}}
$$

The dimensionless bed profile can be expressed

$$
\begin{aligned}
& \frac{z}{Z_{0}}=1-\frac{x}{\sqrt{K \star t}}+\frac{(n-1)}{2} \frac{x}{\sqrt{K \star t}} \ln \frac{x^{2}}{\bar{K} \star t}+\sum_{j=0}^{n-3}\left\{\frac{(n-1) !(-1)^{n-1-j}}{j !(n-1-j) !(2-n+j)}\right. \\
& \left.\left[\frac{x^{n-1-j}}{(\bar{K} \star t)(n-1-j) / 2}-\frac{x}{\sqrt{\bar{K} \star t}}\right]\right\}
\end{aligned}
$$

which completes the solution for the morphological processes considered herein.

The analytical solutions given in the above equations involve two parameters, namely $m$ and $n$, that can be selected with certain degree of freedom. However, there exist some basic criteria to limit the range or guide the possible choices, which are based on the accuracy of the solution obtained in every specific case. As far as the exponent $n$ is concerned, it has been stated previously (Goodman, 1961 and 1964) that the accuracy of a solution obtained by the method of moments might be improved by increasing the order of the polynomial (i.e., $n$ ) used to represent the dependent variable (i.e., the sediment transport variable $G^{\star}$ ). However, cases have been reported for which the accuracy actually worsens using this procedure (Goodman, 1964). In fact, there is no a priori guarantee that increasing the order of the polynomial will improve the accuracy. For problems in which the governing equation is linear and contain nonlinearities in the boundary conditions only, Chambre's (1959) iterative scheme provides a method to improve the accuracy of any initially chosen trial function $\left(G^{*}\right)$. In the present case, due to the nonlinearity of the governing equation (3.27), Chambre's scheme is of no use; consequently, to a large extent the accuracy of the solution will depend on judicious selection of the exponent $n$. In propagation problems, like the one considered here, a trial solution must be constructed so that a maximum information can be extracted with a minimum of computation. The more is known 
about the expected behavior of the solution the better the trial solution would be. A careful study of the expected behavior is very important; therefore, an adequate procedure to limit the range of possible values of the exponent $n$ must be devised in every particular case.

It can be shown that for $b=3$, or for any value of $b$ and $\Delta G_{0}+0$, the sediment-diffusion equation (3.27) becomes

$$
\frac{\partial G^{\star}}{\partial t}-\frac{b G_{0}}{3(1-\lambda) S_{0}} \frac{\partial^{2} G^{\star}}{\partial x^{2}}=0
$$

The exact solution of (6.39) has al ready been obtained earlier (see (4.8)), as to give

$$
G^{\star}=\operatorname{erfc}\left[\frac{x}{\sqrt{\frac{4 b G_{0} t}{3(1-\lambda) S_{0}}}}\right]
$$

Equation (6.40) provides the opportunity to carry out a preliminary study aimed towards the determination of the appropriate value or range of values for the exponent $n$. Another goal of this study is to inquire into the adequacy of the weighting functions themselves. The basic idea behind this study is to solve (6.39), subject to the corresponding initial and boundary conditions, using various values of the exponent $n$ and fixed weighting functions, and compare these approximate solutions with the exact one (i.e., $(6.40)$.

Some of the results of this sensitivity study are shown in figures 6.1 and 6.2. The approximate solutions of $(6.39)$ for a weighting function equal to unity (i.e., $W=x^{0}=G^{*}=1$ ) and several values of $n$ are presented in figure 6.1. The solutions corresponding to $W=x$ and $W=G^{*}$ and various values of the exponent $n$ are shown in figure 6.2. A rather interesting preliminary conclusion (confirmed below) drawn from the above figures concerns the approprietness of the weighting functions. It is evident that, when the independent variable $x$ is taken as weighting factor (i.e., $W=x^{m}$ ), the accuracy of the solution worsens with increase in the value of $m$. On the contrary, the accuracy of the solution improves when the dependent variable $G^{*}$ is chosen as the weighting function (i.e., $W=G * m$ ). Hence, the latter, 


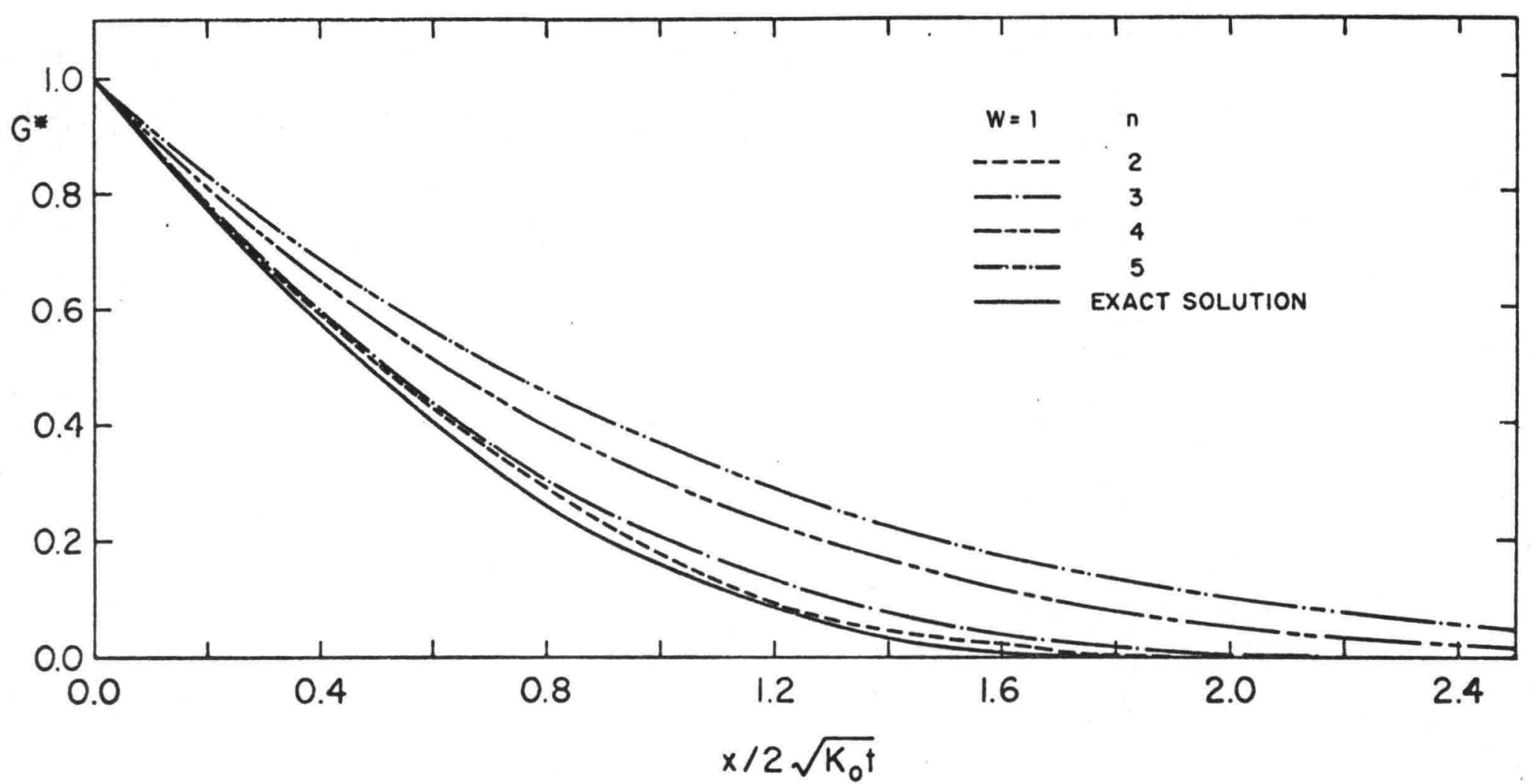

Figure 6.1 Sensitivity Analysis of the Linear Solution for Total Sediment Load Obtained by the Method of Weighted Residuals $(W=1)$ 


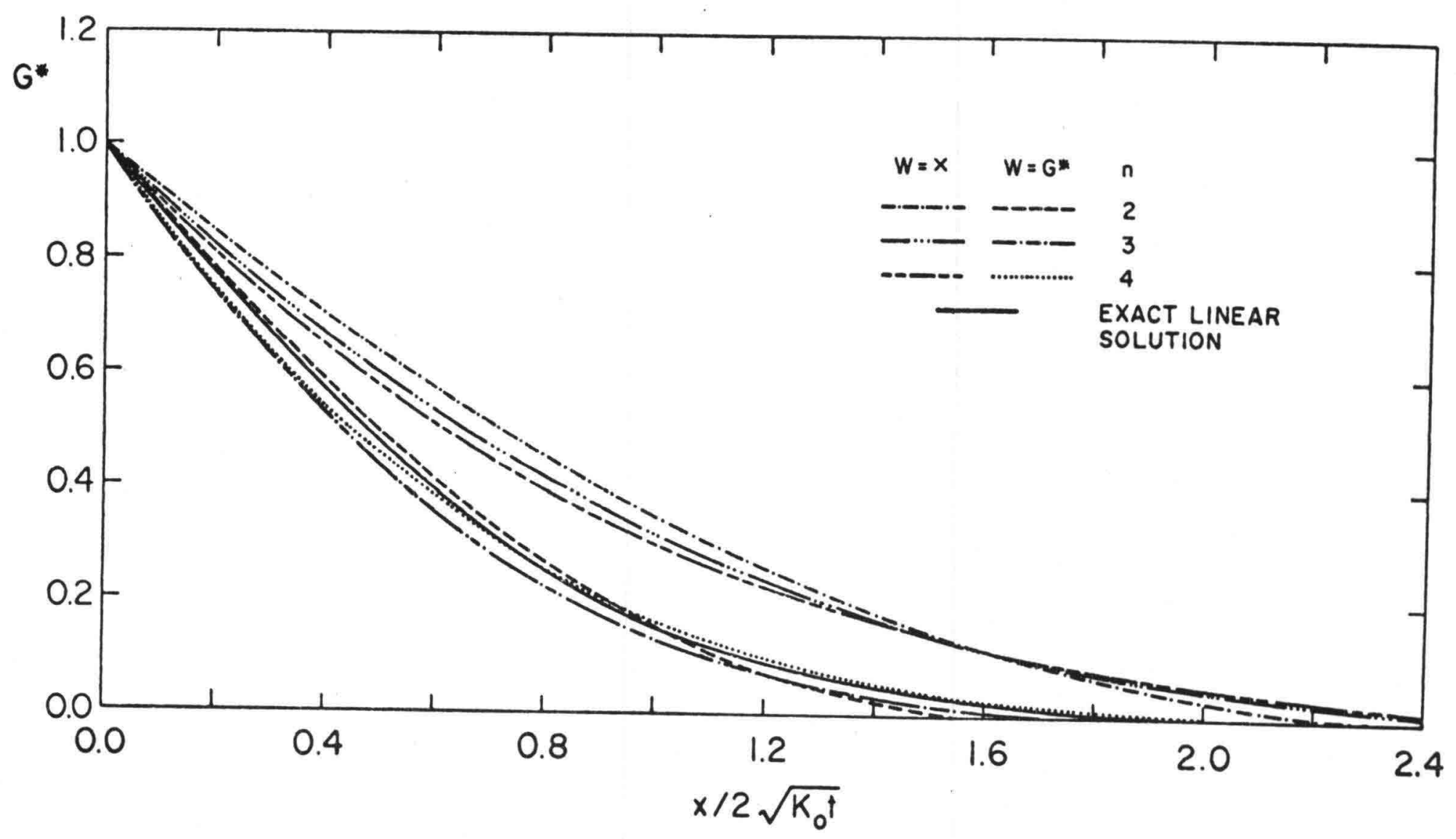
Figure 6.2 Sensitivity Analysis of the Linear Solution for Total Sediment Load Obtained by the
Method of Weighted Residuals 
(i.e., $W=G^{*}$ ) appears to be the better weighting function for the present problem. It is also important to note that solutions based on lower-degree polynomials, which are convenient for practical purposes, compare rather well with the exact analytical solution. Moreover, it should be mentioned that a polynomial of second degree (i.e., $n=2)$, which requires the determination of three coefficients $C_{j}(t)$ (see $(6.9)$ ), is the "natural" choice as it satisfies the definition of the penetration length given by (6.7) and (6.10), and the boundary condition (6.3). Polynomials of higher degree require the introduction of additional ("artificial") boundary conditions, with little or no physical meaning, like those given by $(6.11)$. Consequently, main consideration will be given to second or slightly higher degree polynomials.

Once the weighting function has been preliminarily selected and the spectrum of possible values of $n$ has been conveniently narrowed, the remaining task is the determination of the exponent (or the range of values of the exponent) $m$ of the chosen weighting function. It is believed, in general, that as $m$ increases the accuracy of the solution improves; however, in practice $m$ must be limited because the calculations become tedious. The assessment of the sensitivity of the solution to variations in $m$ or $n$ can be performed without excessive effort from the general analytical solution. Figure 6.3 shows the behavior of the nonlinear solution for $n=$ 2, $\Delta G_{0} / G_{0}=1, b=5$, both weighting functions and various values of the exponent $m$. The different behavior of the solution according to the specific weighting function selected is clear from figure 6.3. It is also evident that the solution for $W=G^{* m}$ converges rapidly, and that there is not significant variation in the solution for values of $m$ larger than about 10 . The previous observation is supported by the solution for bed-profiles shown in figure 6.4 .

It seems appropriate to point out that most of the earlier studies have assumed the value of the exponent $m$ as either one (Ames 1965) or zero (Goodman 1964). However, there is no theory to support this argument. In fact, due to the convergency of the solution with higher values of $m$, any suitable value of m should provide a reasonably accurate solution.

The following observations are in order to select definitively the weighting function $W$ : 


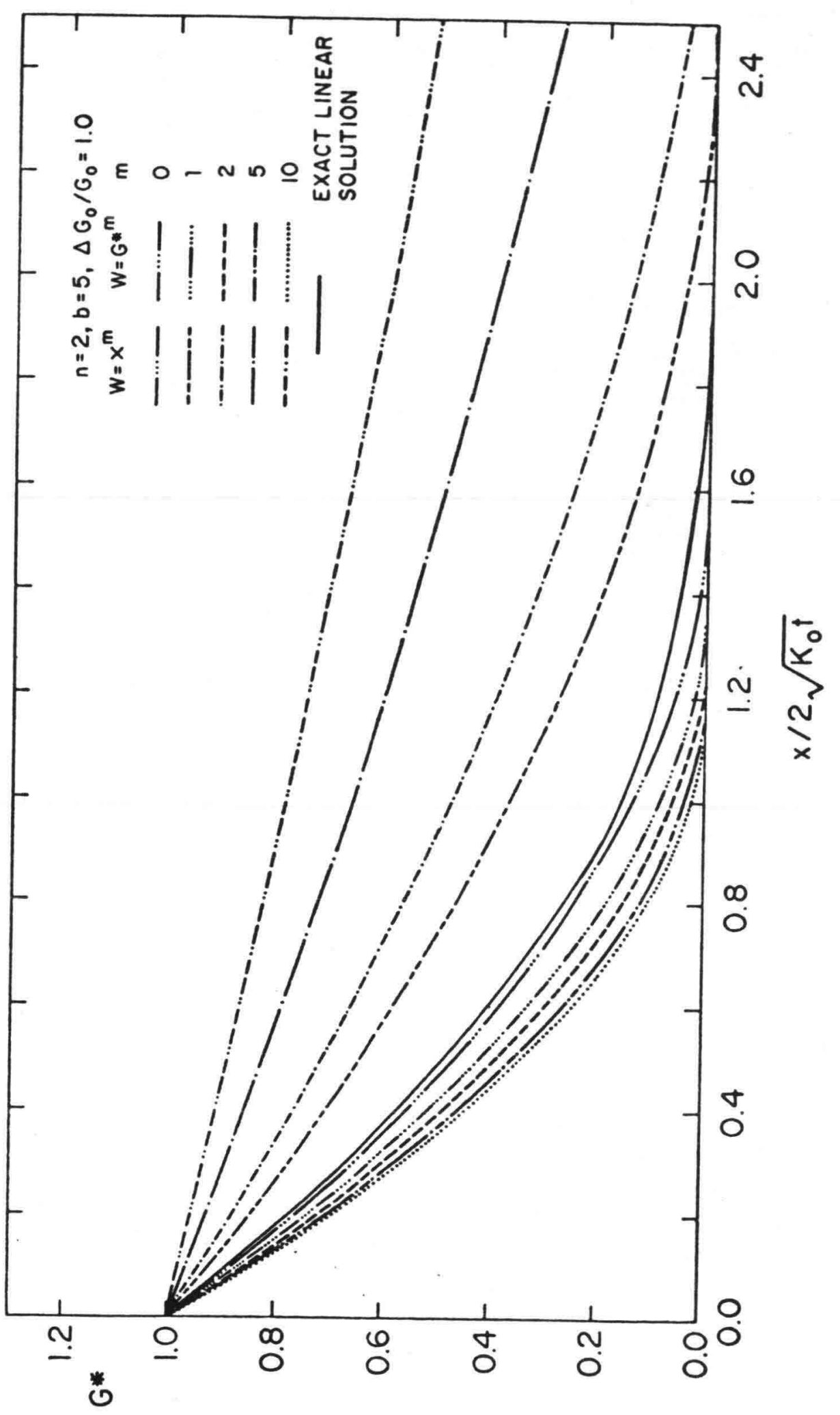

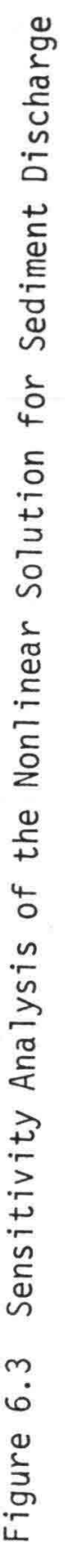




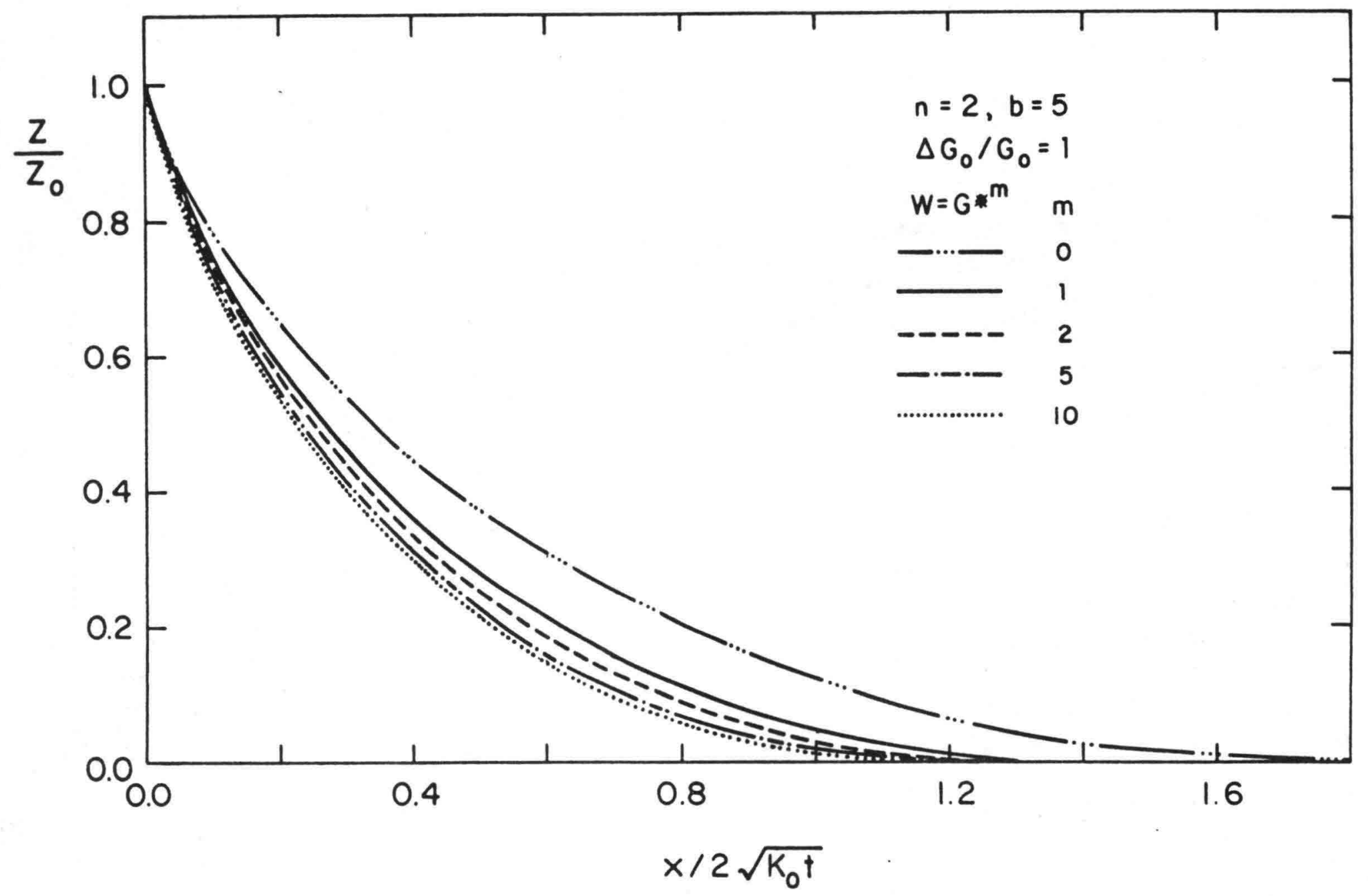

Figure 6.4 Sensitivity Analysis of the Nonlinear Solution for Bed-Profiles 
a) From the mathematical viewpoint it is evident from figure 6.1 and 6.2 that for the linear case $W=G \star m$ provides better and more accurate results than $W=x^{m}$.

b) For the linear and nonlinear cases $W=x^{m}$ gives higher values and $W=$ $G \star m$ gives either equal or lower values than the exact linear solution.

c) From figure 5.8 it is clear that, for moderate changes in sediment discharge, $i . e ., \Delta G_{0} / G_{0} \leq 1$ (the nonlinear model is valid only for $\left.\Delta G / G_{0} \leq 1\right)$, the linear solution overestimates the local sediment transport rate. Hence, the nonlinear solution with a weighting function $W=G \star^{m}$ should provide better estimates of the actual sediment transport rates.

The above considerations support the choice of the dependent variable $G^{\star}$ as the most adequate weighting function (i.e., $W=G \star m$ ).

In order to select, if possible, the appropriate values of the exponents $m$ and $n$ two alternatives were available, namely:

1) Solve the governing nonlinear model by means of an "exact" method, finite differences for instance, and compare this solution with the analytical one for various values of $m$ and $n$.

2) Compare the analytical solution, for several values of $m$ and $n$, with the available experimental data.

The selection of the procedure in this study is based on the following considerations:

a) The assumption in the model which leads to the simplification of (3.23) to (3.24) will also affect the results obtained by means of any "exact" method.

b) Any alternative method of solution will involve errors (discretization, truncation, etc.) which will make such comparison difficult. 
c) The experimental information is, by all measures, the most valuable source of information and should be used as extensively as possible, because all or most of the complex mechanisms present in real riverprocesses, some of which are either not well understood or not properly formulated up to the present day, are reproduced in the experiments.

d) The purpose of the research reported herein is to obtain a simple and adequately accurate engineering "tool" for predic*ing actual morphological processes, rather than to approach them with unjustified or excessive mathematical rigor.

e) Conveniently chosen values of $m$ and $n$, based on the available flume experiments may hopefully, account for the simplifications contained in the basic equations and in the nonlinear parabolic model.

In the light of the above discussion, the values of $m$ and $n$ were selected by comparing the analytical solution with the available experimental data.

B. Comparison of the Nonlinear Parabolic Model

with Experimental Data

The comparative study between the analytical solution for bed profiles and flume experimental data collected by Soni et al (1980) for the case of aggradation due to augmentation of the sediment load, for relative overloading rates $\Delta G_{0} / G_{0}$ ranging between 0.3 and 1 , is summarized in figures 6.5 through 6.8. All of the experimental bed-profile data for aggradation expressed as a function of the similarity variable $x / \sqrt{\bar{K}^{*} t}$ is shown in figure 6.9 . The theoretical and experimental dimensionless bed elevations at $x=0$ are compared in figure 6.10. The measured values of $z_{0}$ are in better agreement with the computed values of $Z_{0}$ by the nonlinear model than the linear model. 


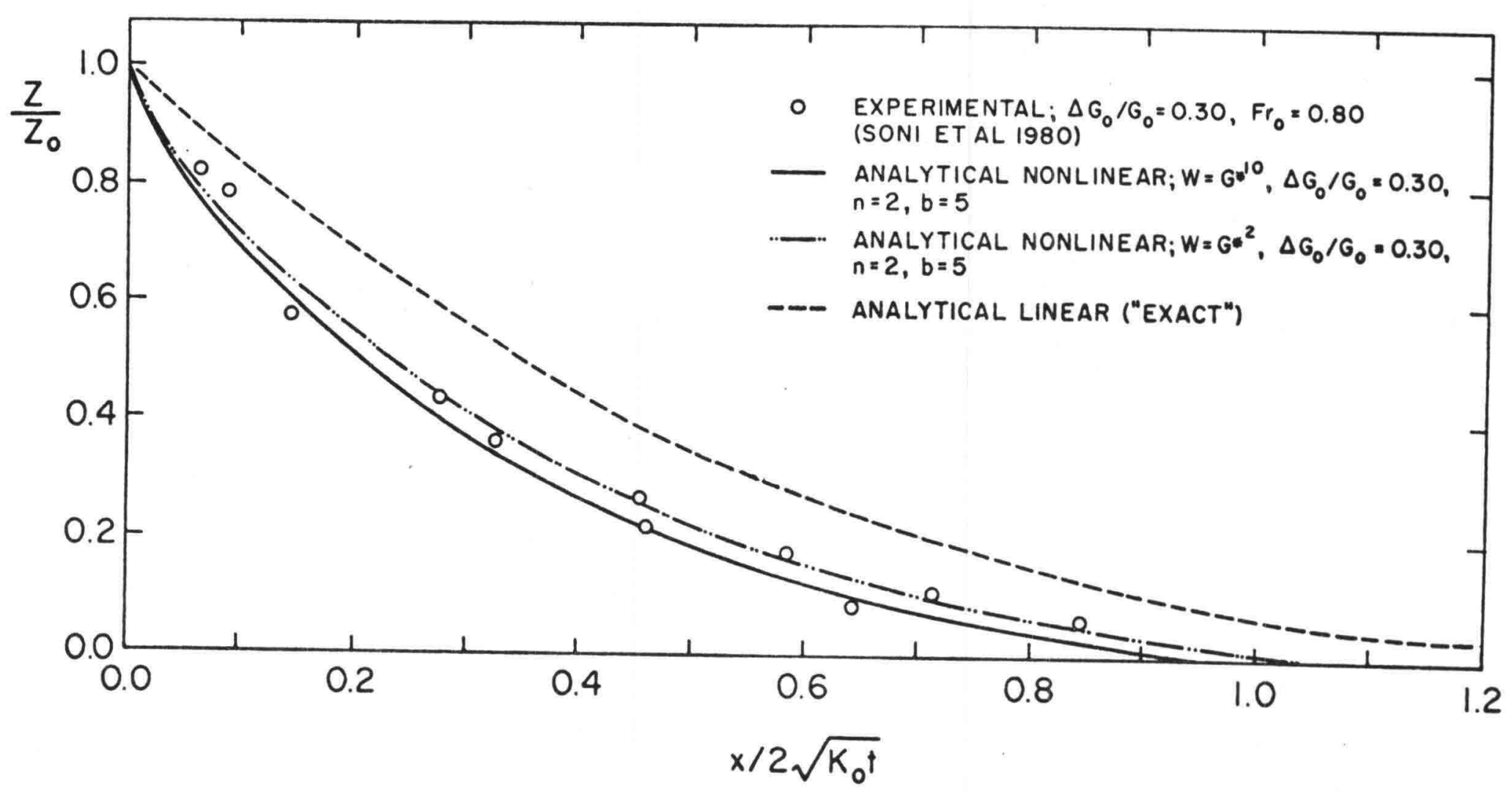

Figure 6.5 Comparison of Experimental Bed-Profile Data for Aggradation with Nonlinear Solution 


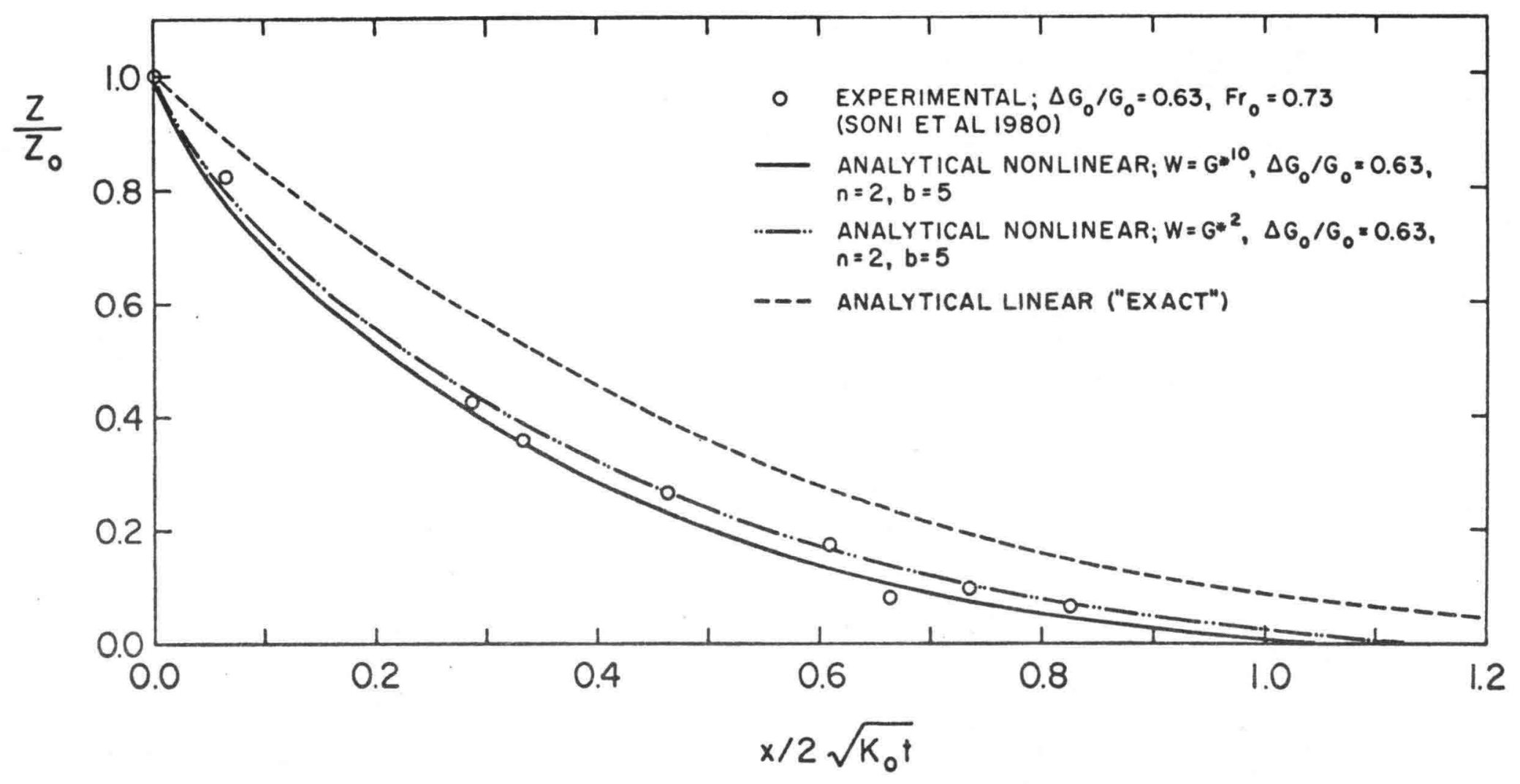

Figure 6.6 Comparison of Experimental Bed-Profile Data for Aggradation with Nonlinear Solution 


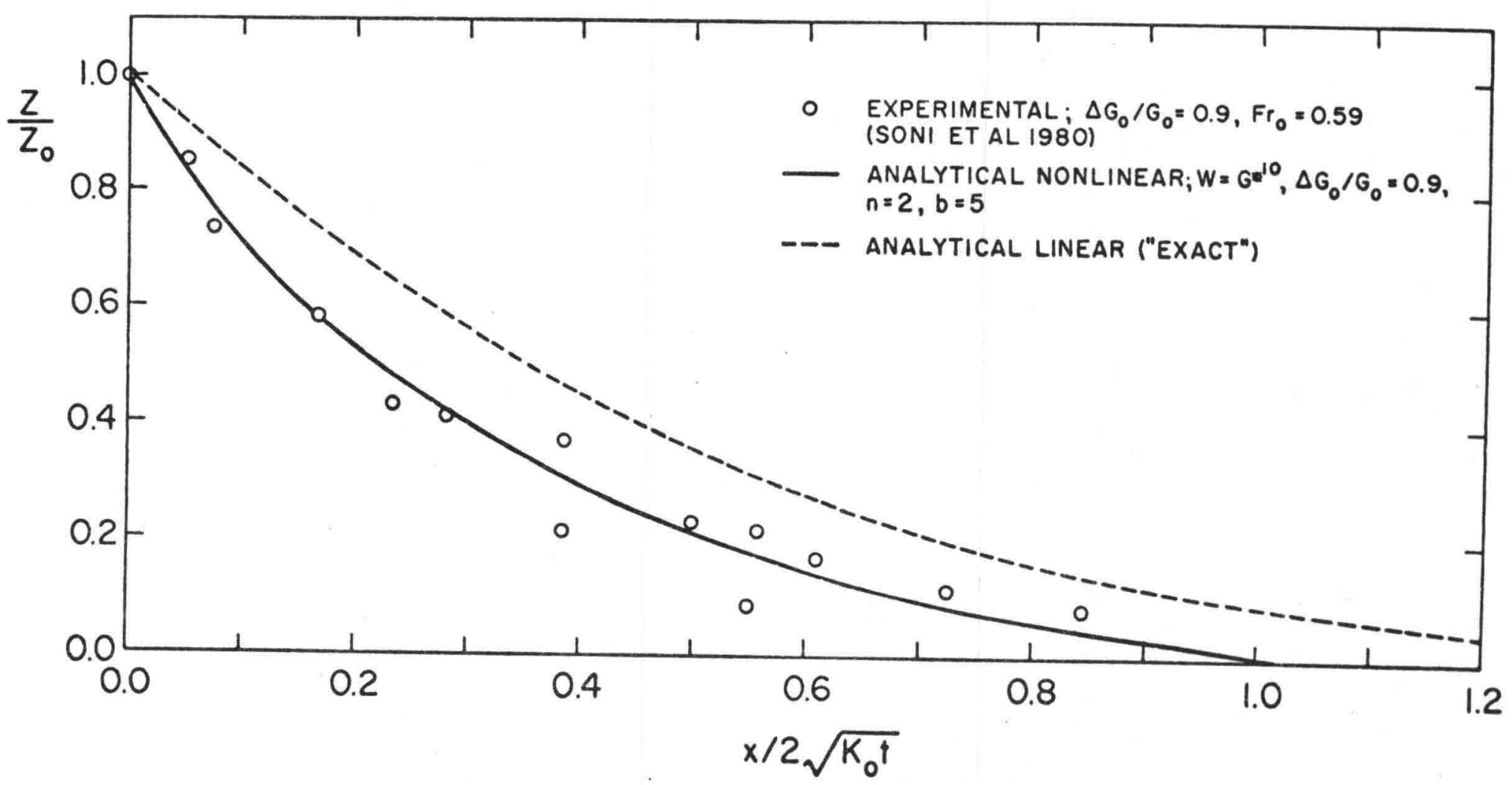

Figure 6.7 Comparison of Experimental Bed-Profile Data for Aggradation with Nonlinear Solution 


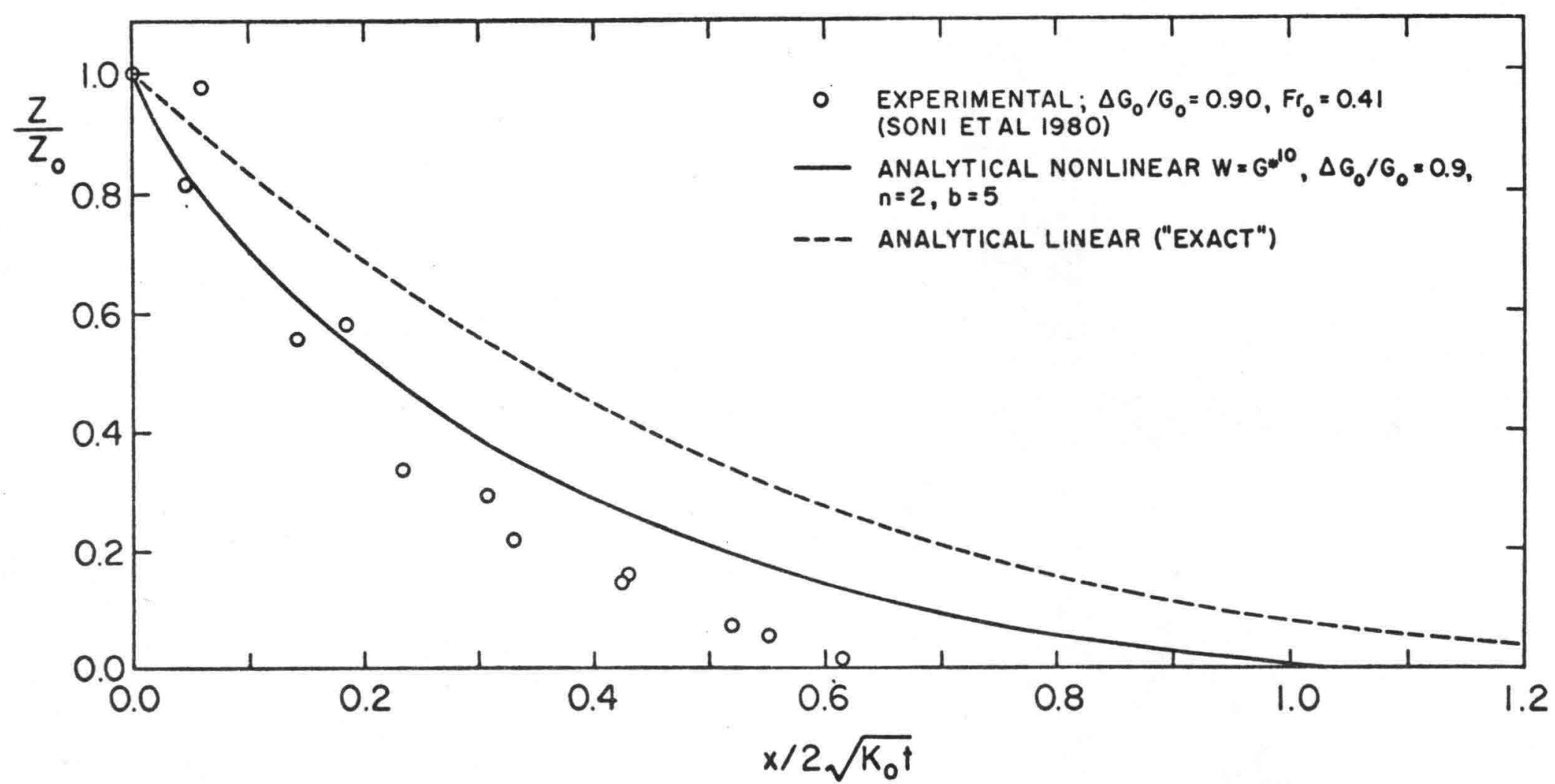

Figure 6.8 Comparison of Experimental Bed-Profile Data for Aggradation with Nonlinear Solution 


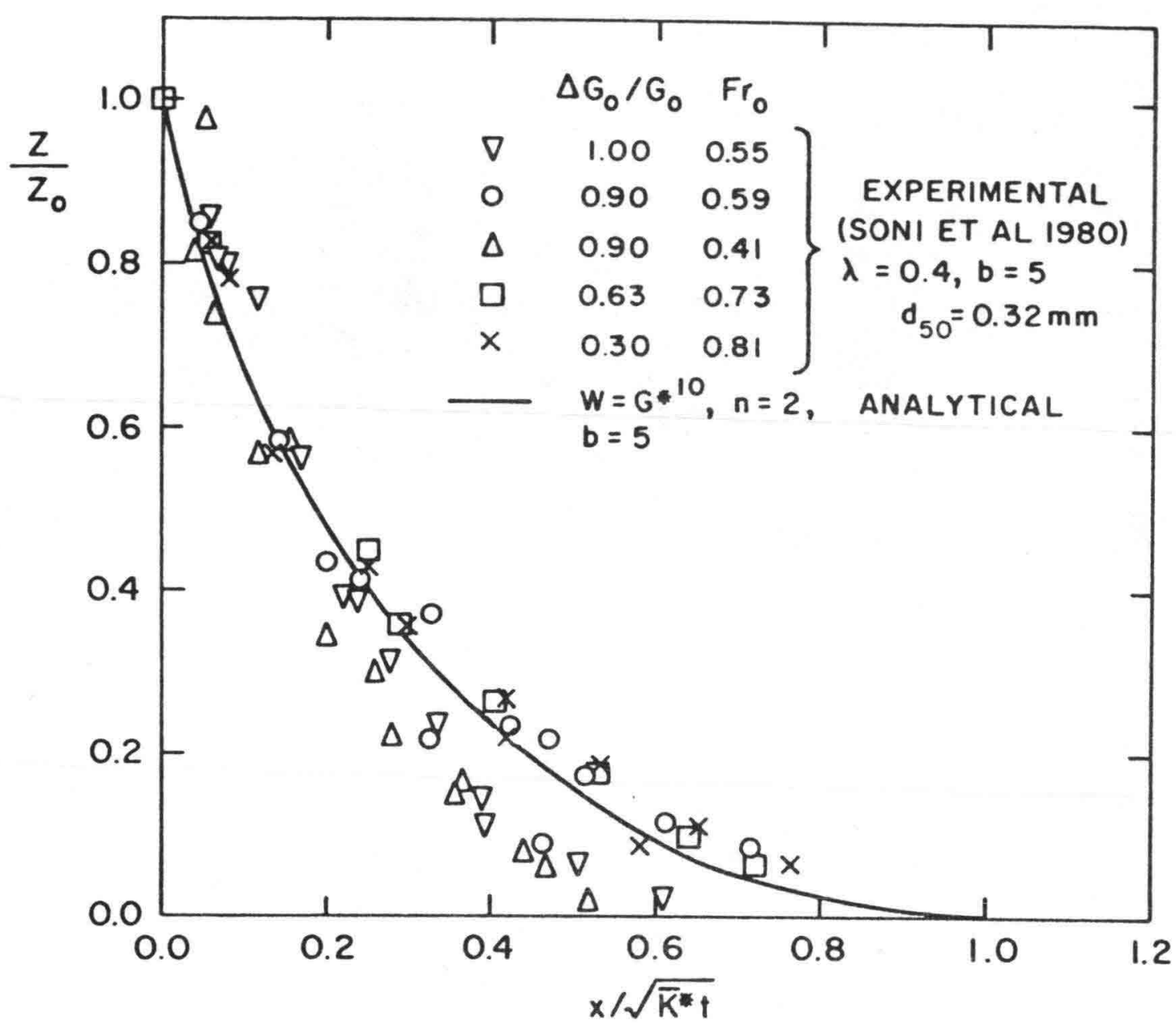

Figure 6.9 Comparison of the Nonlinear Solution with Experimental Bed-Profile Data for Aggradation 


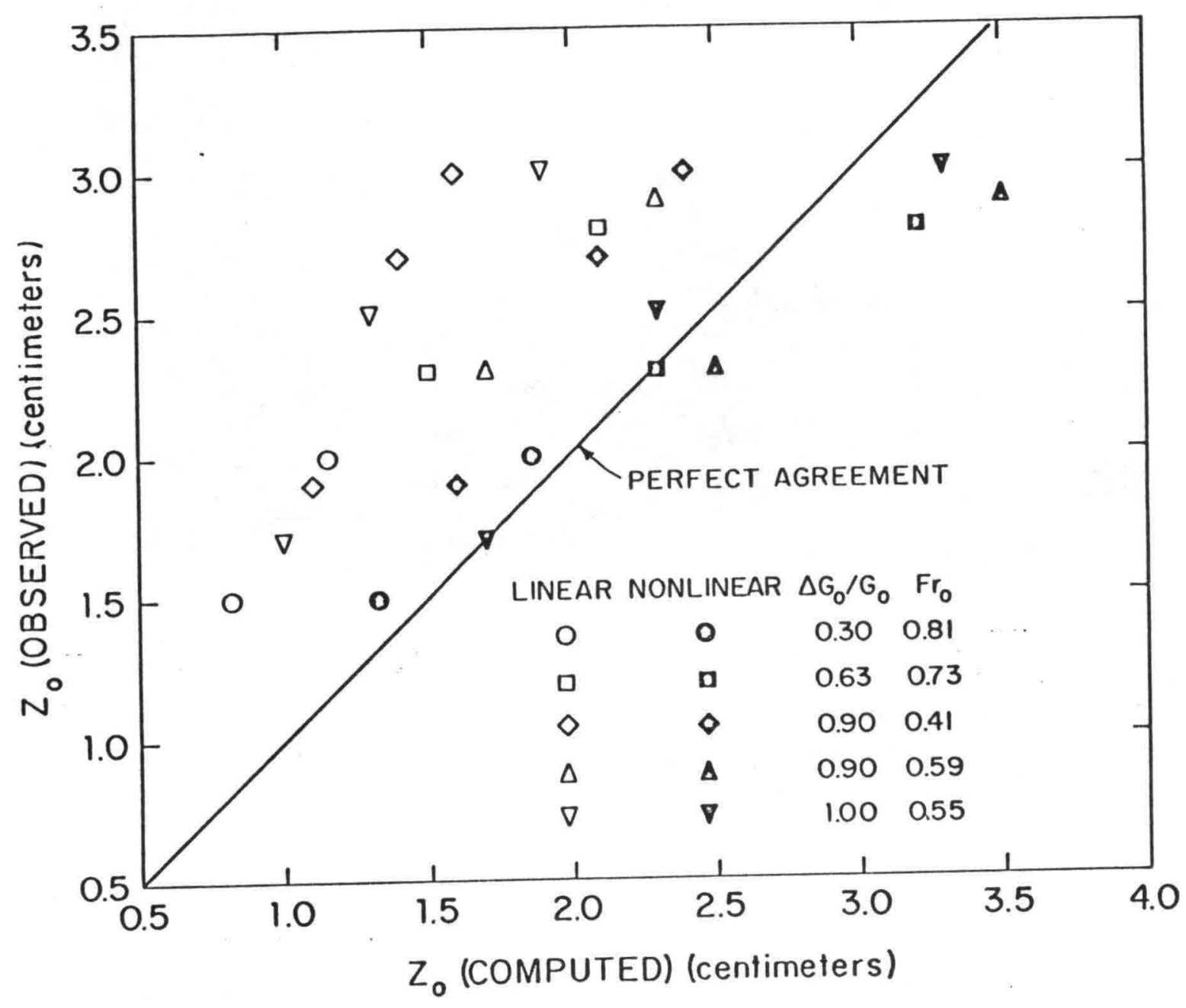

Figure 6.10 Comparison of Fxperimental and Computed Values of $\mathrm{Z}_{\mathrm{O}}$ 
It is evident that values of $m=10$ and $n=2$ provide, in general, good agreement between the analytical and experimental for bed profiles and bed elevation at $x=0$. The agreement observed is, indeed, better than that obtained by means of the linear model.

The comparison between the nonlinear solution and laboratory data concerning degradation due to sediment diminution obtained by Newton (1951) for $\Delta G_{0} / G_{0}=-1$ is shown in figure 6.11 .

It is important to note that in the case of degradation, a value of $\mathrm{m}$ equal to 2 provides better agreement between the analytical and experimental results than a value of $m$ equal 10 . However, no definitive conclusion can be drawn from this comparison due to the fact that the water depth and related flow parameters at the downstream end of the flume were not kept constant (Newton 1951), as required for the applicability of the analytical solution. Moreover, it should be mentioned that the length of the flume used by Newton was only $9.20 \mathrm{~m}$, which may be considered somewhat short for accurate measurements.

C. Application of the Nonlinear Solution to Practical Problems

The final purpose of any research endeavor is the utilization of the analytical, numerical, or experimental results for the solution of actual engineering problems. The aim of this section is to present the analytical results in a ready-to-use format, illustrate the calculation procedures, and suggest some possibilities of using existing experimental or field data to improve the predictions of nonequilibrium processes in alluvial channels.

The analytical solutions for the dimensionless total sediment transport rate $\left(G^{*}\right)$ and dimensionless bed profiles $\left(Z / Z_{0}\right)$ expressed as functions of the similarity variable $x / \sqrt{\overline{\mathrm{k}}^{\star}} t$, for several values of the exponent $n$, are shown in figures 6.12 and 6.13 .

It is interesting to note that for prescribed values of the exponents $n, m$ and $b$ the normalized diffusion coefficient, $\bar{K} * / K_{0}$, is a function of the relative change in total sediment load, $\Delta G_{0} / G_{0}$, only. Hence, plots similar to figure 6.14 (which shows the variation of $K \star / K_{0}$ with $\Delta G_{0} / G_{0}$ for $n=2, b=5$ and several values of $m$ ) can be readily prepared. At this point it should be mentioned that values of $n$ and $m$ equal to 2 and 10, respectively, have been 


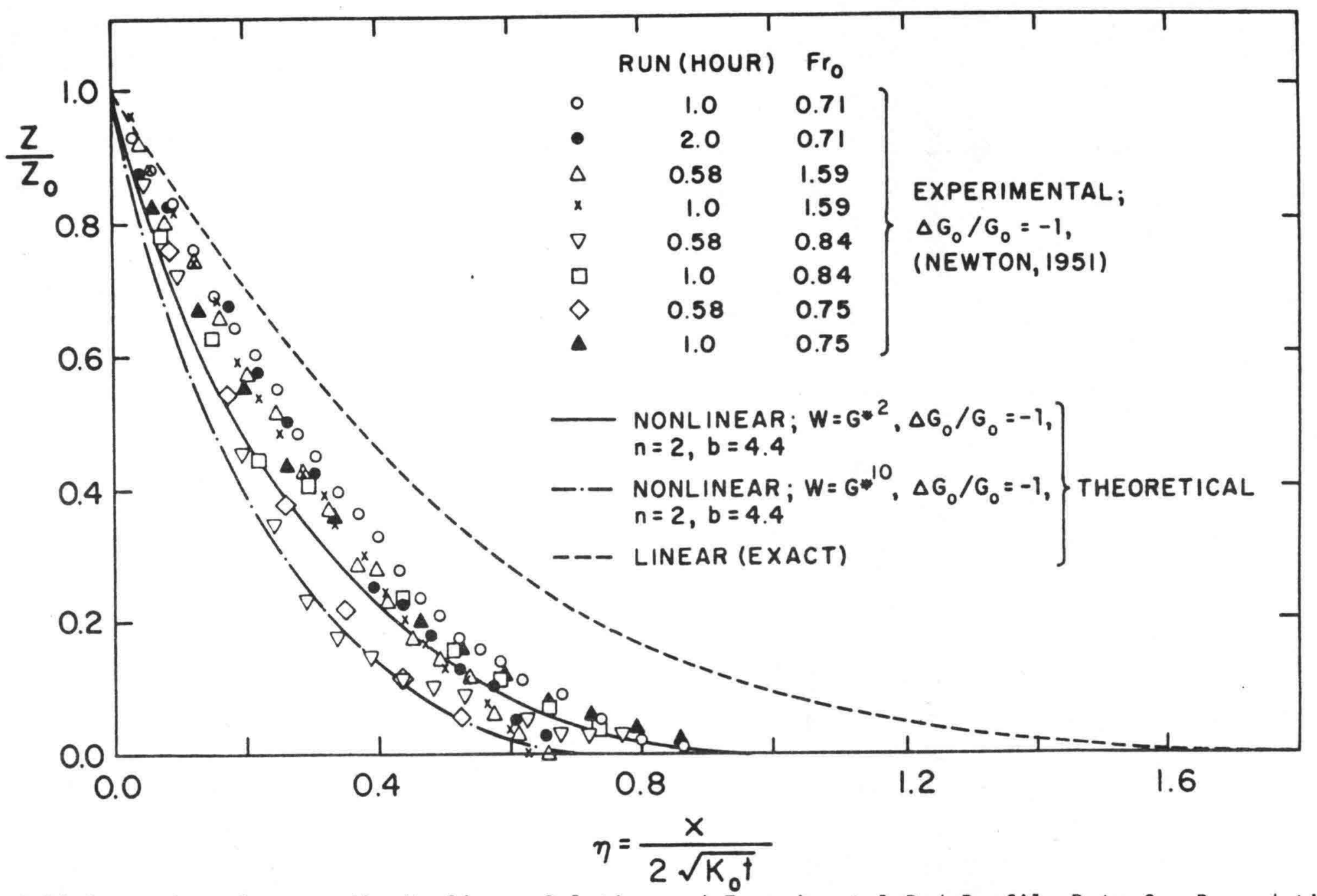

Figure 6.11 Comparison Between the Nonlinear Solution and Experimental Bed-Profile Data for Degradation 


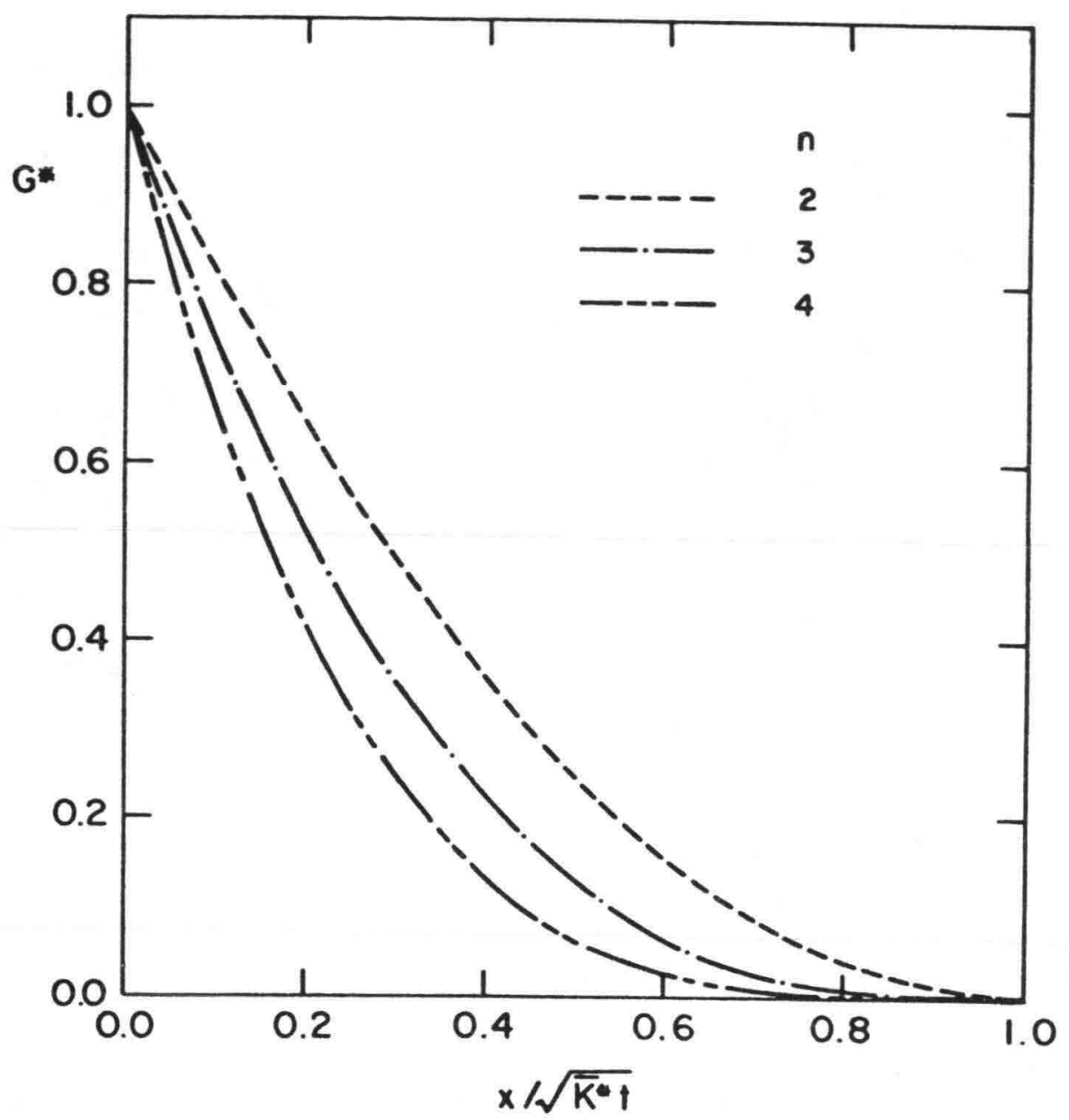
Figure 6.12 Dimensionless Total Sediment Transfer Rate Obtained by
the Nonlinear Solution 


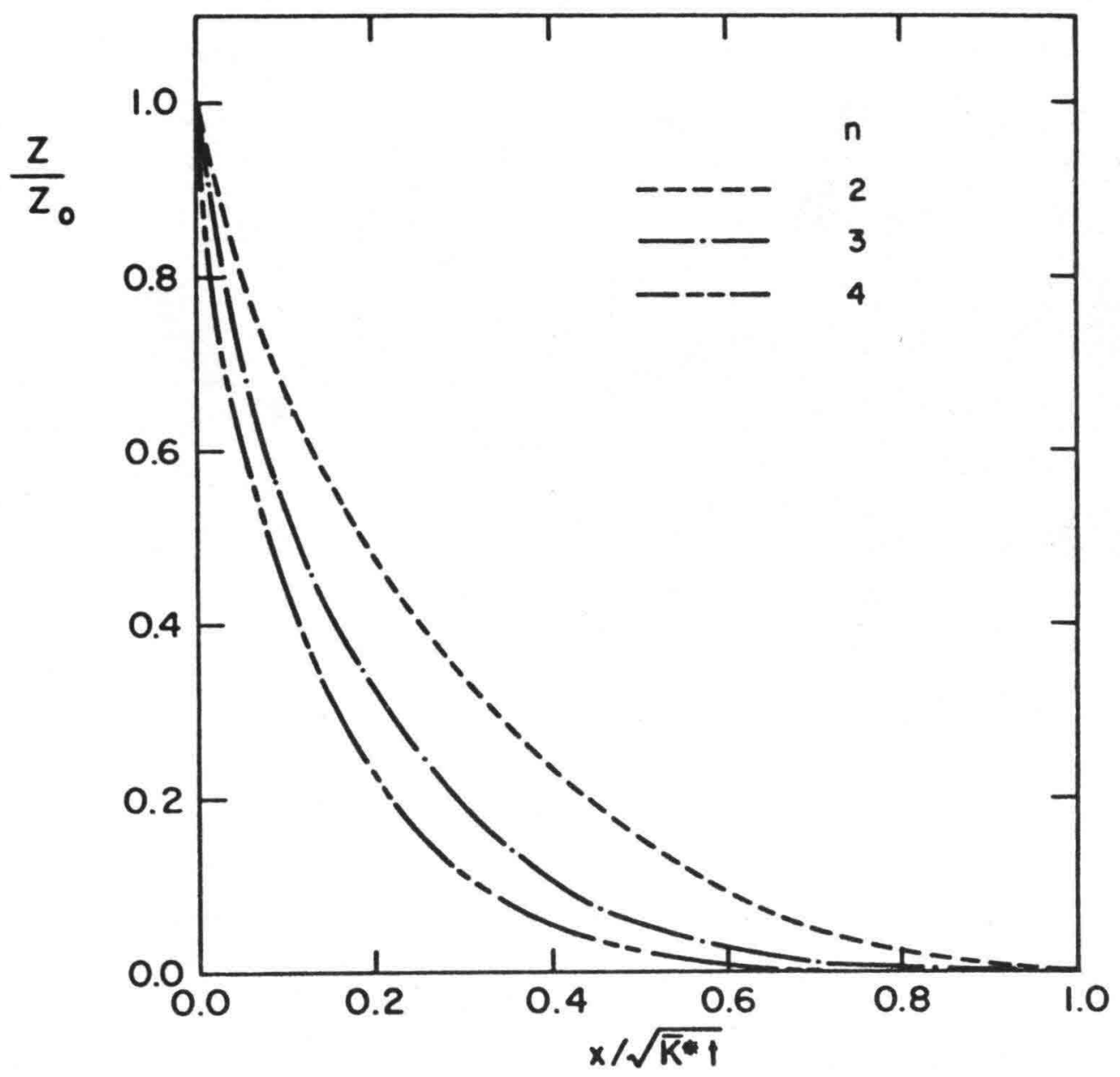

Figure 6.13 Dimensionless Bed Profile Obtained by the Nonlinear Solution 


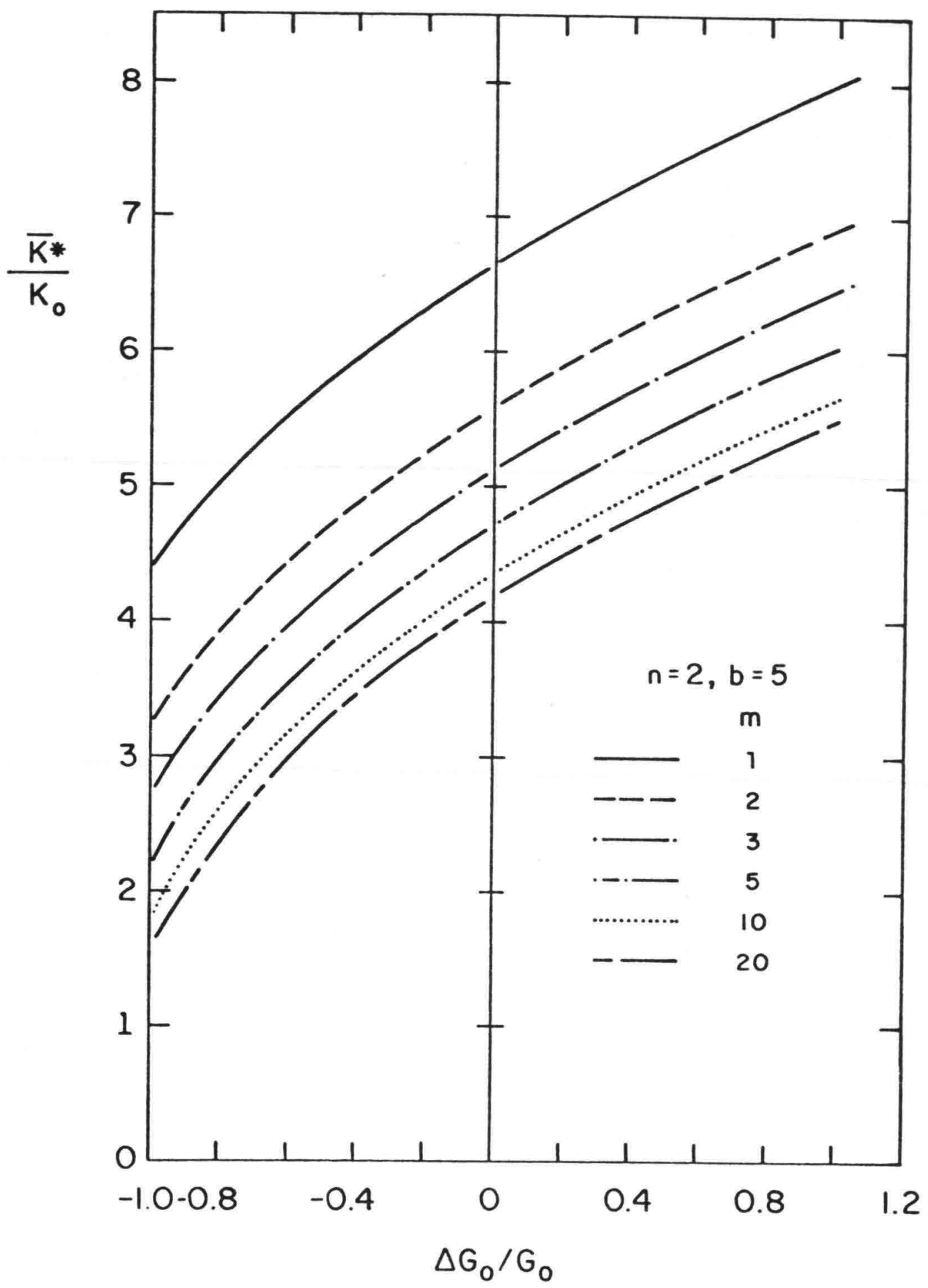

Figure 6.14 Variation of the Normalized Diffusion Coefficient with the Normalized Change in Sediment Discharge 
found to provide good agreement between experiments and theory. However, as mentioned earlier, a value of $n$ equal to 2 appears to be the most appropriate from the theoretical standpoint.

Depending on the available prototype data; two calculation procedures are presented as follows.

1. Data for calibration of the model is not available

a) Compute $K_{0}$ and $\Delta G_{0} / G_{0}$ from the known uniform flow data.

b) Assume $n=2$ and $m=10$ and determine $\bar{K}^{\star}$ from figure 6.14. If experience from similar channels is available, improved estimates for $n$ and $m$ may be used.

c) Determine the time dependent bed profiles from figure 6.13 .

d) Compute the time dependent total sediment load by using figure 6.12 .

2. Data for calibration of the model is available.

a) Compute $K_{0}$ and $\Delta G_{0} / G_{0}$ from the known uniform flow information.

b) Assume $n=2$ and $m=10$ (use improved estimates if possible). and determine $\bar{K} \star$ from figure 6.14 .

c) Plot the nonequilibrium bed profile data in figure 6.13 . If agreement between the experimental and theoretical bed profiles in dimensional and nondimensional coordinates are not satisfactory choose another value of $\mathrm{m}$ and repeat the comparison.

d) Repeat step a) for different values of the exponent $n$.

e) Select the values of $n$ and $m$ that provide the best agreement between the field data and the analytical solution, and use the appropriate figures or equations for predicting future bed profile evolution and local sediment transport rates.

If nonequilibrium sediment-transport-rate data is available instead of the bed profile data, the procedure is similar but figure 6.12 should be used insteady of figure 6.13 in steps $c$ ) and $d$ ).

Due to the binomial-series expansion introduced in the mathematical treatment of the problem, the analytical solution converges for values of the relative change in sediment load less than unity (i.e., $-1 \leqslant \Delta G_{0} / G_{0} \leqslant 1$ ). This means that the solution is applicable to any degradation process and aggradation processes in which the relative variation in sediment discharge is 
less or equal to $100 \%$. It is believed that this range will cover most of the practical needs. However, for extreme cases in which the relative variation in sediment load exceeds $100 \%$ (i.e., $\Delta G_{0} / G_{0}>1$ ), a reasonable estimate of $\bar{K}^{*}$ can be obtained by extrapolation of the curves in figure 6.14. Once $\bar{K} *$ is suitably determined the application of either one of the above given procedures will provide the solution to the morphological process under consideration. In order to illustrate the suggested extrapolation procedure, the measured and computed bed profiles for an aggradation process in which $\Delta G_{0} / G_{0}$ equals 1.80 (Soni et al. 1980) are shown in figure 6.15. The values used in the calcuations were; $n=2 ; m=10 ; \Delta G_{0} / G_{0}=1.80, b=5$. From figure 6.14 a value of 6.45 was extrapolated for $\bar{K}^{\star} / K_{0}$. The agreement between the experimental and theoretical bed profiles is encouraging and does not require any further comment. 


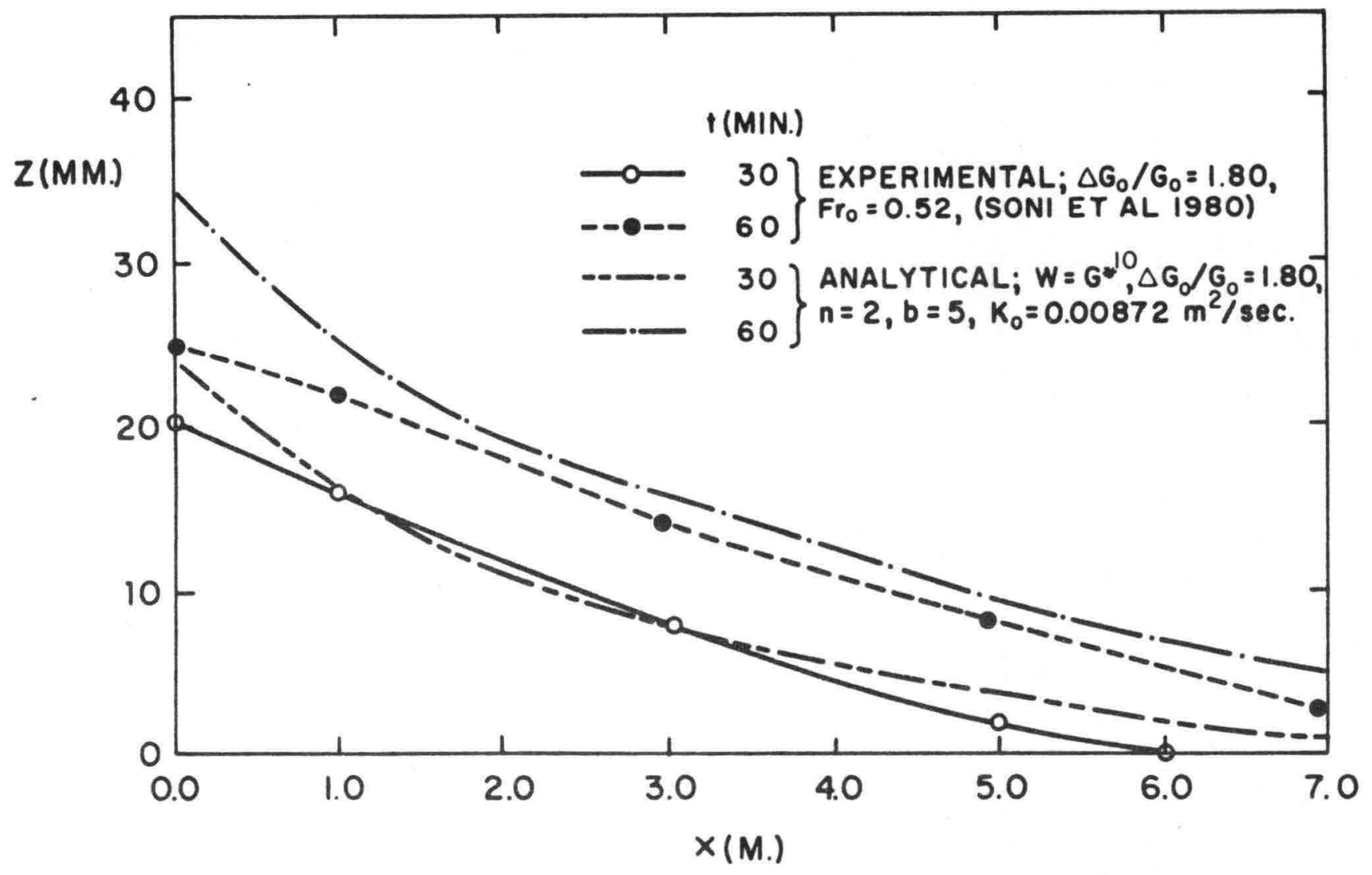

Figure 6.15 Comparison of the Nonlinear Solution (Using Extrapolation Procedure) with Experimental Bed-Profile Data 


\section{EXPERIMENTAL STUDY}

A. General

As mentioned earlier, there exists a wealth of studies dealing with bed form resistance in alluvial channels under uniform flow conditions. However, hardly any data concerning bed configuration and resistance under nonequilibrium flows are available.

Shen and Bamidipathi (1969) reported flume laboratory experiments on the variation of roughness during degradation. The analysis of Newton's (1951) and their own data led them to the conclusion that "the variation of roughness during degradation is the same as that of the equilibrium flow", and that depending on the sediment size the part of the total roughness associated to the bed forms increased for sand finer than $0.6 \mathrm{~mm}$ and decreased for sand coarser than $0.6 \mathrm{~mm}$. Soni et al. (1977), on the basis of application of Manning's flow resistance equation to measured nonequilibrium bed and water surface profiles, concluded that the value of Manning's roughness coefficient in an aggraded reach is generally smaller than the values for uniform flow. Roughness coefficients reductions of the order of $30 \%$ were reported; however, no systematic variations of the roughness coefficient with sediment injection rate and other parameters were found. The friction factor predictor developed for Raju (1970) for uniform flow conditions was found applicable to nonequilibrium flows, provided that the local friction slope is used instead of the bed slope.

The development of a reliable friction-factor predictor for nonequilbrium flows is a formidable task to be undertaken in the years ahead. The understanding of the complex interrelations among the multiple bed features and the flow, sediment and water parameters involved will surely require long and systematic theoretical and experimental efforts. The knowledge and experience accumulated over the years on steady uniform flows will prove to be useful in many aspects of the new studies to come.

From the brief overview of the work done in the past, it may be concluded that there has been no attempt to study in a systematic and quantitative 
fashion the bed form characteristics in unsteady, nonuniform flows. As the flow resistance associated to the bed forms is a very interesting subject from the practical and theoretical viewpoints, a preliminary research program was planned. The experimental program was intended to study the time evolution of the bed forms during an aggradation process due to a sudden increase in sediment discharge and to develop the basis of a methodology to be used in future research in unsteady-nonuniform flows.

\section{B. Experimental Apparatus and Procedures}

1. Equipment. The main experimental facility was a recirculating flume with a glass-walled working section measuring $27.4 \mathrm{~m}$ in length, $0.914 \mathrm{~m}$ in width, and $0.45 \mathrm{~m}$ in depth. An elevation view of the installation is shown in figure 7.1. The power to recirculate the water-sediment mixture was provided by two 7.5-horsepower variable-speed motor-pump units located under the downstream end of the flume, each discharging into separate $0.30 \mathrm{~m}$ spiral weld return pipes terminating at a transition to the flume inlet. Discharge could be measured at side-contracted orifices in each return pipe. The flume was supported by a central pivot and four synchronized motor-driven cam jacks so that the slope was changed without interrupting the operation of the flume. Flume slope was measured by means of a dial gage and a point gage at the downstream end of the flume. Steel rails for the instrument carriage, mounted at the top of the flume walls, provided a reference frame for the elevation relative to a plane tilted at the flume slope.

The bed was composed of quartz foundry sand with a median diameter, d $d_{50}$, of $0.35 \mathrm{~mm}$ and a geometric standard deviation, $\sigma_{\mathrm{g}}$, of 1.42 . A plot of the sieve-diameter distribution for the sand is shown in figure 7.2

Sand identical to the one on the bed was used to generate the aggradation process. Dry sand was fed into the flow at a section $6 \mathrm{~m}$ from the upstream end of the flume by means of a mechanically operated sand-feeder. The sand level in the hopper of the feeder was kept unchanged to maintain a constant sediment rate. A motor-driven vibrator attached to the bottom of the hopper facilitated the flow of the sand through a series of small openings located at the bottom of the hopper. 

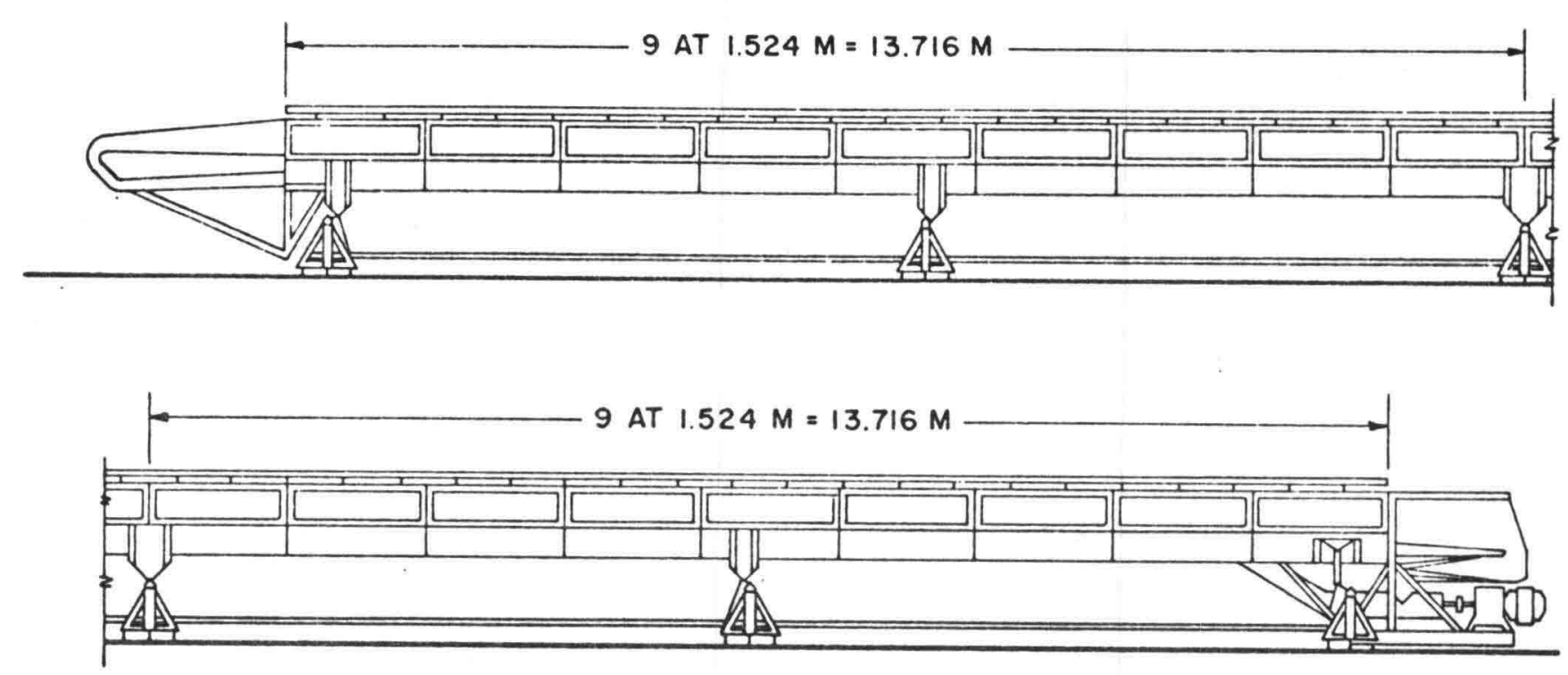

Figure 7.1 Longitudinal Elevation View of Experimental Flume 


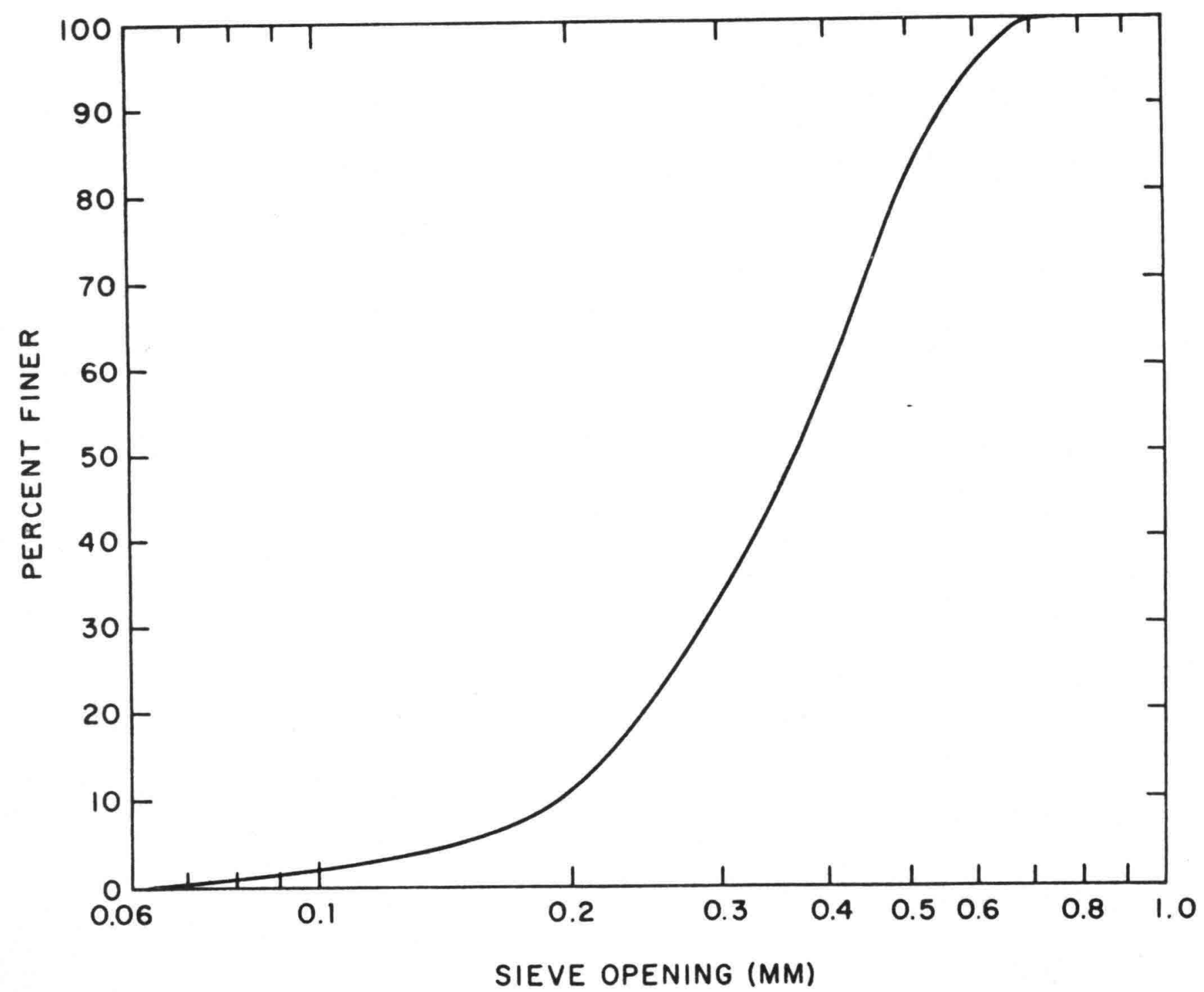

Figure 7.2 Sediment Size Distribution

ㅇ 
Water-surface elevations were measured by means of a point gage mounted atop the motor-driven carriage. Longitudinal bed profiles were measured with a Delft bed profile indicator that was mounted on the motor-driven instrument carriage. The sensing tip of the probe was $3 \mathrm{~mm}$ above the sand bed. The analog output from the bed profile follower was sampled and digitized at 50 millisecond intervals by the IIHR HP-1000 Data Acquisition and Control System. The carriage speed was set so that the 50 millisecond interval corresponded to $1 \mathrm{~cm}$ intervals along the working section of the flume. The digitized data sets were subsequently plotted and statistically analyzed by means of the HP-1000 Data Processing System.

Samples for determining total sediment transport load were obtained by withdrawing a representative water-sediment mixture through a vertical slot sampler, consisting of two parallel sheet metal plates connected to a hose on a pump, at the downstream end of the flume. This device sampled a 1-cm wide vertical slice extending over the entire depth of flow at the centerline. Samples were pumped into a $0.65-\mathrm{m}^{3}$ collecting tank at such a rate that the mean entrance velocity into the slot equalled the depth-averaged flow velocity in the flume. Makeup water was added during sampling to maintain a constant volume of water in the flume system. Following collection and sufficient time for the sediment to settle, the water was decanted and the sediment was carefully flushed into a beaker for subsequent drying and weighing.

2. Experimental procedure. Before starting the experiment, the sand bed was leveled over the length and width of the flume with the aid of a screed that was mounted to the instrument carriage. Next, water was added to the flume to bring the water depth to $0.13 \mathrm{~m}$. The slope was set to the estimated value for uniform flow, and the flow was started at the desired discharge of $0.0375 \mathrm{~m}^{3} / \mathrm{sec}$. From time to time the water surface slope was checked by means of a point gage mounted to the instrument carriage, and the flume slope was adjusted to make it equal to the water-surface slope. This procedure of successive adjustments was continued as the bed configuration came into equilibrium with the flow conditions. After the water surface slope had remained equal to the flume slope for a period of several hours, and the flow depths at several points along the flume had been checked to see if the flow depth was approximately $0.13 \mathrm{~m}$. along the entire length of the flume, the flow was stopped and the bed profile along the center line was measured with the 
Delft-bed profile indicator. The output from the HP-1000 Data Acquisition and Control system was plotted on the HP-9872A graphics plotter and reviewed for stationarity, i.e., any consistently rising or falling trend along the flume in the bed elevation with respect to the mean bed elevation. If a visual scan indicated stationarity of the data, and the mean bed slope proved to be approximately equal to the water surface slope, the initial uniform flow condition was considered achieved. The bed profile and flow data was then stored on disk by the computer; otherwise the flow was started again and continued for a few more hours. Once the uniform flow condition was reached, the flow was started again and three total-sediment-load samples were obtained, taking care to add sufficient makeup water to maintain uniform flow at the proper slope and depth.

After uniform flow conditions were set along the flume, sediment was supplied at the upstream end at a constant rate, by means of the sand-feeder, to cause aggradation. During the aggradation process bed and water surface profiles were measured and recorded for future analysis at either 3 - or 6-hour intervals. Bed profiles corresponding to the initial uniform flow $(T=0)$ and various times after the initiation of the aggradation process are shown in figures 7.3 through 7.5. A summary of the experimental data is presented in table 7.1

C. Qualitative Observations

As was expected, the excess sediment discharge deposited on the bed and caused its level to rise. The bed slope and flow parameters adjust gradually to the new imposed sediment discharge. The sediment wave or aggrading front migrates downstream, as illustrated by figures 7.3 through 7.5 , and causes a bed level increase. The magnitude of the increase in bed elevation at a given location decreases with time.

In general, it is possible to distinguish two types of waves or perturbations, a macro-perturbation or aggrading front and micro-perturbations or bed-forms which travel over the surface of the bed. It was clear that the speed of propagation of the dunes (micro-perturbations) was large at the upstream sections and decreased towards downstream. In fact, it was also possible to observe that the fast-moving dunes merged the slower moving 


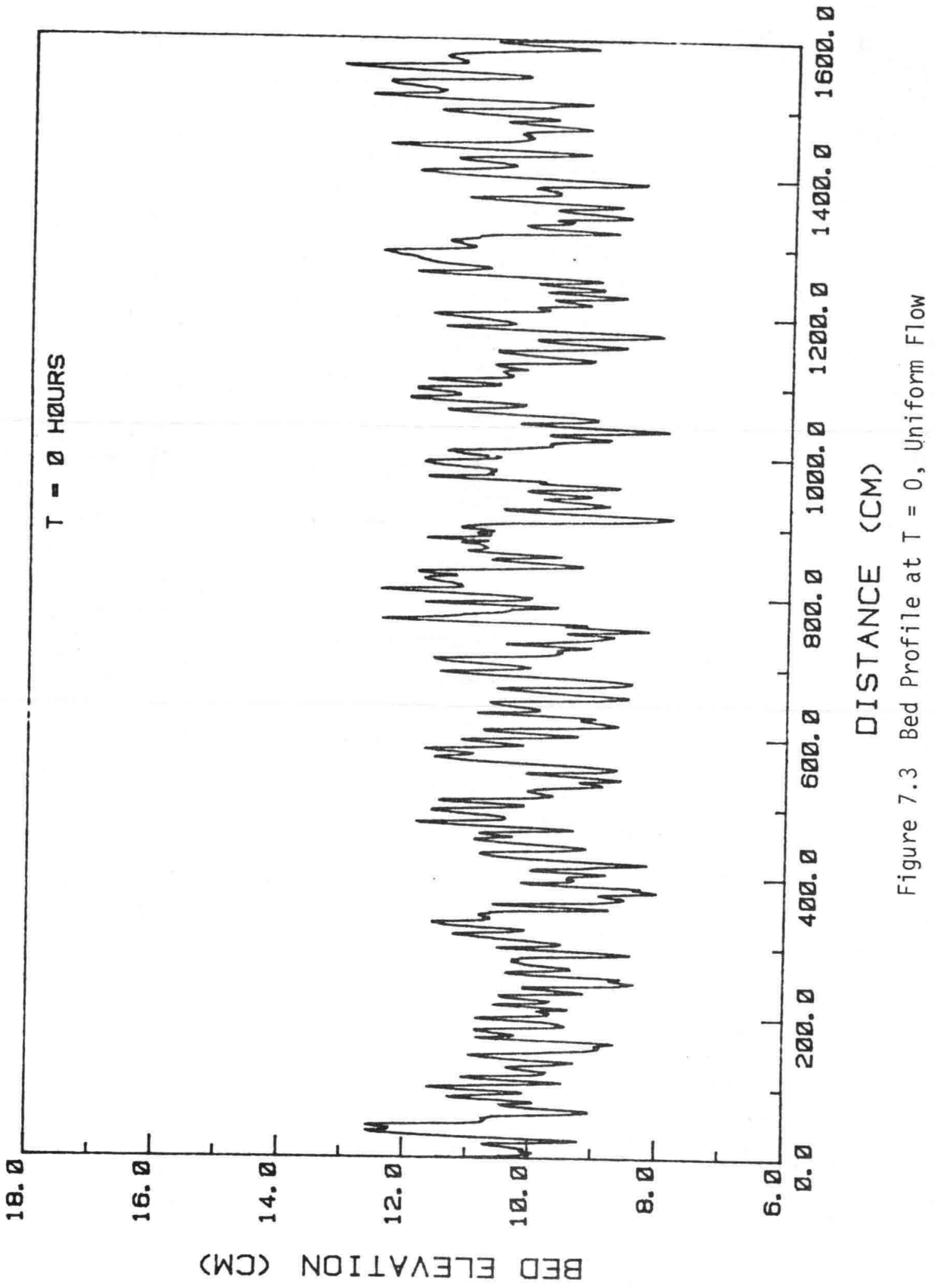




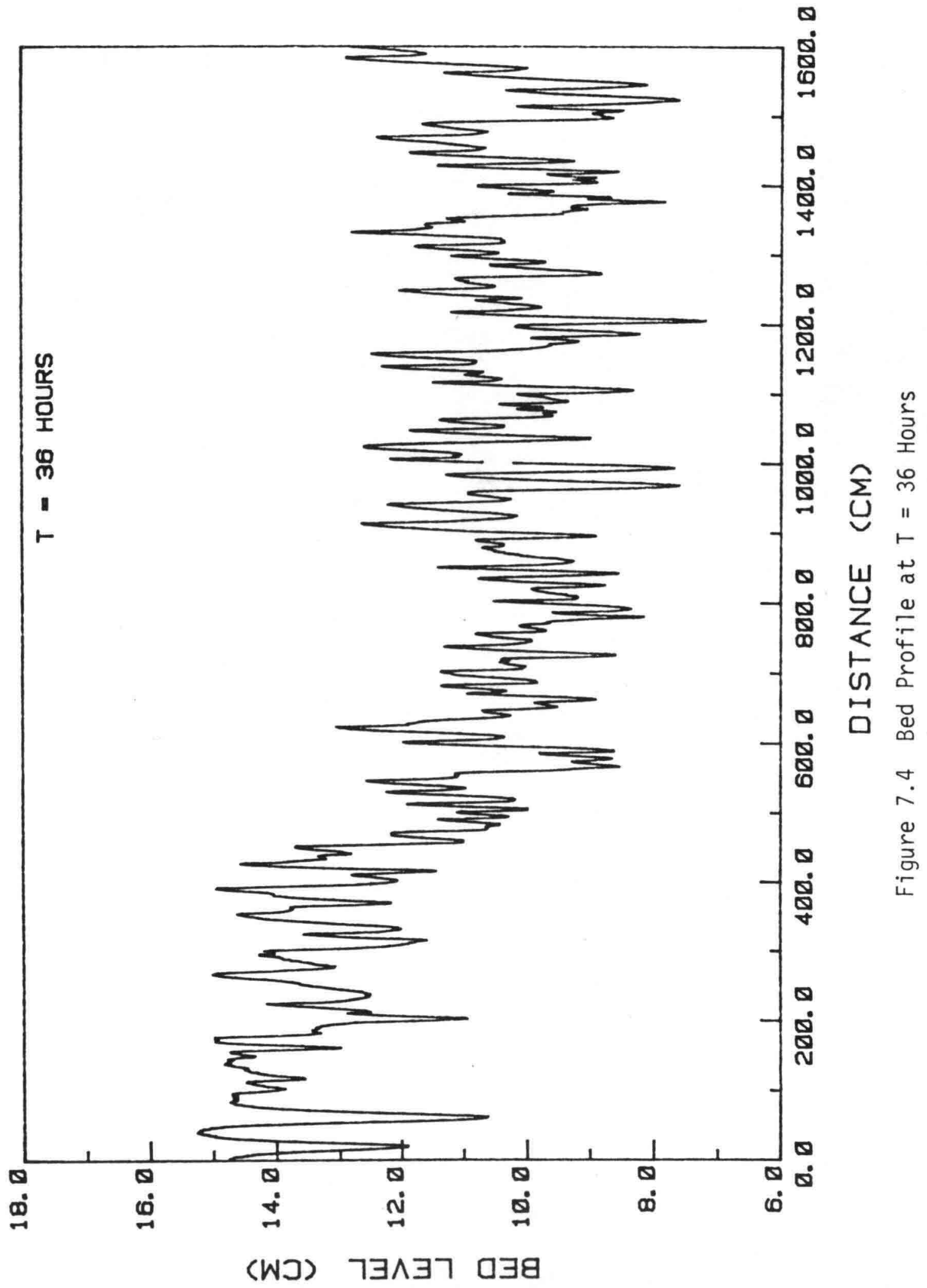




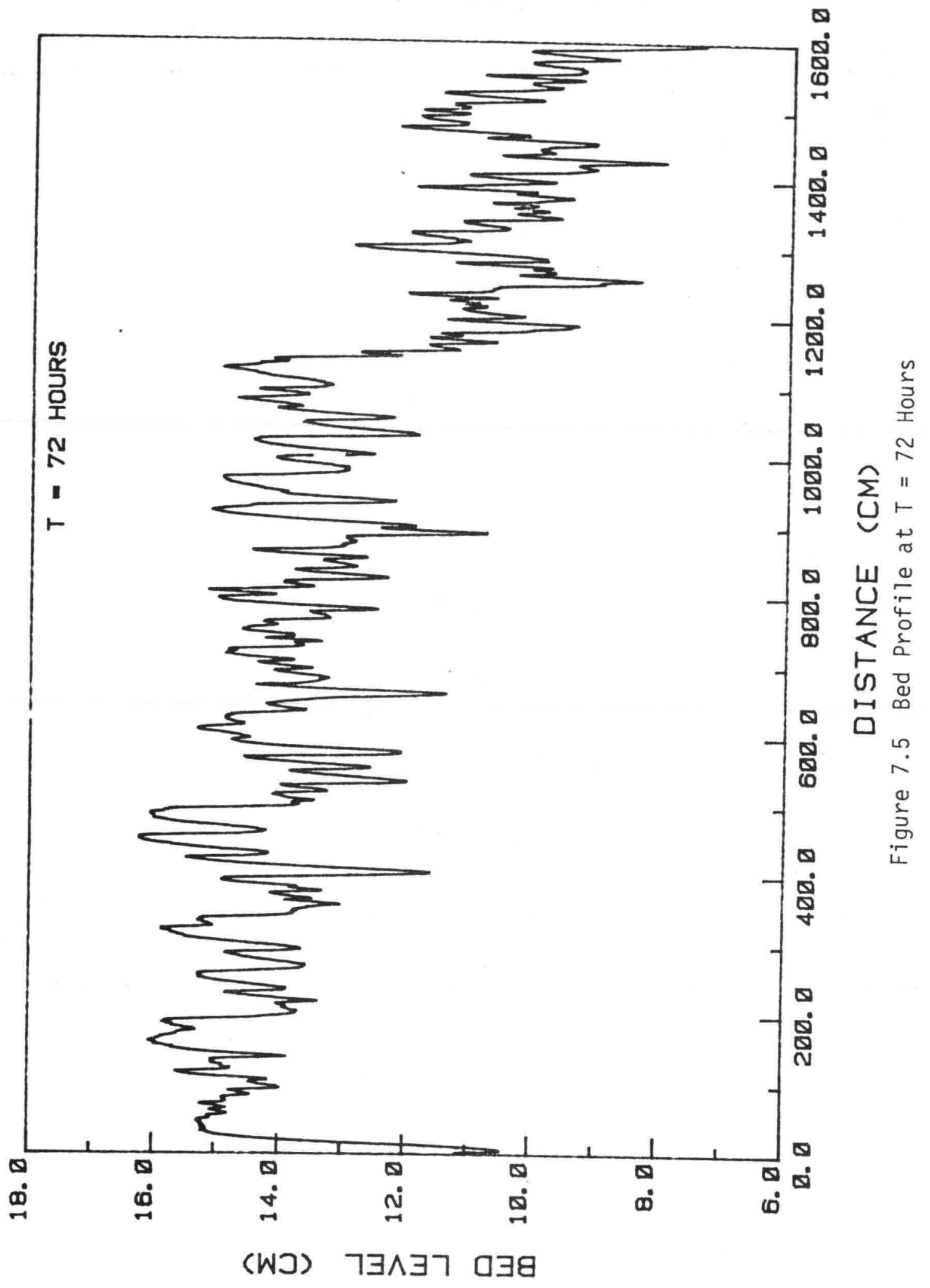


Table 7.1

Summary of Experimental Data

$$
\begin{gathered}
q=4.42 \times 10^{-2} \mathrm{~m}^{3} / \mathrm{s} . \mathrm{m} \\
H_{0}=0.13 \mathrm{~m} \\
U_{0}=0.34 \mathrm{~m} / \mathrm{s} \\
S_{0}=7.7 \times 10^{-4} \\
F_{r_{0}}=0.3 \\
d_{50}=0.35 \mathrm{~mm} \\
\sigma_{g}=1.42 \\
\lambda=0.4 \\
G_{0}=1.96 \times 10^{-8} \mathrm{~m}^{3} / \mathrm{s} . \mathrm{m} \\
\Delta G_{0} / G_{0}=2.4
\end{gathered}
$$

Temperature $\simeq 20-22^{\circ} \mathrm{C}$ 
ones. According to de Vries (1969), the celerity at which a small bed perturbation propagates is given by

$$
c=\frac{b G U}{q\left(1-F r^{2}\right)}
$$

As $G, U$ and $F r$ decrease towards downstream the celerity of the small bed perturbations is larger upstream and diminishes towards downstream which qualitatively agrees with the experimental observations reported above.

D. Bed Profile Analysis

Quantitative measures of the bed-form characteristics during aggradation were obtained from a statistical analysis of the zero-crossing distances and amplitudes of the digitized longitudinal bed profiles taken at distinct times of the process.

A definition sketch for the zero-crossing distances and amplitudes analysis of a bed profile is shown in figure 7.6. A zero-crossing is defined as a point where the bed profile crosses the line defining the mean bed level in a cartesian coordinate system that is tilted at the initial bed slope $S_{0}$. In figure 7.6 this line is coincident with the $x$-axis. In general, the mean bed level was obtained by fitting a polynomial to the raw bed-profile data. The zero-crossing distance is defined as the longitudinal distance between two successive zero-crossings. A bed-form length, $L$, is the sum of two successive zero-crossing distances. The positive and negative amplitudes, $\mathrm{a}^{+}$and $\mathrm{a}^{-}$, are defined as the maximum positive and negative displacements of the bed form from the mean level between two successive upward (or downward) zerocrossings. The height, $h$, of the bed-form is the sum of the magnitudes of a pair of adjacent positive and negative amplitudes.

From figures 7.3 through 7.5 the existence of two distinct portions of the bed profiles during an aggradation process is evident: an upstream reach over which sediment deposition takes place; and a downstream reach which remains practically unaffected by the process. Consequently, for the statistical analysis of bed-form characteristics only the upstream reach was considered. In order to investigate any spatial dependence of the bed-form parameters, the upstream reach for larger times ( $t \geqslant 54$ hours) was divided in two halves. 


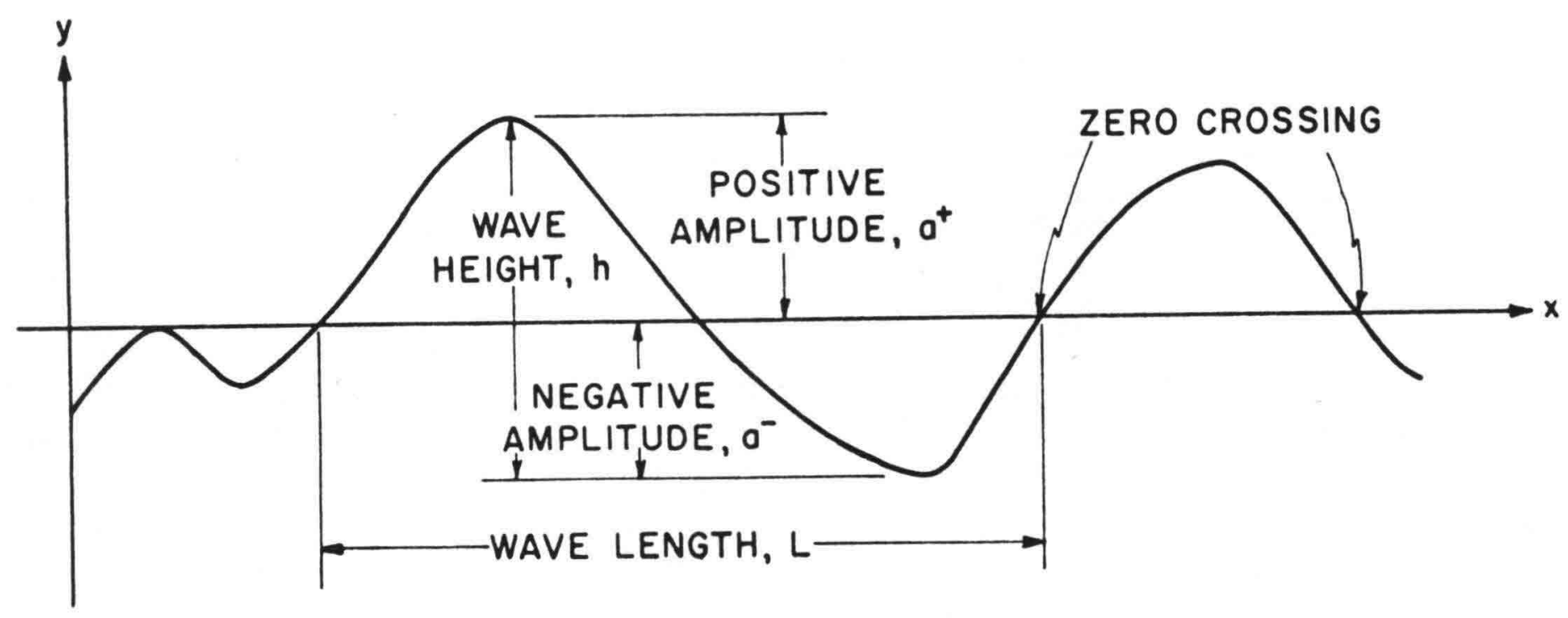

Figure 7.6 Definition Sketch of Bed-Profile for Zero-Crossing and Amplitude Analysis 
Mean values, unbiased standard deviations, and unbiased skewness coefficients were computed for $h, L$, and $a^{+}$, and $a^{-}$from each bed profile. For a set of $\mathrm{N}$ discrete values $\mathrm{z}_{1}, \mathrm{z}_{2}, \mathrm{z}_{3}, \ldots, \mathrm{z}_{n}$, in this case representing any of the above four bed-form characteristics, the mean, $\mu$, is computed by

$$
\mu=\frac{1}{N} \sum_{j=1}^{N} z_{j}
$$

the unbiased standard deviation, $\sigma$, by

$$
\sigma=\left[\frac{m}{N-1}\right]^{1 / 2}
$$

and the unbiased skewness coefficient, $\theta$, by

$$
\theta=\frac{N^{2}}{(N-1)(N-2)} \frac{m_{3}}{m_{2}{ }^{2 / 3}}
$$

where $m_{2}$ and $m_{3}$ are the second and third central moments defined respectively by

$$
m_{2}=\sum_{j=1}^{N}\left(z_{j}-\mu\right)^{2}
$$

and

$$
m_{3}=\sum_{j=1}^{N}\left(z_{j}-\mu\right)^{3}
$$

The results of the statistical analysis are listed in table 7.2. Percentage-distribution histograms for $h, L, a^{+}$and $a^{-}$, for the initial equilibrium bed profile and for the 72-hour bed profile are shown in figures 7.7 and 7.8. No attempt was made to fit them by the proba-bility-density function corresponding to probability laws. They are included to add visual reinforcement to the result summarized in table 7.2 .

The following trends can be seen from the results in table 7.2. The mean dune length $L$ and the dune flatness $L / h$ increase significantly during aggradation. The mean dune length shows increases up to $49 \%$ of the initial wave length. The mean dune height in its turn does not show any consistent and significant change during aggradation. The above mentioned trends are graphically illustrated by figures 7.9 through 7.11 . From the above it can be 
Table 7.2

Statistical Measures of Bed-Form Characteristics

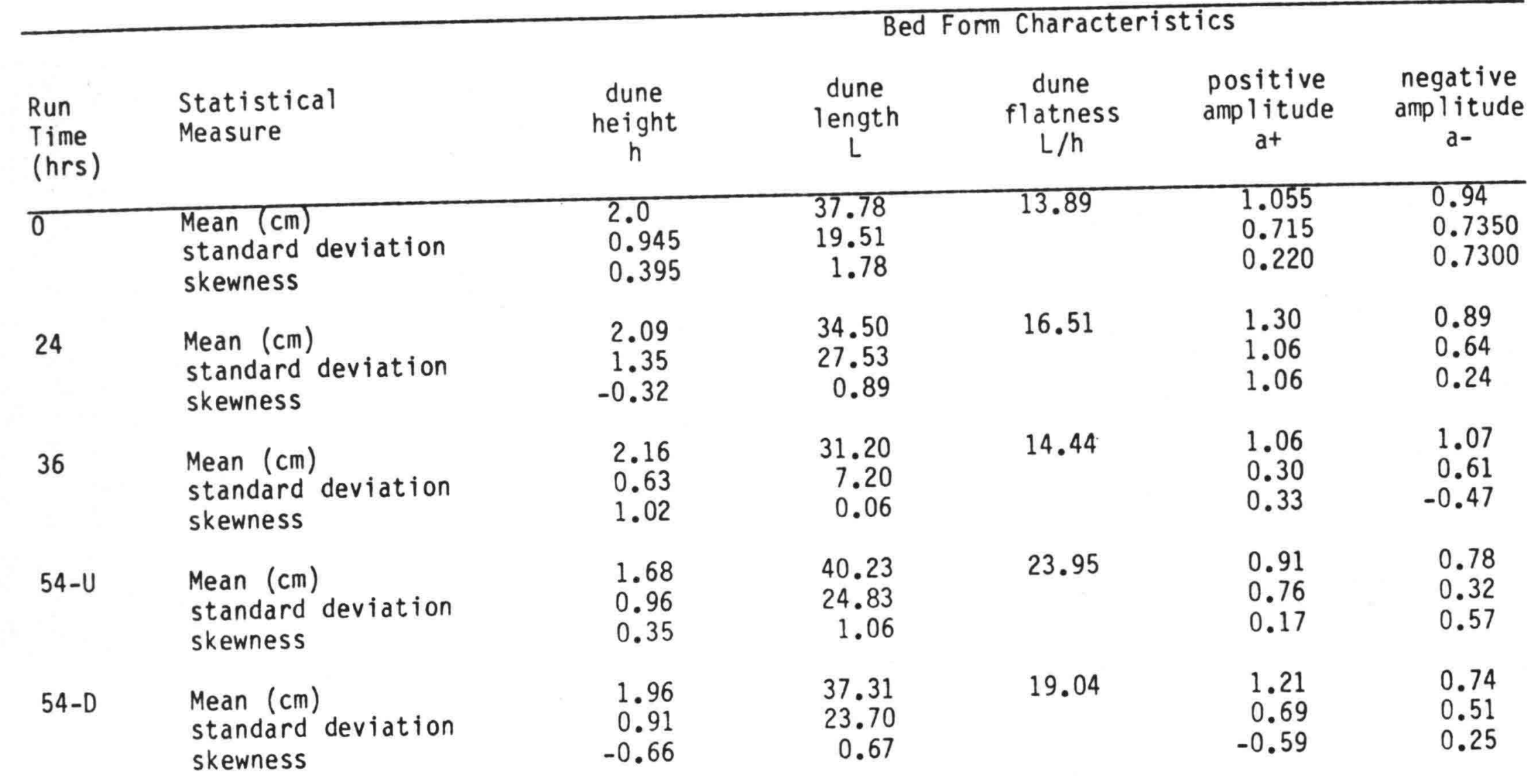


Table 7.2. Continued.

\begin{tabular}{|c|c|c|c|c|c|c|}
\hline \multirow[b]{2}{*}{$\begin{array}{l}\text { Run } \\
\text { Time } \\
\text { (hrs) }\end{array}$} & \multirow[b]{2}{*}{$\begin{array}{l}\text { Statistical } \\
\text { Measure }\end{array}$} & \multicolumn{5}{|c|}{ Bed Form Characteristics } \\
\hline & & $\begin{array}{l}\text { dune } \\
\text { height } \\
h\end{array}$ & $\begin{array}{l}\text { dune } \\
\text { length } \\
L\end{array}$ & $\begin{array}{c}\text { dune } \\
\text { flatness } \\
L / h\end{array}$ & $\begin{array}{c}\text { positive } \\
\text { amplitude } \\
a^{+}\end{array}$ & $\begin{array}{c}\text { negative } \\
\text { amplitude } \\
\text { a- }\end{array}$ \\
\hline $60-U$ & $\begin{array}{l}\text { Mean }(\mathrm{cm}) \\
\text { standard deviation } \\
\text { skewness }\end{array}$ & $\begin{array}{l}1.44 \\
0.75 \\
1.31\end{array}$ & $\begin{array}{r}33.07 \\
18.61 \\
1.95\end{array}$ & 22.97 & $\begin{array}{l}0.74 \\
0.58 \\
0.87\end{array}$ & $\begin{array}{l}0.79 \\
0.52 \\
0.41\end{array}$ \\
\hline $60-D$ & $\begin{array}{l}\text { Mean }(\mathrm{cm}) \\
\text { standard deviation } \\
\text { skewness }\end{array}$ & $\begin{array}{l}1.98 \\
0.83 \\
0.60\end{array}$ & $\begin{array}{r}40.89 \\
26.57 \\
1.06\end{array}$ & 20.65 & $\begin{array}{r}0.98 \\
0.43 \\
-0.84\end{array}$ & $\begin{array}{l}1.00 \\
0.65 \\
0.65\end{array}$ \\
\hline $66-U$ & $\begin{array}{l}\text { Mean ( } \mathrm{cm}) \\
\text { standard deviation } \\
\text { skewness }\end{array}$ & $\begin{array}{l}1.94 \\
i \\
0.41\end{array}$ & $\begin{array}{r}34.47 \\
16.77 \\
0.41\end{array}$ & 17.77 & $\begin{array}{l}1.12 \\
0.76 \\
0.04\end{array}$ & $\begin{array}{l}0.82 \\
0.59 \\
0.04\end{array}$ \\
\hline $66-D$ & $\begin{array}{l}\text { Mean }(\mathrm{cm}) \\
\text { standard deviation } \\
\text { skewness }\end{array}$ & $\begin{array}{l}2.470 \\
1.16 \\
1.09\end{array}$ & $\begin{array}{r}37.09 \\
26.27 \\
1.08\end{array}$ & 15.07 & $\begin{array}{l}1.35 \\
0.73 \\
0.88\end{array}$ & $\begin{array}{l}1.11 \\
0.64 \\
0.48\end{array}$ \\
\hline $72-U$ & $\begin{array}{l}\text { Mean ( } \mathrm{cm}) \\
\text { standard deviation } \\
\text { skewness }\end{array}$ & $\begin{array}{l}1.98 \\
1.02 \\
0.54\end{array}$ & $\begin{array}{r}41.44 \\
18.30 \\
0.10\end{array}$ & 20.92 & $\begin{array}{l}1.17 \\
0.79 \\
0.45\end{array}$ & $\begin{array}{l}0.81 \\
0.64 \\
0.74\end{array}$ \\
\hline $72-D$ & $\begin{array}{l}\text { Mean ( } \mathrm{cm}) \\
\text { standard deviation } \\
\text { skewness }\end{array}$ & $\begin{array}{l}1.71 \\
0.89 \\
0.79\end{array}$ & $\begin{array}{r}28.66 \\
13.45 \\
0.31\end{array}$ & 16.41 & $\begin{array}{l}0.82 \\
0.71 \\
1.34\end{array}$ & $\begin{array}{l}0.95 \\
0.55 \\
0.17\end{array}$ \\
\hline
\end{tabular}



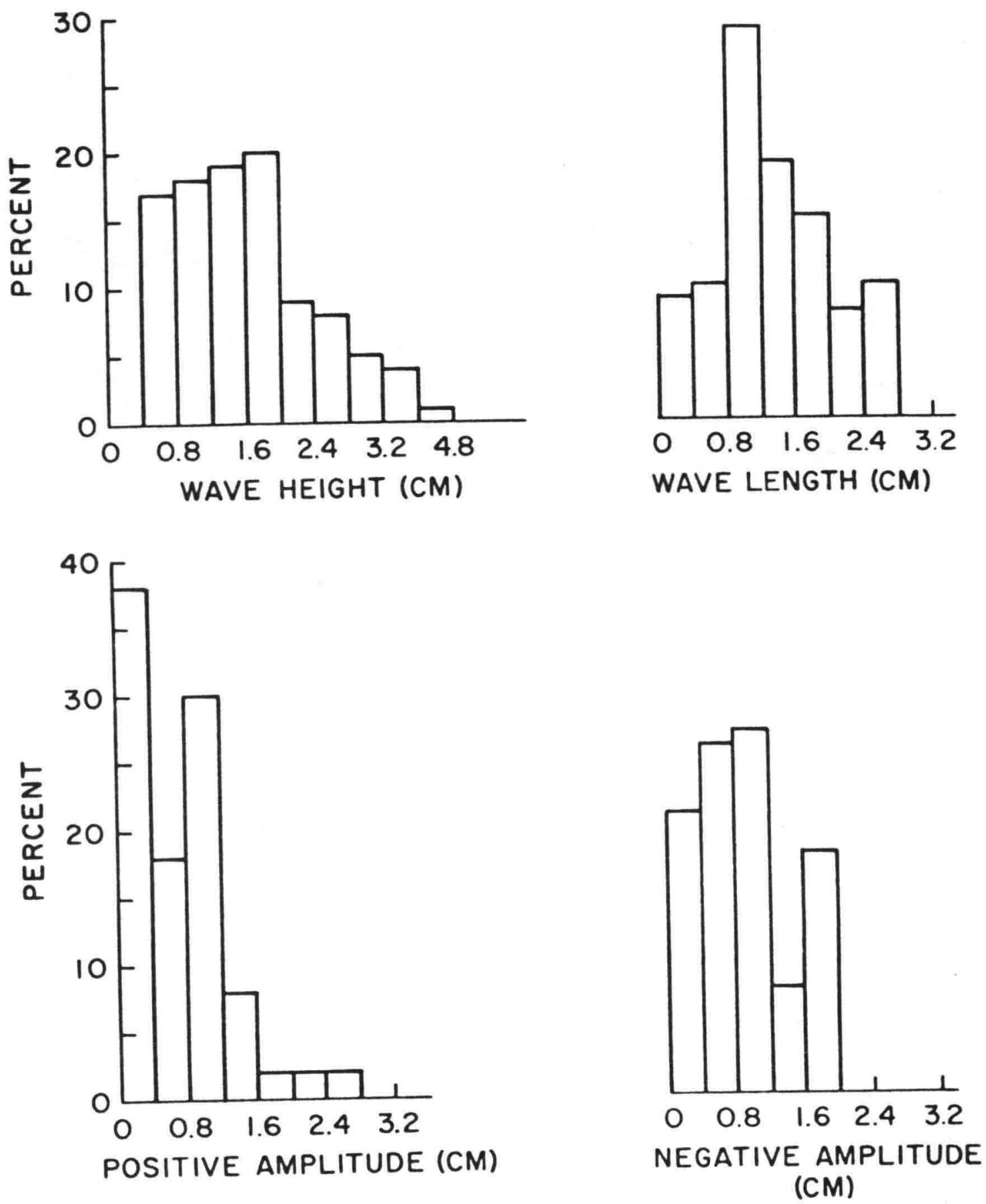

Figure 7.7 Percent Distribution Histograms for Bed-Form Characteristics ( $T=0$ Hours, Uniform Flow) 

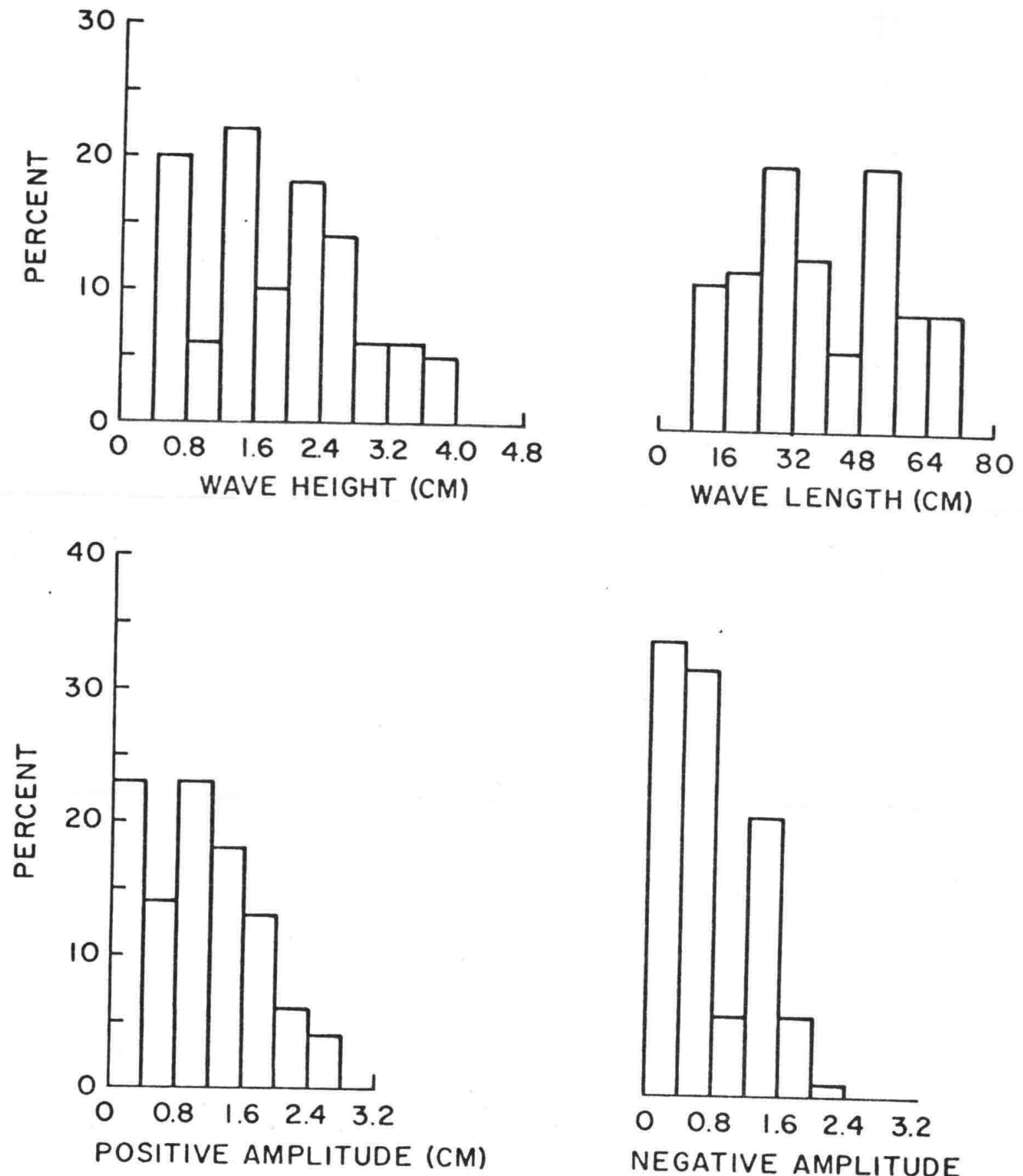

a. $T=72$ Hours, Upstream-Half

Figure 7.8 Percent Distribution Histograms for Bed-Form Characteristics 

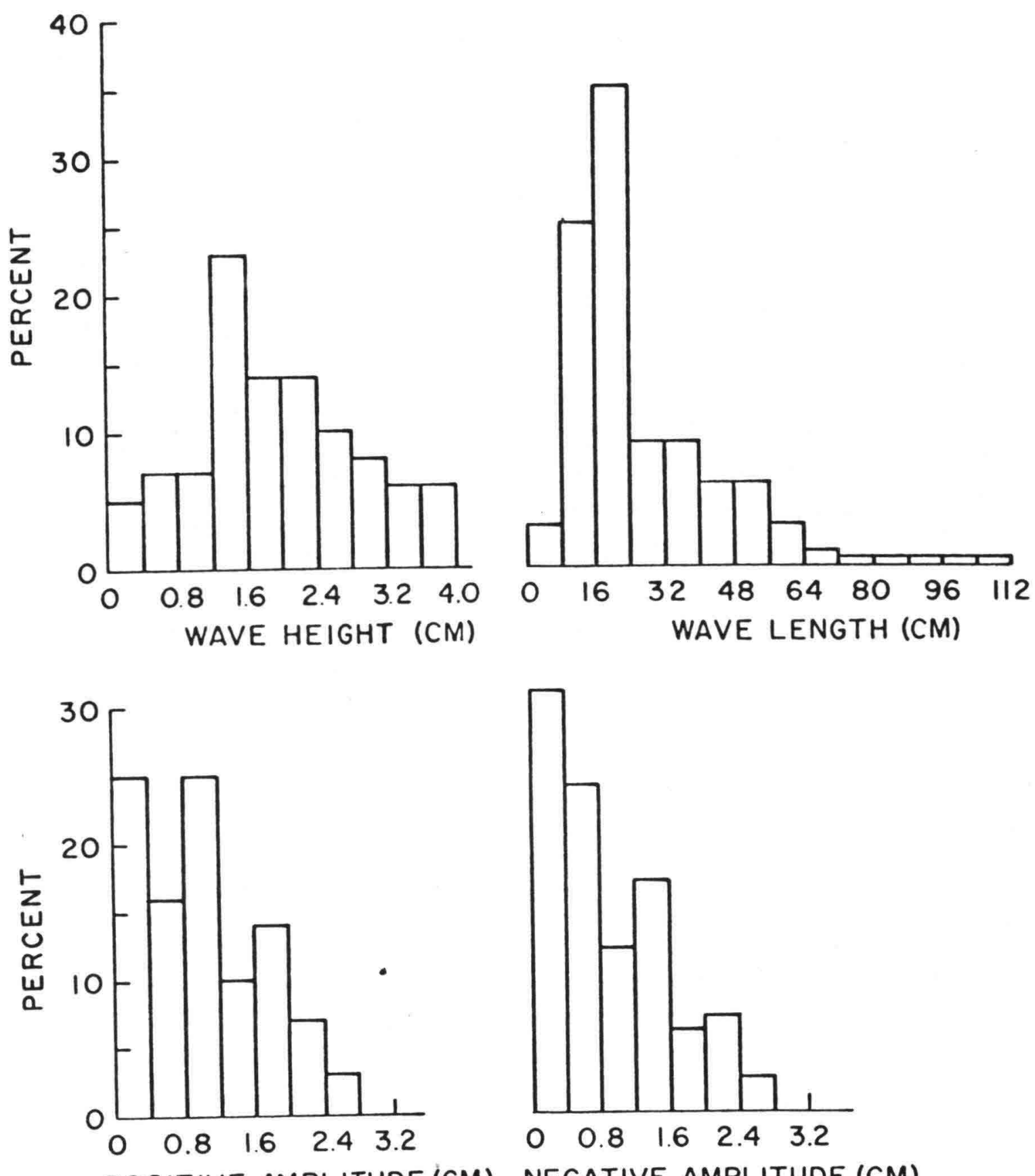

POSITIVE AMPLITUDE (CM) NEGATIVE AMPLITUDE (CM)

b. $T=72$ Hours, Downstream-Half

Figure 7.8 Continued 


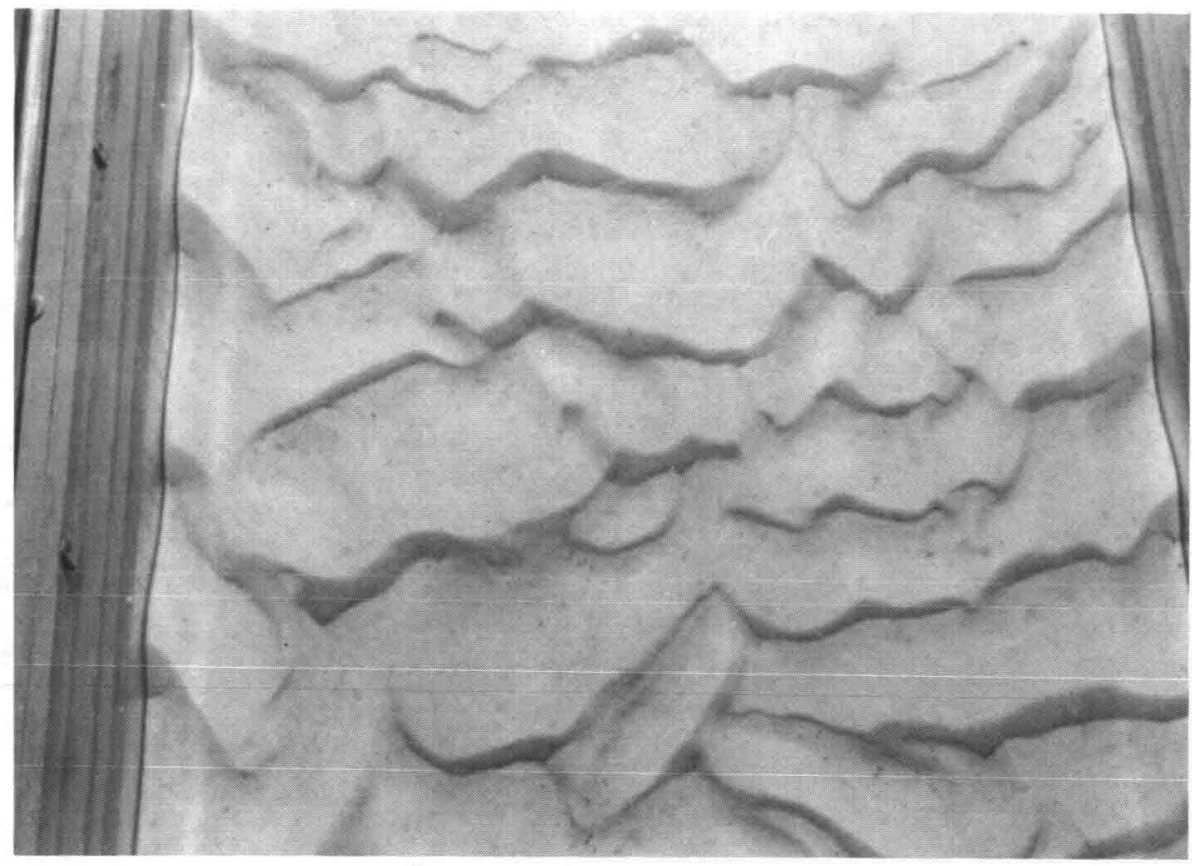

Figure 7.9 Initial Bed Configuration

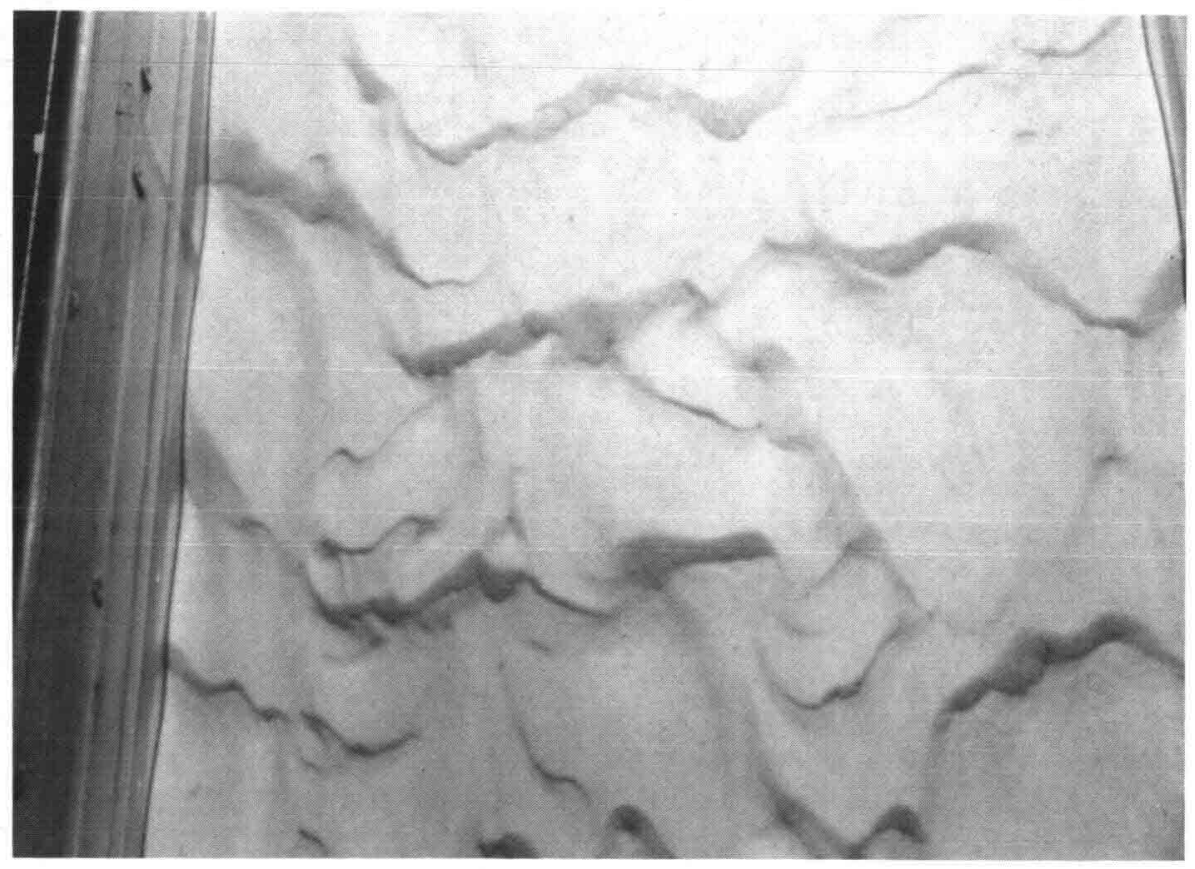

Figure 7.10 Bed Configuration During Aggradation 


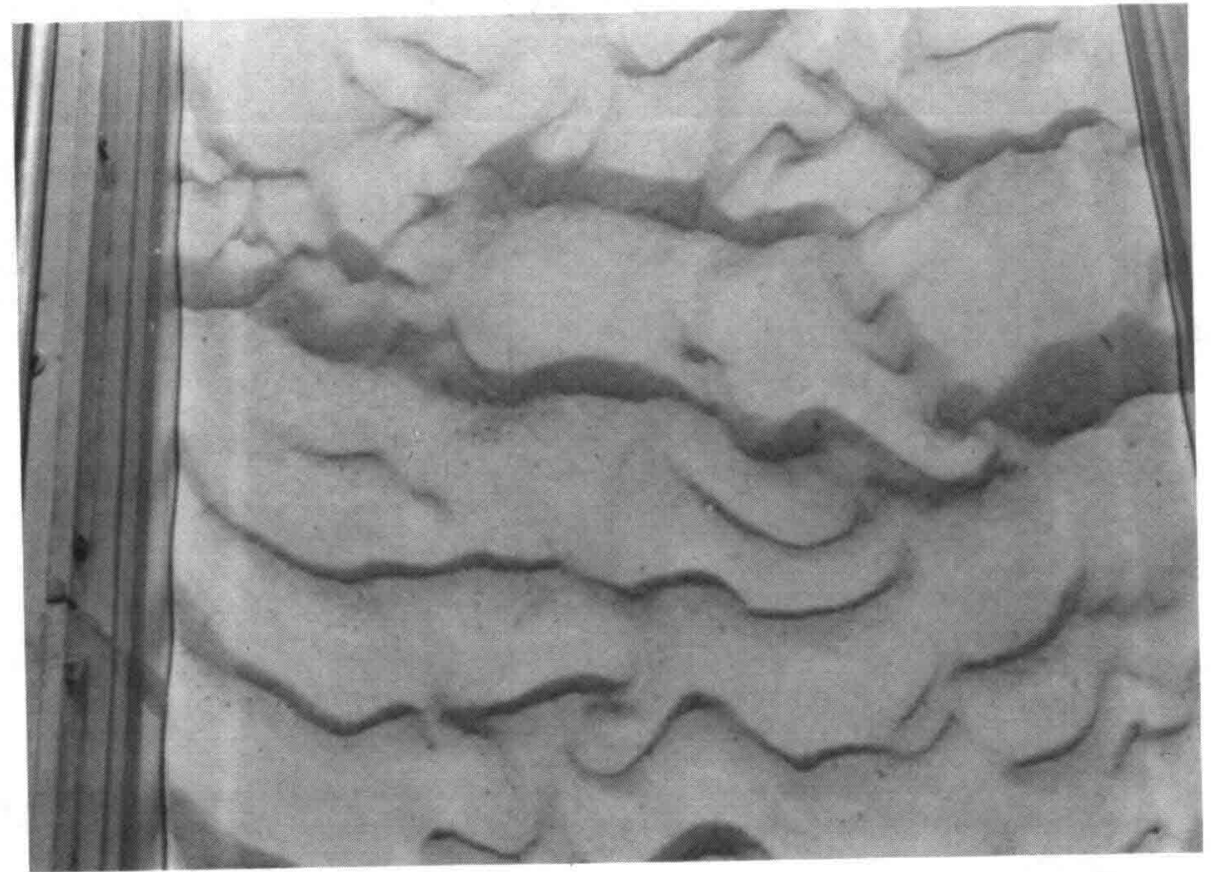

Figure 7.11 View of the Aggrading Front 
concluded that due to an increase in total sediment load which leads to an increase in flow velocity, bed and energy slope and a diminution in water depth, that the bed-form resistance diminishes.

Although the scope of the present study and the amount of data available do not allow quantitative conclusions to be drawn regarding the variation of the bed-form resistance, it seems useful to sketch a methodology which may be useful for future investigations. Following Einstein and Barbarossa (1952), the Darcy-Weisbach friction factor is separated in two parts

$$
f=f^{\prime}+f^{\prime \prime}
$$

where $f^{\prime}$ is due to the roughness of the sand grains, and $f^{\prime \prime}$ is due to the form drag associated with the large scale features of the bed forms. Values of the bed-form friction factor $f^{\prime \prime}$ may be determined by subtracting $f^{\prime}$ from $f$, where $f^{\prime}$ is evaluated by means of the Lovera and Kennedy (1969) flat-bed frictionfactor diagram or any other suitable method, and $f$ is the experimental friction factor. Next, the bed-form friction factor could be related to the dune geometry and flow characteristics. It seems noteworthy that Vanoni and Hwang (1967) developed a bed-form friction factor predictor applicable to uniform flows over ripple covered beds, which reads

$$
\frac{1}{\sqrt{f^{\pi}}}=3.3 \log \frac{L H}{h^{2}}-2.3
$$

It appears that equations of similar type, which account for the nonuniformity of the flow and bed patterns, can be developed in order to enable an accurate estimation of the friction factor in nonequilibrium processes.

Although the experimental data indicates a significant increase in dune length during aggradation, the effect of this change in dune length on the variation (diminution) of the bed-form resistance is not yet quantitatively known. Nevertheless, a rough preliminary estimate can be obtained on assuming that (7.7) is valid for nonequilibrium flows. From the available data is it seen that the dune flatness $L / h$ during the experiments increased up to about $50 \%$, while the dune height $h$ remained almost unaffected; as the local flow depth $H$ decreases along the aggradation reach, the modified relative roughness, $H L / h^{2}$, during aggradation will be larger than that in the uniform 
flow case $\left(H_{0} L_{0} / h_{0}{ }^{2}\right)$. The ratio of the modified relative roughness to that for the uniform flow for the experiments reported herein ranges between about 1 and 1.5. As the relationship between $f^{\prime \prime}$ and the modified relative roughness is of logarithmic type, the relative change in $f$ "during the experiments is likely to be smaller than $20 \%$. At this point it is convenient to recall that due to the diminution of the water depth, the grain roughness $f^{\prime}$ increases; hence, the relative variation in friction factor $f$ will be even smaller.

Karim (1981) proposed several sediment-discharge predictors which are applicable to dune covered alluvial channels under uniform flow conditions. Their main feature is the enormous amount of laboratory and field data used in the multiple regression analysis which led to their formulation, and the fact that they allow the establishment of a definite relationship between the sediment discharge and the friction parameters. The predictor considered in the present discussion is

$$
\frac{G}{\sqrt{g(s-1) d^{3}}}=10^{-6.54}\left(\frac{U}{\sqrt{g(s-1) d}}\right)^{2.62}\left(\frac{H}{d}\right)^{1.34}\left(S \times 10^{3}\right)^{1.38}
$$

which may be written

$$
f=C G^{0.72} / U^{3.92}
$$

where

and

$$
s=\gamma_{s} / \gamma
$$

$$
c=c(q, d, s, g)
$$

If one assumes that (7.9) is applicable to nonequilibrium flows, it is readily seen that depending on the relationship between the sediment discharge $G$ and the flow velocity $U$, the friction factor $f$ may behave differently with $G$. For instance, if as before it is assumed that $G=a U^{b}$, the friction factor $f$ for values of $b<5.45$, will decrease during an aggradation process and increase during a degradation one. On the contrary, the friction factor $f$ for values of the exponent $b>5.45$, will show an increase during aggradation and $a$ diminution during degradation. It is evident that the magnitude of the variation of the friction factor depends on the magnitude of the change in 
sediment load as well as on the value of the exponent b. In order to further assess the sensitivity of the friction factor to variations in sediment load during nonequilibrium processes and the validity of the assumptions customarily introduced in the derivation of mathematical models (e.g., constant friction factor), the following discussion appears to be relevant. In the experiment reported herein the relative overload $\Delta G_{0} / G_{0}$ equalled 2.4 and the maximum reduction of the friction factor was estimated in about $20 \%$. Furthermore, for the bed material and flow conditions of such experiment Sayre and Song (1979) empirically determined the following equation for the sediment transport rate

$$
G=1.26 \times 10^{-3}\left(U-U_{c}\right)^{4} \quad\left(m^{3} / \mathrm{s} \cdot \mathrm{m}\right)
$$

Soni et al (1977) performed several aggradation experiments in which the relative variation in sediment discharge $\Delta G_{0} / G_{0}$ ranged between 0.3 and 4 . They found that the friction factor diminished up to about $30 \%$. The equation that provided the best empirical fit to their sediment transport rate data, measured under uniform flow conditions, was

$$
G=1.45 \times 10^{-3} U^{5} \quad\left(\mathrm{~m}^{3} / \mathrm{s} . \mathrm{m}\right)
$$

On assuming that (7.9), (7.10) and (7.11) apply locally for nonequilibrium flows, it is readily found that the maximum diminution of the friction factor $f$ during aggradation, with respect to the value corresponding to the initial uniform flow, is $27 \%$ in the former case and $34 \%$ in the latter one. These values are in good agreement with the above mentioned values.

These analyses lead to the conclusion that the assumption of a constant friction factor for moderate changes in total sediment load is a reasonable first approximation. The usage of suitable sediment-transport-rate formulae valid for uniform flows in nonequilibrium processes may also be considered acceptable under such conditions. The previous conclusions are also supported by the good agreement between the nonlinear analytical solution, which contains both assumptions, and the available experimental data. However it should be pointed out that the models can be used in conjunction with any type of sediment and friction factor (constant or variable) equations; hence, as soon as improved knowledge and formulations regarding these two important 
aspects become available, they may easily be incorporated in the mathematical models and their solutions. 


\section{SUMMARY AND CONCLUSIONS}

\section{A. Summary}

Linear and nonlinear parabolic models for nonequilibrium processes in alluvial rivers, based on validated mathematical expressions of the constituent phenomena, were developed. Analytical solutions for the characteristic parameters of relevant aggradation and degradation processes in alluvial channels of semi-infinite and finite length subjected to both, timedependent and time-independent boundary conditions were obtained. The analytical solutions developed allow the use of almost any of the sediment transport rate and friction factor predictors available.

The validity and limitations of the linear and nonlinear parabolic models and their corresponding analytical solutions was assessed by means of comparison with flulme experimental data available. Ranges of application for both linear and nonlinear models were established. Due to its more rigorous formulation, the nonlinear parabolic model was found particularly useful and accurate for a wide range of practical applications. The good prediction capabilities of the nonlinear model can be improved through the use of available laboratory and/or field data which will enable the easy and effective calibration of the model. Easy to follow application, calibration, and extrapolation procedures were suggested.

Experiments regarding the time evolution of the bed-forms during an aggradation process due to a sudden increase in total sediment load were performed. Analysis of the experimental data led to a better understanding of the phenomena involved to the explanation of the experimental findings of the present and similar investigations, and to the justification of some of the main assumptions introduced in the development of mathematical models.

B. Conclusions and Recommendations

The principal conclusions derived from the present theoretical and experimental investigation may be summarized as follows: 
1. Nonlinear and linear parabolic models based on the fundamental hydrodynamic equations for two-phase flows constitute a rather simple and powerful tool for solving a variety of morphological processes in alluvial rivers of relevance to hydraulic engineers and geologists.

2. The parabolic models allow the use of almost any of the current sediment-transport-rate and friction-factor predictors.

3. Aggradation and degradation processes due to sediment load augmentation and sediment discharge curtailment, respectively, are similar to each other and their characteristic parameters are governed by the same equations.

4. The analytical solutions for the characteristic parameters of aggradation and degradation processes due to variations in sediment discharge in alluvial channels of finite length for small times is identical to that for a semi-infinite channel.

5. The analytical solution provided by the classical linear parabolic model (i.e., Z-model) and those afforded by the alternative linear model (i.e., G-model) are identical if and only if the initial river bed is plane. Otherwise, they are different due to the different assumptions introduced in the development of each model.

6. The deviation of the experimental data from the analytical results provided by the linear parabolic models is mainly due to the two simplifications introduced in the models. That is, the flow is considered quasi-steady and quasi-uniform. The experimental values agree with the analytical results for moderate values of the relative sediment overloading (i.e., $2<G_{0} / G_{0}<6$ ). The linear parabolic model should not be used for predicting the characteristic parameters of degradation processes due to curtailment of the sediment discharge.

7. Certain degradation processes due to base level lowering can also be studied by means of the linear parabolic model. However, the range of application of the model has not been investigated as yet.

8. The nonlinear parabolic model introduced herein is an accurate and flexible tool for predicting one-dimensional nonequilibrium processes in alluvial channels due to a sudden change in sediment transport rate at the upstream end of the channel. It is applicable to both 
degradation and aggradation processes in which the relative variation in sediment discharge, $G_{0} / G_{0}$, ranges between -1 and 1 .

9. The agreement between the nonlinear analytical solution and the available experimental data is good and encouraging.

10. Laboratory and/or field data may be readily used in order to enhance the prediction capabilities of the nonlinear model by means of a simple calibration procedure.

11. Extrapolation of the analytical results for large values of the relative overloading (i.e., $G_{0} / G_{0}>1$ ) has been found possible and accurate. However, more exhaustive research is needed on this regard before a final conclusion can be made.

12. The mean dune length increases significantly during aggradation, while the mean dune height remains almost unaffected. Therefore, the part of the resistance to flow associated to bed-form diminishes. However, the sand grain roughness increases and tends to compensate the diminution of the bed form resistance.

13. Suitable formulae for sediment transport rate and friction factor obtained for uniform flow may be considered a good first approximation for nonequilibrium flows where the variation in sediment discharge is moderate.

On the basis of the knowledge and experience gained in the present study, the following recommendations are set forth for future research:

1. It appears useful to perform a set of experiments concerning degradation processes due to diminution of the sediment discharge, which will serve to test in a more appropriate manner the accuracy of the nonlinear parabolic model for this important type of process.

2. An extensive and systematic study of the friction-factor evolution during nonequilibrium flows may be worthwhile and useful in order to improve the physical understanding and the mathematical formulation of this important aspect of the subject. The methodology suggested in Chapter VII may be helpful to this particular purpose.

3. The usefulness of the sediment transport and friction factor predictors developed at the IIHR, or similar ones, for nonequilibrium flows should be assessed in a quantitative fashion. 
4. The possibility of introducing the phenomenon of bed-armoring into the mathematical formulation of the model deserves particular attention, because, it would notably increase its capabilities.

5. The extension of the nonlinear analytical solution to cases in which the variation in sediment load is time dependent seems to be interesting from the theoretical and practical viewpoints. Experiments concerning this type of nonequilibrium processes will be useful to test the accuracy and determine the range of application of the linear solution reported in this study as well as those pertaining to any propsective nonlinear solution.

6. Stochastic modelling of the bed-profiles may be a useful and original contribution towards the better understanding of the evolution of the bed profiles and bed-forms under nonequilibrium flow conditions. 
REFERENCES

Adachi, S., Nakato, T., 1969, "Changes of Top-Set Bed in a Silted Reservoir", 13 th Congress, IAHR, Vol. 5-1, pp. 269-272.

Adams, C., 1944, "Mine Waste as a Source of Galena River Bed Sediment", Journal of Geology, Vol. 52, pp. 275-282.

Aksoy, S., 1970, "River-Bed Degradation of Downstream Large Dams", Transactions of the 9th Congress on Large Dams, paper Q. 38-R. 43, p. 835.

Aksoy, S., 1971, "River-Bed Degradation Downstream of Dams", 14th Congress, IAHR, Vol. 3, pp. 275-282.

Alam, A.M.Z., Kennedy, J.F., "Friction Factors for Flow in Sand Bed Channels", Journal of the Hydraulics Division, ASCE, Vol. 95, No. HY6, pp. 1973-1992.

Al Khafif, S.M., 1965, "A Study of Open Channel Degradation and Corresponding Bed Roughness, Doctor of Engineering Dissertation, University of California, Davis, California.

Ames, W.F., 1965, "Nonlinear Partial Differential Equations in Engineering", Academic Press, Vol. 18.

Ariathurai, C.R., 1974, "A Finite Element Model for Sediment Transport in Estuaries", Ph.D. Dissertation, University of California, Davis, California.

Ashida, K., Michiue, M., 1971, "An Investigation of River Bed Degradation Downstream of a Dam", 14th Congress, IAHR, Vol. 3, pp. 247-255.

Ashida, K., Tanaka, Y., 1967, "A Statistical Study of Sand Waves", 12th Congress, IAHR, Vol. 2, pp. 103-110.

Begin, Z.B., Meyer, D.F., Schumm, S.A., 1980, "Knickpoint Migration Due to Baselevel Lowering", Journal of the Waterway, Port, Coastal and Ocean Division, ASCE, Vol. 106, No. WW3, pp. 369-388.

Begin, Z.B., Meyer, D.F., Schumm, S.A., 1981, "Development of Longitudinal Profiles of Alluvial Channels in Response to Base-Level Lowering", Earth Surface Processes and Landforms, Vol. 6, pp. 49-68.

Bhamidipathy, S., Shen, H.W., 1971, "Laboratory Study of Degradation and Aggradation", Journal of the Waterways, Harbors and Coastal Engineering Division, ASCE, Vol. 97, No. WW4, pp. 615-630.

Blaisdell, F.W., 1977, Discussion of "Stability of Channel Beds by Armoring", by Little, W.C., Mayer, P.G., Journal of the Hydraulics Division, ASCE, Vol. 103, No. HY10, pp. 1253-1254.

Bouvard, M., Chollet, J.P., Cunge, J.A., 1977, "Progres Recents et Difficultes de Simulation Mathematiques des Rivieres Alluvionnaires", 17th Congress, IAHR, Vol. 1, pp. 165-172. 
Brown, G.0., Li, R.M., 1979, "Known Discharge Sediment Routing", Water Resources Publications, Fort Collins, Colorado.

Brownlie, W.R., 1981, "Unsteady Sediment Transport Modeling", Proceedings of the Water Forum '81, ASCE, Vol. II, pp. 1193-1200.

Brush, L.M., Wolman, M.G., 1960, "Knickpoint Behavior in Noncohesive Material: A Laboratory Study", Bulletin of the Geological Society of America, Vol. 71, pp. 59-74.

Budiansky, B., Roth, R.S., 1962, "Axisymmetric Dynamic Buckling of Clamped Shallow Spherical Shells", National Aeronautics Space Administration Report No. NASA-TN-D-1510, p. 597.

Carslaw, H.S., Jaeger, J.C., 1978, "Conduction of Heat in Solids", Oxford University Press.

Chambre, P.L., 1959, "Nonlinear Heat Problem", Journal of Applied Physics, Vol. 30, No. 11, p. 1683-1688.

Chang, F.F.M., 1969, "Computer Simulation of Riverbed Aggradation and Degradation by the Method of Characteristics", 13th Congress, IAHR, Vol. 1, pp. 337-344.

Chang, F.F.M., Richards, D.L., 1971, "Deposition of Sediment in Transient Flow", Journal of the Hydraulics Division, ASCE, Vol. 97, No. HY6, pp. 837849.

Chang, H.H., 1982, "Mathematical Model for Erodible Channels", Journal of the Hydraulics Division, ASCE, Vol. 108, No. HY5, pp. 678-689.

Chang, H.H., Hill, J.C., 1977, "Minimum Stream Power for Rivers and Deltas", Journal of the Hydraulics Division, ASCE, Vol. 103, No. HY12, pp. 1375-1389.

Chen, Y.H., Holly, F.M., Mahmood, K., Simons, D.B., 1975, "Transport of Material by Unsteady Flow", In: "Unsteady Flow in Open Channels", Water Resources Publications, Fort Collins, Colorado, Vol. 1, pp. 313-365.

Colby, B.R., Hembree, C.H., 1955, "Computation of Total Sediment Discharge, Niobrara River near Cody, Nebraska", U.S. Geological Survey Water-Supply Paper 1357.

Collatz, L., 1960, "The Numerical Treatment of Differential Equations", Springer, Berlin.

Crandal1, S.H., 1958, "Engineering Analysis", McGraw-Hi1l, New York.

Culling, W.E.H., 1960, "Analytical Theory of Erosion", Journal of Geology, No. 3, pp. 336-344.

Cunge, J.A., Perdreau, N., 1973, "Mobile Bed Fluvial Mathematical Models", La Houille Blanche, No. 7, pp. 561-580. 
Cunge, J.A., Simons, D.B., 1975, "Mathematical Model of Unsteady Flow in Movable Bed Rivers with Alluvial Channel Resistance", 16th Congress, IAHR, Vol. 2, pp. 48-56.

Davis, W.M., 1909, "Geographical Essays", Dover Publications.

De Vries, M., 1959, "Transients in Bed Load Transport (basic considerations)", Report R3, Waterloopkunding Laboratorium, Delft.

De Vries, M., 1965, "Considerations About Non-Steady Bed-Load Transport in Open Channels", 11th Congress, IAHR, Vol. 3, Paper No. 3.8.

De Vries, Mo, 1969, "Solving River Problems by Hydraulic and Mathematical Models", Delft Hydraulic Laboratory, Publication 76-II.

De Vries, M., 1971, "Aspecten van Zantransport in Open Waterlopen", Delft University of Technology, Department of Civil Engineering.

De Vries, M., 1973, "River-Bed Variations-Aggradation and Degradation", Delft Hydraulics Laboratory, Publication No. 107.

Einstein, H.A., 1950, "The Bed-Load Function for Sediment Transportation in Open Channel Flows", Technical Bulletin No. 1026, Soil Conservation Service, U.S. Department of Agriculture, Washington.

Einstein, H.A., Barbarossa, N., 1952, "River Channel Roughness", Transactions, ASCE, Vol. 117, pp. 1121-1146.

Engelund, F., Hansen, E., 1967, "A Monograph on Sediment Transport in Alluvial Streams", Teknisk Forlag, Copenhagen.

Ferguson, H. $B_{0}, 1939$, "Construction of Mississippi Cut-0ffs", Civil Engineer, Vol. 8, p. 725-729, 826-829.

Frederiksen, E., 1957, Inginieur Archiv, Vol. 25, No. 100.

Frisi, P., 1762, "Treatise on Rivers and Torrents with Methods of Regulating their Courses and Channels", London.

Galerkin, B.G., 1915, "Vestn. Inzhenerov i Tekhnikov", p. 879.

Garde, R.J., Hasan, S.M., 1967, "An Experimental Investigation of Degradation in Alluvial Channels", 12th Congress, IAHR, Vol. 3, pp. 38-45.

Garde, R.J., Ranga Raju, K.G., 1966, "Resistance Relationships for Alluvial Channel Flow", Journal of the Hydraulics Division, ASCE, Vol. 92, No. HY4, pp.
$77-100$.

Garde, R.J., Ranga Raju, K.G., 1977, "Mechanics of Sediment Transportation and Alluvial Stream Problems", John Wiley \& Sons, Inc.

Garde, R.J., Ranga Raju, K.G., Mehta, P.J., 1981, "Bed Level Variation in Aggrading Alluvial Streams", 19th Congress, IAHR, Vol. 3, Paper No. 4, pp. 247-253. 
Gessler, J., 1965, "The Beginning of Bed-Load Movement of Mixtures Investigated as Natural Armoring in Channels, Report No. 69, Laboratory of Hydraulic Research and Soil Mechanics, Swiss Federal Institute of Technology, Zurich.

Gessler, J., 1970, "Self-Stabilization Tendencies of Alluvial Channels", Journal of the Waterways and Harbors Division, ASCE, Vol. 96, No. WW2, pp.

Gessler, J., 1971, "Aggradation and Degradation", In: "River Mechanics", edited and published by Shen, H.W., Vol. 1, Chapter 8, pp. 1-24.

Gessler, J., 1971, "Beginning and Ceasing of Sediment Motion", In: "River Mechanics", edited and published by Shen, H.W., Vol. 1, Chapter 7, pp. 1-22.

Gilbert, G.K., 1917, "Hydraulic-Mining in the Sierra Nevada", U.S. Geological Survey, Professional Paper No. 105.

Goodman, T.R., 1955, Journal of Heat Transfer, Vol. 83, p. 83.

Goodman, T.R., 1964, "Advances in Heat Transfer", Vol. 1, Academic Press.

Graf, W.H., 1971, "Hydraulics of Sediment Transport", McGraw-Hill Book Company.

Happ, S.C., 1944, "Sedimentation in South Carolina Piedmont Valleys", American Journal of Science, Vol. 243, pp. 53-68.

Happ, S.C., 1948, Discussion of "Causes and Effects of Channel and Floodway Aggradation", by Jones, V.C., Proceedings of the Federal Inter-Agency Sedimentation Conference, pp. 180-184.

Harrison, A.S., 1950, "Report on Special Investigations of Bed Sediment Segregation in a Degrading Bed", Report Series No. 33, University of California, Institute of Engineering Research, Issue No. 1, Berkeley, California.

Hathaway, G.A., 1948, "Observations on Channel Changes, Degradation and Scour below Dams", 2nd Congress, IAHR, pp. 297-307.

Henriques, A.G., 1977, "Mathematical Modelling of Unsteady Flow in Alluvial Channels", 17th Congress, IAHR, Vol. 1, pp. 145-150.

Holland, W.N., Pickup, G., 1976, "Flume Study of Knickpoint Development in Stratified Sediments", Bulletin of the Geological Society of America, Vol. 87, pp. 76-82.

Hwang, J.C., 1975, "Degradation of Sand-Bed Channel", 16th Congress, IAHR, Vol. 2, pp. 181-188.

Ilo, G.C., Narasimhan, S., 1976, "Mathematical Modelling of River-Bed Degradation: Solution by Implicit Numerical Methods", Central Water and Power Research Station, Poona, Diamond Jubilee Symposium, Vol. paper B10, pp. 1-14. 
Ismail, H.M., Wahby, H., 1964, "Experimental Study of Mechanics of River Degradation", The Bulletin of the Faculty of Engineering, Cairo University, pp. 73-89.

Jain, M.K., 1962, Applied Science Research, A11, 177.

Jain, S.C., 1981, "River Bed Aggradation Due to Overloading", Journal of the Hydraulics Division, ASCE, Vol. 107, No. HYl, pp. 120-124.

Jaramillo, W.F., Paez, G., Velez, V., 1979, "Estudio en Modelo Hydraulico del Vertedero de Excesos de la Presa Amaluza Proyecto Paute, Informe Tecnico No. 1-010, Escuela Politecnica Nacional, Quito-Ecuador.

Joglekar, D.V., Wadekar, G.T., 1951, "The Effects of Weirs and Dams on the Regime of Rivers", 4th Congress, IAHR, pp. 349-363.

Jones, V.H., 1948, "Causes and Effects of Channel and Floodway Aggradation", Proceedings of the Federal Inter-Agency Sedimentation Conference, pp. 168-178.

Karim, Md. F., 1981, "Computer-Based Predictors for Sediment Discharge and Friction Factor of Alluvial Streams", Ph.D. dissertation, The University of Iowa, Iowa City, Iowa.

Kennedy, J.F., Jain, S.C., 1980, "Characteristic Times and Rates of Nonequilibrium River Processes", Unpublished Paper.

Komura, S., 1971, "Prediction of River-Bed Degradation Below Dams", 14th Congress, IAHR, Vol. 3, pp. 257-264.

Komura, S., Simons, D.B., 1967, "River-Bed Degradation Below Dams", Journal of the Hydraulics Division, ASCE, Vol. 87, No. HY2, pp. 1-14.

Krumbine, W.D., 1932, "A History of the Principles and Methods of Mechanical Analysis", Journal of Sedimentary Petrology, Vol. 2, p. 90.

Kuiper, E., 1965, "Water Resources Development", Butterworth, Inc.

Landahl, H.D., 1953, Bulletin of Mathematical Biophysics, No. 15, 49.

Lane, E.W., 1934, "Retrogression of Levels in River-Beds Below Dams", Engineering News Records, Vol. 112, p. 836.

Lane, E.W., 1947, "Sediment Engineering as a Quantitative Science", Proceedings of the Federal Inter-Agency Sedimentation Conference, p. 68.

Lane, E.W., 1955, "The Importance of Fluvial Morphology in Hydraulic Engineering", Journal of the Hydraulics Division, ASCE, Vol. 81, Paper 795, pp. 1-17.

Lane, E.W., Carlson, E.J., 1953, "Some Factors Affecting the Stability of Canals Constructed in Coarse Granular Material", 5th Congress, IAHR, pp. 3787. 
Little, W.C., Mayer, P.G., 1970, "Stability of Channel Beds by Armoring", Journal of the Hydraulics Division, ASCE, Vol. 102, No. HY11, pp. 1647-1661.

Livesey, R.H., 1963, "Channel Armoring Below Fort Randall Dam", Federal InterAgency Sedimentation Conference, pp. 461-470.

Lovera, F., Kennedy, J.F., 1969, "Friction Factors for Flat-Bed Flows Sand Channels", Journal of the Hydraulics Division, ASCE, Vol. 56, No. 1, pp. 4547.

Mackin, J.H., 1948, "Concept of the Graded River", Bulletin of the Geological Society of America, Vol. 59, pp. 463-512.

Mahmood, K., 1975, "Mathematical Modeling of Morphological Transients in SandBed Canals", 16th Congress, IAHR, Vol. 2, pp. 57-64.

Mahmood, K., Ponce, V.M., 1976, "Mathematical Modeling of Sedimentation Transients in Sand-Bed Channels", Report CER75-76-KM-VMP28, Engineering Research Center, Colorado State University, Fort Collins, Colorado.

Malhotra, S.L., 1951, "Effects of Barrages and Weirs on the Regime of Rivers", 4 th Congress, IAHR, pp. 335-347.

Matthes, G.H., 1941, "Basic Aspects of Stream-Meanders", Transactions of the American Geophysical Union, Part III, p. 632.

McHenry, R.J., Ritchie, J.C., Verdon, J., 1976, "Sedimentation Rates in the Upper Mississippi River", Rivers '76 Proceedings, 3rd Annual Symposium, Waterways, Harbors and Coastal Engineering Division, ASCE, pp. 1339-1349.

Mehta, P.J., Garde, R.J., Ranga Raju, K.G., 1982, "Transient Bed Profiles in Aggrading Streams", Unpublished Paper.

Meyer-Peter, E., Muller, R., 1948, "Formulas for Bed-Load Transport", 3rd Congress, IAHR, pp. 39-64.

Miloradov, M., Muskatirovic, D., 1971, "Calculation of River Bed Deformation in Unsteady Flow", 14th Congress, IAHR, Vol. 3, pp. 175-185.

Miloradov, M., Radojkovic, M., 1975, "Flood Routing in Natural Streams with Non-Steady Morphological Characteristics", 16th Congress, IAHR, Vol. 2, pp. 330-337.

Mushtari, Kh.M., Galimov, K.Z., 1957, "Nonlinear Theory of Thin Elastic Shells", U.S. Department of Commerce, Washington, D.C.

Nakato, T., Vadnal, J.L., 1981, "Field Study and Test of Several OneDimensional Sediment-Transport Computer Models for Pool 20, Mississippi River", IIHR Report No. 237, The University of Iowa, Iowa City, Iowa.

Newton, C.T., 1951, "An Experimental Investigation of Bed Degradation in an Open Channel", Transactions of Boston Society of Civil Engineers, pp. 28-60. 
Parker, G., Andres, D., 1976, "Detrimental Effects of River Channelization", Rivers ' 76 Proceedings, 3rd Annual Symposium, Waterways, Harbors and Coastal Engineering Division, ASCE, pp. 1248-1266.

Ponce, V.M., Lopez Garcia, J., Simons, D.B., 1977, "Modeling Alluvial Channels Bed Transients", Journal of the Hydraulics Division, ASCE, Vol. 105, No. HY3,

Pick, L.A., 1951, "Sedimentation Problems in the Missouri River Basin," Vol. 14, pp. 47-68.

Pickup, G., 1975, "Downstream Variations in Morphology, Flow Conditions and Sediment Transport in an Eroding Channel", Z. Geomorph. N.F., Vol. 19, No. 4,
pp. 443-459. Polhausen, K., 1921, "Zur Naherungsweisen Integration der Differentialgleichung der Laminaren Grenzschicht", Zeitschr. f. Angew. Math.
u. Mech., Vol. 1, pp. 262-268. Puls, W., Sundermann, J., Vollmers, H., 1977, "A Numerical Approach to Solid Matter Transport Computation", 17th Congress, IAHR, Vol. 1, pp. 129-135.

Rathbun, R.E., Guy, H.P., 1967, "Effect of Non Equilibrium Flow Conditions on Sediment Transport and Bed Roughness in a Laboratory Alluvial Channel", 12th
Congress, IAHR, Vol. 1, pp. 187-193.

Raudkivi, A.J., 1967, "Analyses of Resistance in Fluvial Channels", Journal of the Hydraulics Division, ASCE, Vol. 93, No. HY5, pp. 73-84.

Rouse, H., Ince, S., 1980, "History of Hydraulics", Iowa Institute of Rzhanitzin, N.A., Rabkova, E.K., Artemiev, P.A., 1971, "Deformation of Alluvial Channel Downstream from Large Hydro-Projects", 14th Congress, IAHR,
Vol. 3, pp. 265-274.

Salisbury, E.F., 1937, "Influence of the Diversion on the Mississippi and Atchafalaya Rivers", Transactions ASCE, Vol. 102, pp. 75-122.

Sato, S., Kikkawa, H., Ashida, K., 1958, "Research on the Bed Load Transportation", Journal of Research, Public Research Institute, No. 98, pp.
1-71.

Sayre, W.W., Kennedy, J.F., 1978, "Degradation and Aggradation of the Missouri River", Iowa Institute of Hydraulic Research, Report No. 215, The University
of Iowa, Iowa City, Iowa.

Sayre, W.W., Song, G. B., 1979, "Effects of Ice Covers on Alluvial Channel Flow and Sediment Transport Process", Iowa Institute of Hydraulic Research, Report
No. 218, The University of Iowa, Iowa City, Iowa.

Schetz, J.A., 1963, "Approximate Solution of Boundary Layer Problems with Mass Transfer", Department of Aerospace Engineering, Report No. 65-2, University of 
Schlichting, H., "Boundary Layer Theory", 7th edition, McGraw-Hill Book Company, New York.

Schmit, L.A., 1956, "WADC Technical Report", 56-287 (ad97326), Massachusetts Institute of Technology.

Shen, H.W., 1962, "Development of Bed Roughness", Journal of the Hydraulics Division, ASCE, Vol. 88, No. HY3, pp. 45-58.

Shen, H.W., Suryanarayana, B., 1969, "Variation of Roughness During Degradation", 13th Congress, IAHR, Vol. 5-1, pp. 277-280.

Shulits, S., 1934, "Experience with Bed Degradation Below Dams on European Rivers", Engineering News Records, Vol. 112, p. 836.

Shu-Tien, 1937, "China's River Problems", Commercial Press Co.

Simons, D.B., Li, R.M., Fullerton, W.T., 1980, "Multiple Watershed Model for Water and Sediment Routing from Mined Areas", Simons and Li and Associates, Inc.

Sonderegger, A.L., 1935, "Modifying the Physiographic Balance by Conservation Measures', Transactions ASCE, Vol. 100, pp. 248-346.

Soni, J.P., 1981, "Laboratory Study of Aggradation in Alluvial Channels", Journal of Hydrology, Vol. 49, pp. 87-106.

Soni, J.P., 1981a, "Unsteady Sediment Transport Law and Prediction of the Aggradation Parameters", Water Resources Research, Vol. 17, No. 1, pp. 33-40.

Soni, J.P., Garde, R.J., Ranga Raju, K.G., 1977, "Nonuniform Flow in Aggrading Channels", Journal of the Waterway, Port, Coastal and Ocean Engineering, ASCE, Vol. 103, No. WW3, pp. 321-333.

Soni, J.P., Garde, R.J., Ranga Raju, K.G., 1980, "Aggradation in Streams Due to Overloading", Journal of the Hydraulics Division, ASCE, Vol. 106, No. HYl, pp. 117-132.

Stanley, J.W., 1947, "Effect of Dams on Channel Regimen", Proceedings of the Federal Inter-Agency Sedimentation Conference, pp. 163-167.

Stanley, J.W., 1951, "Retrogression on Lower Colorado River after 1935", Transactions ASCE, Vol. 116, pp. 943-957.

Stantchev, S., Kaltchev, L., Petrova, R., 1975, "On Determination of River Bed Deformation Resulting from Barring the River", 16th Congress, IAHR, Vol. 2, pp. 113-124.

Tani, I., 1954, "On the Approximate Solution of the Laminar Boundary-Layer Equations", Journal of Aeronautical Sciences, Vol. 21, pp. 487-495.

Thomas, W.A., Prasuhn, A.L., 1977, "Mathematical Modeling of Sediment Transport Scour and Deposition in River Channels", 17th Congress, IAHR, Vol. 1, pp. 137-144. 
Tinney, E.R., 1962, "The Progress of Channel Degradation", Journal of Geophysical Research, Vol. 67, No. 4.

Todd, 0.J., Eliassen, S., 1940, "The Yellow River Problem", Transactions ASCE, Vol. 105, pp. 346-453.

Tsuchiya, A., Ishizaki, K., 1969, "Estimation of Rivers Bed Aggradation Due to a Dam", 13th Congress, IAHR, Vol. 1, pp. 297-304.

USBR, 1963, "Guide for Computing Degradation", USBR, Denver, Colorado.

USBR, 1977, "Design of Small Dams", USBR, Denver, Colorado.

Vanoni, V.A., 1975, "Sedimentation Engineering", ASCE-Manuals and Reports on Engineering Practice, No. 54.

Vanoni, V.A., Hwang, Li-San, 1967, "Relation Between Bed Forms and Friction in Streams", Journal of the Hydraulics Division, ASCE, Vol. 93, No. HY3, pp. 121144.

Vittal, N., Mittal, M.K., 1980, "Degradation of Ratmau Torrent Downstream of Dhanauri", Proceedings of the International Workshop on Alluvial River Problems, IAHR, Ppaer No. 5, pp. 43-54.

Walz, A., 1948, "Anwendung des Energiesatzes von Weighardt auf Einparametrige Geschwindigkeitsprofile in Laminarer Grenzschichten", Ingenieur-Archiv", Vol. 20, pp. 243-248.

Weighardt, K., 1948, "Ueber einen Energiesatzes zur Berechnung Laminarer Grenzschichten, Ingenieur-Archiv, Vol. 16, pp. 231-242.

Wong, Fa-Yao, 1939, "Chinese River Control During the 16th Century", M.S. thesis, The University of Iowa, Iowa City, Iowa.

Yamada, H., 1947, "An Approximate Integration of Differential Equation", Report, Ryutaikogaku Kenkyusyo No. 3, Vol. 3, pp. 29-35.

Yamada, H., 1950, "A Method of Approximate Integration of the Laminar Boundary Layer Equations", Report, Research Institute for Fluid Engineering, Kyushu University, Vol. 6, pp. 87.

Yang, C.T., Molinas, A., 1982, "Rate of Energy Dissipation and Sediment Transport", Proceedings of the ASCE Conference "Applying Research to Hydraulic Practice", ASCE, Jackson, Mississippi, pp. 466-479. 
It is well known (Garde and Ranga Raju, 1977; Yang and Molinas, 1982) that, when the larger portion of the sediment discharge is transported as bed load, most of the currently used sediment transport equations can be classified in the following types:

Type I

$$
G=a U^{b}
$$

Type II

$$
G=a\left(U-U_{C}\right)^{b}
$$

Type III

$$
G=a\left(Q-Q_{C}\right)^{b}
$$

Type IV

$$
G=a\left(\tau-\tau_{c}\right)^{b}
$$

where $a$ and $b$ are constants that depend on the specific formula adopted $\tau=$ shear stress; $c=$ subscript denoting the critical value required at incipient sediment-motion, which is considered constant and equal to the value corresponding to the initial equilibrium flow.

There exist a number of friction-factor predictors for alluvial channels under uniform flow (Einstein-Barbarossa 1952; Alam and Kennedy 1969, Garde and Raju 1966; Engelund 1967; Lovera and Kennedy 1969, Raudkivi 1967, etc.); however, for constant discharge, most of them can be expressed as

$$
f=f(U)
$$


Because of its simplicity and due to the fact that there is no friction factor predictor for nonuniform flows available, a constant friction factor has been frequently considered a reasonable assumption.

Karim (1981) based in a multiple regression analysis of an impressive amount of experimental and field data derived a friction factor predictor that can be written under the form

$$
f=e G^{m} U^{n} H^{P}
$$

where $m, n$, and $p$ are constants; $e$ is a constant that depends on the sediment and flow characteristics (i.e., grain size $d$, fall velocity $w$, specific weight $\gamma_{s}$, kinematic viscosity $\nu$, gravitational acceleration $g$, etc.).

As (I.1) can be considered a special case of the more general expression (I.2), for clarity two types of friction factor relations are considered in the following. First, a constant friction factor and second, a varying friction factor (as given by (I.2)).

The general expression that enables the determination of the coefficients $K_{0}$ and $k$ is

$$
K=\frac{U \frac{\partial G}{\partial U}}{S_{f}(1-\lambda)\left(3+\frac{U}{f} \frac{d f}{\partial U}\right)}
$$

By substituting the sediment transport and friction factor relations presented above in (I.3) one obtains different relations for the linear and nonlinear coefficients $K_{0}$ and $k$ respectively, which are tabulated below. 
Table I. 1

Expressions for the Coefficients $K$ and $K_{0}$ for Constant Friction Factor

Sediment Transport Eq.

$\mathrm{K}_{0}$

Type I

$\frac{b}{3} \frac{G}{S_{f}(1-\lambda)}$

$\frac{b}{3} \frac{G_{0}}{S_{0}(1-\lambda)}$

Type II

$\frac{b}{3 S_{f}(1-\lambda)\left(1-U_{c} / U\right)}$

$\frac{b \quad G_{0}}{3 S_{0}(1-\lambda)\left(1-U_{c} / U_{0}\right)}$

Type III

$$
\frac{b G}{3 S_{f}(1-\lambda)}\left(\frac{U_{c} / U}{1-U_{c} / U}\right) \quad \frac{b G_{0}}{3 S_{0}(1-\lambda)}\left(\frac{U_{c} / U_{0}}{1-U_{c} / U_{0}}\right)
$$

Type IV

$$
\frac{b G}{3 S_{f}(1-\lambda)\left[1-\left(U_{c} / U\right)^{2}\right]} \frac{b \quad G_{0}}{3 S_{0}(1-\lambda)\left[1-\left(U_{c} / U_{0}\right)^{2}\right]}
$$

If $b=3, K=K_{0}$ and no linearization is required. 
Table I.2

Expressions for the Coefficients $\mathrm{K}$ and $\mathrm{K}_{0}$ for Varying Friction Factor

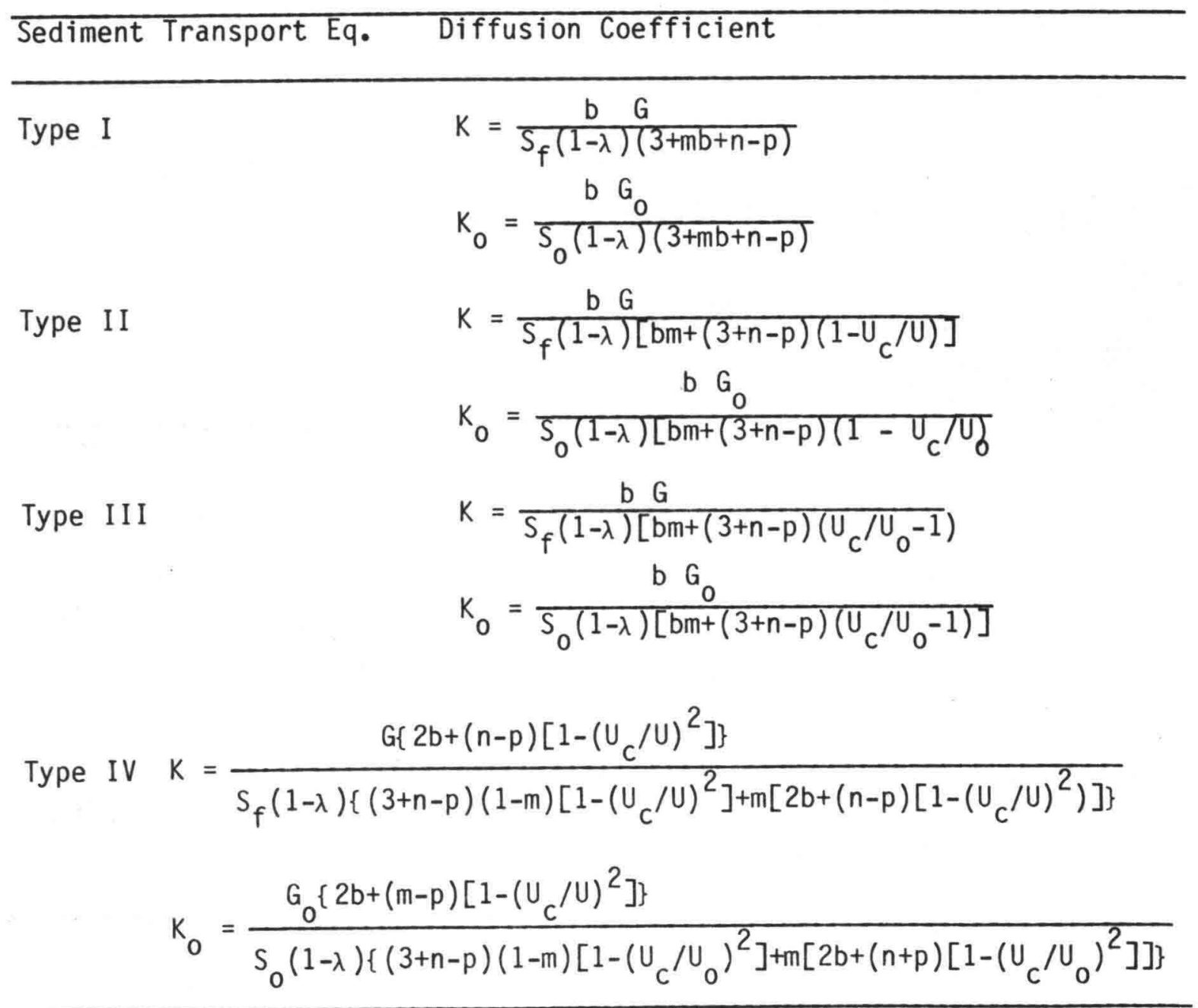


The integration of (4.49) solution for the second phase of the morphological process (degradation) triggered by a lowering in the base-level and its corresponding time scale are presented in this appendix.

$$
\bar{Z}(x, t)=\frac{1}{2 \sqrt{\pi K_{0} t}} \int_{0}^{\infty}\left\{\exp \left[-\frac{(x-v)^{2}}{4 K_{0} t}\right]-\exp \left[-\frac{(x+v)^{2}}{4 K_{0} t}\right]\right\} F(v) d v
$$

The solution in terms of the original dependent variable $Z(x, t)$, after substituting (4.47) and (4.45) into equation (II.1), is

$$
\begin{gathered}
Z(x, t)=\frac{2 \Delta G_{0}}{K_{0}(1-\lambda)}\left(\frac{K_{0} T}{\pi}\right)^{1 / 2}+\frac{\Delta G}{K_{0}(1-\lambda) \sqrt{\pi K_{0} t}}\left\{\int_{0}^{\infty} f-\left(\frac{K_{0} T}{\pi}\right)^{1 / 2}\right. \\
\exp \left[-\frac{(x-v)^{2}}{4 K_{0} t}\right]+\left(\frac{K_{0} T}{\pi}\right)^{1 / 2} \exp \left[-\frac{(x+v)^{2}}{4 K_{0} t}\right]+\left(\frac{K_{0} T}{\pi}\right)^{1 / 2} \exp
\end{gathered}
$$

$\left[-\frac{v^{2}}{4 K_{0} t}-\frac{(x-v)^{2}}{4 K_{0} t}\right]-\left(\frac{K_{0} T}{\pi}\right)^{1 / 2} \exp \left[-\frac{v^{2}}{4 K_{0} T}-\frac{(x+v)^{2}}{4 K_{0} t}\right]-\frac{v}{2} \operatorname{erfc}\left(\frac{v}{2 \sqrt{K_{0} T}}\right)$

$$
\left.\left.\exp \left[-\frac{(x-v)^{2}}{4 K_{0} t}\right]+\frac{v}{2} \operatorname{erfc}\left(\frac{v}{2 \sqrt{K_{0} T}}\right) \operatorname{erfc}\left[-\frac{(x+v)^{2}}{4 K_{0} t}\right]\right\} d v\right\}
$$

Considering that:

$$
\begin{aligned}
& A=-\left(\frac{K_{0} T}{\pi}\right)^{1 / 2} \int_{0}^{\infty} \exp \left[-\frac{(x-v)^{2}}{4 K_{0} t}\right] d v=k_{0} \sqrt{T t}\left[\operatorname{erfc}\left(\frac{x}{2 \sqrt{K_{0} t}}\right)-2\right] \\
& B=\left(\frac{K_{0} T}{\pi}\right)^{1 / 2} \int_{0}^{\infty} \exp \left[-\frac{(x+v)^{2}}{4 K_{0} t}\right] d v=k_{0} / T t \operatorname{erfc}\left(\frac{x}{2 \sqrt{K_{0} t}}\right)
\end{aligned}
$$


$c=-\int_{0}^{\infty} \frac{v}{2} \operatorname{erfc}\left(\frac{v}{2 \sqrt{K_{0} T}} \exp \left[-\frac{(x-v)^{2}}{4 K_{0} t}\right] d v=-\sqrt{K_{0} t}\left[\sqrt{K_{0} t} \exp \left(-\frac{x^{2}}{4 K_{0} t}\right)-\right.\right.$

$\left.\frac{x \sqrt{\pi}}{2} \operatorname{erfc}\left(\frac{x}{2 \sqrt{K_{0} t}}\right)\right]+\sqrt{\frac{K_{0} t^{2}}{\pi T}} \int_{0}^{\infty} \exp \left[-\frac{v^{2}}{4 K_{0} T}-\frac{(x-v)^{2}}{4 K_{0} t}\right] d v-\frac{x}{2} \frac{\bar{t}}{T} \int_{0}^{\infty}$

$$
\exp \left(-\frac{v^{2}}{4 K_{0} T}\right) \operatorname{erfc}\left(\frac{x-v}{2 \sqrt{K_{0} t}}\right) d v
$$

$D=\int_{0}^{\infty} \frac{v}{2} \operatorname{erfc}\left(\frac{v}{2 \sqrt{K_{0} T}}\right) \exp \left[-\frac{(x+v)^{2}}{4 K_{0} t}\right] d v=\sqrt{K_{0} t}\left[\sqrt{K_{0} t} \exp \left(-\frac{x^{2}}{4 K_{0} t}\right)-\right.$

$\frac{x \sqrt{\pi}}{2} \operatorname{erfc}\left(\frac{x}{2 \sqrt{K_{0} t}}\right)+-\sqrt{\frac{K_{0} t^{2}}{\pi T}} \int_{0}^{\infty} \exp \left[-\frac{v^{2}}{4 K_{0} t}-\frac{(x+v)^{2}}{4 K_{0} t}\right] d v+\frac{x}{2} \frac{\bar{t}}{t} \int_{0}^{\infty} \operatorname{erfc}$

$$
\frac{x+v}{2 \sqrt{K_{0} t}} \exp \left(-\frac{v^{2}}{4 K_{0} T}\right) d v
$$

$E=\int_{0}^{\infty} \exp \left[-\frac{v^{2}}{4 K_{0} T}-\frac{(x-v)^{2}}{4 K_{0} t}\right] d v=\sqrt{\frac{\pi K_{0} t}{1+t / T}} \exp \left[-\frac{x^{2}}{4 K_{0} T(1+t / T)}\right]$

$$
\left[2-\operatorname{erfc}\left[\frac{x}{2 \sqrt{K_{0} t(1+t / T)}}\right]\right\}
$$

$$
\begin{gathered}
F=\int_{0}^{\infty} \exp \left[-\frac{v^{2}}{4 K_{0} T}-\frac{(x+v)^{2}}{4 K_{0} t}\right] d v=\frac{\overline{\pi K_{0} T}}{1+t / T} \exp \left[-\frac{x^{2}}{4 K_{0} T(1+t / T)}\right] \operatorname{erfc} \\
{\left[\frac{x}{2 \sqrt{K_{0} t(1+t / T)}}\right]}
\end{gathered}
$$

the solution can be expressed as

$$
Z(x, t)=\frac{2 \Delta G_{0}}{K_{0}(1-\lambda)}\left(\frac{K_{0} T 1 / 2}{\pi}\right)+\frac{\Delta G_{0}}{K_{0}(1-\lambda) \sqrt{\pi K_{0}}}\left\{-2 K_{0} \sqrt{T t}\right. \text { erf }
$$


$\left(\frac{x}{2 \sqrt{K_{0} t}}\right)+2 K_{0} \sqrt{t(T+t)} \exp \left[\frac{-x^{2}}{4 K_{0} T(1+t / T)}\right] \operatorname{erf}\left[\frac{x}{2 \sqrt{K_{0} t(1+t / T)}}\right]-$

$\left.\frac{1}{2} \times \sqrt{\frac{t}{T}} \int_{0}^{\infty}\left[\exp \left(\frac{-v^{2}}{4 \mathrm{~K}_{0} T}\right)\left[\operatorname{erf}\left(\frac{x-v}{2 \sqrt{\mathrm{K}_{0} \mathrm{t}}}\right)-\operatorname{erf}\left(\frac{x+v}{2 \sqrt{\mathrm{K}_{0} \mathrm{t}}}\right)\right]\right\} d v\right\}$

Introducing the Taylors' series expansion of erf(u) as given by

$$
\operatorname{erf}(u)=\frac{2}{\sqrt{\pi}}\left(u-\frac{u^{3}}{3.1 !}+\frac{u^{5}}{5.2 !}-\frac{u^{2}}{7.3 !}+\ldots\right)=\frac{2}{\sqrt{\pi}} \sum_{n=0}^{\infty}(-1)^{n} \frac{u^{2 n+1}}{(2 n+1) n !}
$$

where $u=a \pm b=\frac{x}{2 \sqrt{K_{0} t}} \pm \frac{v}{2 / K_{0} t}$

the last integral in (II.9) becomes

$$
\begin{gathered}
I=-2 \sqrt{\frac{K_{0} t^{2}}{\pi T}} \int_{0}^{\infty} \exp \left(-b^{2} t / T\right)\left[\sum_{n=0}^{\infty} \sum_{j=0}^{\infty}(-1)^{n} \frac{(2 n+1) ! a^{j} b^{2 n+1-j}}{(2 n+1-j) ! j !(2 n+1) n !}-\right. \\
\left.\sum_{n=0}^{\infty} \sum_{j=0}^{2 n+1}(-1)^{n+j+1} \frac{(2 n+1) ! a^{J} b^{2 n+1-j}}{(2 n+1-j) ! j !(2 n+1) n !}\right] d b
\end{gathered}
$$

as

$$
\int_{0}^{\infty} \exp \left(-b^{2} t / T\right) b^{2 n+1-j} d b=\frac{\Gamma(2 n-j+2) / 2}{2(t / T)^{(2 n+j+2) / 2}}
$$

Equations (II.10) (II.11a) and (II.11b) into (II.9) provide the final solution, that is

$$
\begin{aligned}
& Z(x, t)=\frac{2 \Delta G_{0}}{K_{0}(1-\lambda)}\left(\frac{K_{0} T}{\pi}\right)^{1 / 2}+\frac{\Delta G}{K_{0}(1-\lambda) \sqrt{\pi K_{0} t}}\left\{-2 K_{0} \sqrt{T t} \operatorname{erf}\left(\frac{x}{2 \sqrt{K_{0} t}}\right)+\right. \\
& 2 K_{0} \sqrt{t(T+t)} \exp \left[-\frac{x^{2}}{4 K_{0} T(1+t / T)}\right] \operatorname{erf}\left[\frac{x}{2 \sqrt{K_{0} t(1+t / T)}}\right]-2 K_{0} t \sqrt{\frac{\pi t}{T}}
\end{aligned}
$$

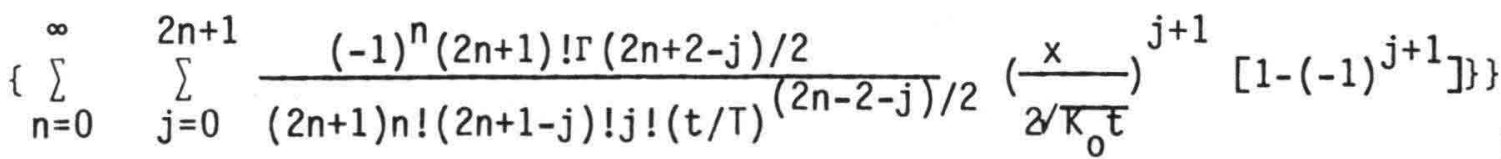


The time scale $T^{*}$ for the second part of the process is obtained by setting the bed slope at $x=0$ equal to $1.01 S_{0}$, that is

$$
\frac{\partial Z}{\partial x}\left(0, T^{*}\right)=-1.01 S_{0} \text { or } \frac{\partial Z}{\partial x}\left(0, T^{*}\right)=-0.01 S_{0}
$$

Taking the spatial derivative of (II.12) and using (II.13) one obtains

$$
0.005(\pi) S_{0} K_{0}(1-\lambda) / \Delta G_{0}=\sqrt{\frac{T \pi}{T}} \sum_{n=0}^{\infty} \frac{(-1)^{n}}{(2 n+1)}\left(\frac{T}{T^{\star}}\right)^{n+1} \text {. }
$$

which provides the desired analytical time scale.

An improved solution, which converges more rapidly than the previously presented and provides an explicit expression for the time scale $T^{*}$ can be obtained as follows. The Taylor's series expansion at the error function can be done in a slightly different fashion, which is based on $f(a+b)=f(a)+$ $b f^{\prime}(a)+\frac{b^{2}}{2 !} f^{\prime \prime}(a)+\ldots .$. where

$$
a=\frac{v}{2 \sqrt{K_{0} t}} \text { and } b=\frac{x}{2 \sqrt{K_{0} t}}
$$

It follows that

$$
\begin{aligned}
& \operatorname{erf}(a+b)=\operatorname{erf}(a)=\frac{2}{\sqrt{\pi}} \exp \left(-a^{2}\right) \sum_{n=0}^{\infty} \frac{(-1)^{n}}{(n+1) !} b^{n+1} H_{n}(-a) \\
& \operatorname{erf}(-a+b)=-\operatorname{erf}(a)+\frac{2}{\sqrt{\pi}} \exp \left(-a^{2}\right) \sum_{n=0}^{\infty} \frac{(-1)^{n}}{(n+1) !} b^{n+1} H_{n}(a)
\end{aligned}
$$

Where: $H_{n}$ is the Hermite polynomial of nth order. Hence,

$$
\begin{gathered}
\operatorname{erf}\left(\frac{x-v}{2 \sqrt{K_{0} t}}\right)-\operatorname{erf}\left(\frac{x+v}{2 \sqrt{K_{0} t}}\right)=2 \operatorname{erf}\left(\frac{v}{2 \sqrt{K_{0} t}}\right)-\frac{4}{\sqrt{\pi}} \exp \left(-\frac{v^{2}}{4 K_{0} t}\right) \\
\sum_{n=0}^{\infty} \frac{1}{[2(n+1)] !}\left(\frac{x}{2 \sqrt{K_{0} t}}\right)^{2(n+1)} H_{2 n+1}\left(\frac{v}{2 \sqrt{K_{0} t}}\right)
\end{gathered}
$$

As

$f_{0}^{\infty} \exp \left(-\frac{v^{2}}{4 K_{0} T}\right) \operatorname{erf}\left(\frac{v}{2 \sqrt{K_{0} T}}\right) d v=\left(\sqrt{\pi K_{0} T}-\frac{2}{\sqrt{\pi}} \sqrt{K_{0} T} \operatorname{arctg} \sqrt{\frac{t_{T}}{T}}\right)$ 
Substituting the last two equations into (II.8) one obtains

$$
\begin{aligned}
& Z(x, t)=\frac{2 \Delta G_{0}}{K_{0}(1-\lambda)}\left(\frac{K_{0} T}{\pi}\right)^{1 / 2}+\frac{\Delta G_{0}}{K_{0}(1-\lambda) \sqrt{\pi K_{0} t}}\left\{-2 K_{0} \sqrt{T t} \text { erf }\left(\frac{x}{2 \sqrt{K_{0} t}}\right)+\right. \\
& 2 K_{0} \sqrt{t(T+t)} \exp \left[-\frac{x^{2}}{4 K_{0} t(1+t / T)}\right] \operatorname{erf}\left[\frac{x}{2 / K_{0} t(1+t / T)}\right]-\frac{1}{2} \times \sqrt{\frac{t}{T}} \\
& \left(\sqrt{\pi K_{0} T}-2 \sqrt{\frac{K_{0} T}{\pi}} \operatorname{arctg} \sqrt{\frac{E}{T}}\right)+2 x \sqrt{\frac{t}{\pi T}} \int_{0}^{\infty} \exp \left[-\left(\frac{1}{4 K_{0} T}+\frac{1}{4 K_{0} t}\right) v^{2}\right] \\
& \sum_{n=0}^{\infty} \frac{1}{[2(n+1)] !}\left(\frac{x}{2 \sqrt{K_{0} t}}\right)^{2(n+1)} H_{2 n+1}\left(\frac{v}{2 \sqrt{K_{0} t}}\right) d v
\end{aligned}
$$

Considering that the integral term in (II.17) involves integrals of the type

$$
\int_{0}^{\infty} \exp \left[-(1+t / T) a^{2}\right] a^{r} d a=\frac{\Gamma\left(\frac{r+1}{2}\right)}{2(1+t / T)^{(r+1) / 2}}
$$

where:

$$
\Gamma() \text { = gamma function }
$$

The solution for the second phase of the problem becomes

$$
\begin{aligned}
& Z(x, t)=\frac{2 \Delta G_{0}}{K_{0}(1-\lambda)}\left(\frac{K_{0} T}{\pi}\right)^{1 / 2}+\frac{\Delta G_{0}}{K_{0}(1-\lambda) \sqrt{\pi K_{0} t}}\left\{-2 K_{0} \sqrt{T t} \operatorname{erf}\left(\frac{x}{2 \sqrt{K_{0} t}}\right)+\right. \\
& \quad+2 K_{0} \sqrt{t(T+t)} \exp \left[-\frac{x^{2}}{4 K_{0} T(1+t / T)}\right] \operatorname{erf}\left(\frac{x}{2 \sqrt{K_{0} t(1+t / T)}}\right)+ \\
& x \sqrt{\frac{t}{T}}\left(\sqrt{\pi K_{0} T}-2 \sqrt{\frac{K_{0} T}{\pi}} \operatorname{arctg} \sqrt{\frac{t}{T}}\right)+2 x \sqrt{\frac{t}{\pi T}} \sum_{n=0}^{\infty} \frac{1}{[2(n+1)] !}\left(\frac{x}{2 \sqrt{K_{0} t}}\right)^{2(n+1)} H_{2 n+1}(\gamma)
\end{aligned}
$$

where: $\mathrm{H}_{2 n+1}(\gamma)$ is a special polynomial whose coefficients are given by the coefficients of the Hermite polynomial of order $2 n+1$, and its argument $\gamma$ follows the law 


$$
\gamma^{n}=\frac{\Gamma n}{2(1+t / T)^{n}} ; n>0
$$

The dimensionless form of the solution is

$$
\begin{gathered}
\frac{Z(x, t)}{Z_{0}}=1-\operatorname{erf}\left(\frac{x}{2 \sqrt{K_{0} T}} \sqrt{\frac{T}{r}}\right)+\sqrt{1+t / T} \exp \left[-\frac{x^{2}}{4 K_{0} T(1+t / T)}\right] \\
\operatorname{erf}\left[\frac{x}{2 \sqrt{K_{0} T}} \sqrt{\left.\frac{T / t}{1+t / T}\right]}-\frac{x}{2 \sqrt{K_{0} T}}\left(\sqrt{\pi}-\frac{2}{\sqrt{\pi}} \operatorname{arctg} \sqrt{\frac{t}{T}}+\frac{4}{\sqrt{\pi}\left(\frac{x}{2 \sqrt{K_{0} T}}\right)^{2} \sum_{n=0}^{\infty}}\right.\right. \\
\frac{1}{[2(n+1)] !}\left(\frac{x}{2 \sqrt{K_{0} T}} \sqrt{\frac{T}{t}}\right)^{2(n+1)} H_{2 n+1}(\gamma)
\end{gathered}
$$

The time scale is obtained, as before, taking the spatial derivative of (II.21) and using (II.13) as to obtain

$$
\frac{\overline{T^{\star}}}{T^{2}}=\operatorname{tg}\left\{\frac{\pi}{2}\left[1-\frac{0.01 S_{0} K_{0}(1-\lambda)}{\Delta G_{0}}\right]\right\}
$$

This completes the analytical solution of the degradation process due to a lowering in the base-level. 
